\title{
Best and Brightest? The Impact of Student Visa Restrictiveness on Who Attends College in the US*
}

\author{
Mingyu Chen
}

\author{
Jessica Howell
}

April 13, 2020
Jonathan Smith ${ }^{+}$

\begin{abstract}
The F-1 student visa program brings more educated migrants to the US than any other immigration program, yet student visa applicants face an approximately 27 percent visa refusal rate that varies by time and region. Using data on the universe of SAT takers between 2004 and 2015 matched with college enrollment records, we examine how the anticipated F-1 visa restrictiveness influences US undergraduate enrollment outcomes of international students. Using an instrumental variables approach, we find that a higher anticipated F-1 student visa refusal rate decreases the number of international SAT takers, decreases the probability of sending SAT scores to US colleges, and decreases international student enrollment in the US. The decreases are larger among international students with higher measured academic achievement. We also document academic achievement of international students and show that over 40 percent of high-scoring international SAT takers do not pursue US college education.
\end{abstract}

JEL classification: I21, I23, F22, J15

Keywords: Human capital investment, migration, international student, F-1 student visa, immigration policy

${ }^{*}$ We thank Leah Boustan, Will Dobbie, Henry Farber, Elisa Jacome, Alexandre Mas, Cecilia Rouse, Kevin Shih, and seminar participants at Georgia State University for their helpful comments and suggestions. Fangyi Xie provided excellent research assistance. Mingyu Chen benefited from generous financial support from the Industrial Relations Section at Princeton University and the Fellowship of Woodrow Wilson Scholars. This paper does not reflect the views of the College Board. Any errors are our own.

${ }^{\dagger}$ Chen: Princeton University, mingyuc@princeton.edu; Howell: The College Board, jhowell@collegeboard.org; Smith: Georgia State University, jsmith500@gsu.edu. 


\section{Introduction}

In 2017, over 5.3 million postsecondary students studied abroad, double the number in 2003 (UNCESCO, 2020). The US has historically been the most popular destination. Through the F-1 student visa program, more than 1 million international students seek higher education in the US each year (IIE, 2019). The F-1 visa brings more highly educated migrants to the US than any other immigration program. ${ }^{1}$ Advocates of immigration and international education stress the value of international students, such as intellectual excellence and support for the skilled labor force. However, we know little about international students's ability and how immigration policies influence their decision to invest in US education.

After being admitted to a school, international students need to apply for an F-1 visa in order to legally enter the US. While the F-1 visa has no official cap, its issuance is far from certain. For example, in the wake of trade tensions between the US and China, the Chinese government warned students about their prospects of receiving a visa (Redden, 2019). Figure 1 shows that the F- 1 visa refusal rate is 27 percent worldwide in 2017, with substantial variation across regions and over time. ${ }^{2}$ Because both applying to US colleges and visas are costly, changes in the expected chances of obtaining a visa may influence who invests in the college application process ahead of time and enrolls in the US.

In this paper, we provide the first evidence on whether the US attracts high academic ability international undergraduates, and how the F-1 visa restrictiveness affects the college application process and enrollment. To address these questions, we compile a student-level dataset that contains information on demographics, SAT scores, SAT score sends, and US college enrollment for the universe of international SAT takers between 2004 and 2015 - many of which do not ultimately enroll in the US. We match our data with region-year visa refusal rates to measure visa restrictiveness.

Understanding who comes to the US to study and why are of particular importance for education and immigration policies. First, international students usually pay full tuition, which subsidizes US institutions, especially those facing increased tuition and decreased state appropriations (e.g., Bound et al., 2020; Chen, 2020). Yet little is known about the potential gains for schools beyond tuition revenue, such as peer quality and campus diversity. Second, the answers to our questions are central to policy debates on high-skilled immigration (e.g., Kerr, 2018). International students have become the major

\footnotetext{
${ }^{1}$ Based on authors' calculations of all skilled visa programs from DOS (2019).

${ }^{2}$ We use "region" to represent the place of origin identified in the data for ease of exposition.
} 
supply of skilled foreign workers for US employers. In 2017, half of H-1B work visas approved for new employment were awarded to students on an F-1 visa. ${ }^{3}$

Our paper begins by documenting the academic ability of international students who enroll in US colleges. We show that on average, international students have stronger credentials than domestic students on multiple measures of academic ability. For example, international students score 0.64 standard deviations (SD) higher on the SAT, with 0.93 SD higher on the math section. The international-US SAT gap is driven by the fact that many top-sending regions have more academically prepared secondary students, based on the worldwide assessment, PISA, and the selection into who enrolls in US colleges is more positive among international students than US students. The SAT gap is consistent with that the graduation rate for international students is 10 percentage points (pp) higher than for domestic students.

We also show that the expansion of international enrollment in the last decade is driven by high-scoring SAT international students. The ability distribution of international students has shifted over time. In 2015, international students in the US were 20 percent more likely to have an SAT score in the top quartile than in 2004. China is the primary driving force: Over 40 percent of high-scoring international students are Chinese in 2015 versus 2 percent in 2004. The rise of Chinese students coincides with a period of decline in its student visa refusal rate.

To motivate our visa policy analysis, we show that many prospective international students who invest in the US college application process never come. Less than half of international SAT takers send test scores to US colleges, and fewer than 30 percent eventually enroll in the US. ${ }^{4}$ Furthermore, although US enrollment probability increases in SAT scores, more than half of high-scoring international SAT takers do not end up enrolling in the US.

Before international students can know whether they can enter the US on an F-1 visa, they have to pay a significant cost upfront to apply to US colleges and for visas. Hence an increase in expected visa restrictiveness can decrease the expected benefit of investing in the college application process, such as taking the SAT and sending test scores. We refer to this discouragement of action as the chilling effect. To assess the impact of anticipated F-1 visa restrictiveness on foreign investment in US college education, we study outcomes for SAT taking, SAT score sending, and enrollment. We measure expected visa restrictiveness

${ }^{3}$ Authors' calculation using administrative data from US Citizenship and Immigration Services.

${ }^{4}$ Prior studies have often used score sending as a proxy for college applications (Card and Krueger, 2005; Pallais, 2015; Smith, 2018). 
with region-year visa refusal rates faced by international students around the time of deciding whether to take the SAT and send scores.

Our identification strategy addresses two potential biases that can prevent a causal estimate of the impact of F-1 visa refusal rate on college outcomes. First, simultaneity bias may arise because the refusal rate can be driven by changes in the supply of students (e.g., less qualified visa applicants) and not the restrictiveness of the visa policy. To address this, we isolate the variation in visa restrictiveness for US entry by instrumenting the F-1 visa refusal rate with the visitor visa refusal rate, which is not driven by student visa applicants. Second, visa refusal rates may be correlated with other region-level factors that also affect our outcomes of interest. We include a set of region-year-level controls, such as economic growth and trade with the US and whenever we can, region-year fixed effects, to address potential omitted variable bias. In practice, the instrument makes an important difference to our estimates, but the controls for omitted variables do not.

We find that a higher F-1 visa refusal rate discourages international students from taking the SAT and sending their scores to US colleges. On average, a $10 \mathrm{pp}$ increase in the F-1 visa refusal rate decreases the number of international SAT takers by 7.4 percent and the probability of sending scores to a US college by 3.7 percent, conditional on taking the SAT. Furthermore, conditional on sending scores, students send scores to slightly more selective US institutions. Our estimates show that a $10 \mathrm{pp}$ increase in the F-1 visa refusal rate leads to a 12.2 percent decrease in new international enrollment, with about 60 percent through the effect on SAT taking and 40 percent via the effect on score sending.

Importantly, we find that students with higher SAT scores are more responsive to the expected visa restrictiveness. A $10 \mathrm{pp}$ increase in the F-1 visa refusal rate decreases the median SAT score of international SAT takers by 0.04 SD and the share of takers above the $75^{\text {th }}$ SAT percentile by $2 \mathrm{pp}$. The probability of sending test scores to a US college is reduced nearly double the amount for high-scoring students than for low-scoring students. Consequently, the enrollment impact on high-scoring students is larger than low-scoring students. We discuss potential explanations, such as differences in outside options and use of information, in Section 7.5.

Our paper makes several contributions to the literature and to policies on education and immigration. First, it contributes to our broad understanding of human capital investment. A large literature has studied educational decisions in response to shocks to labor market returns (e.g., Jensen, 2010; Abramitzky and Lavy, 2014; Wiswall and Zafar, 2014; Shah and Steinberg, 2017; Charles et al., 2018; Kuka et al., 2020) and college cost 
(e.g., Deming and Dynarski, 2010; Dynarski et al., 2018). In particular, Kato and Sparber (2013) and Shih (2016) study how international students respond to the expected chance of working in the US after graduation. Kato and Sparber (2013) use data aggregated from a subsample of SAT takers prior to the mid-2000s and find that a reduction in the H-1B visa quota decreases scores received by US colleges. Shih (2016) finds that the region-level stock of international students decreases after the quota reduction. In contrast to these studies, we examine how global human capital investment responds to changes in the expected chances of obtaining a student visa, which is a more immediate uncertainty. Our studentlevel data allow us to evaluate the impact of F-1 visa policy on individual score-sending decisions and enrollment outcomes. We are able to create a measure of enrollment inflow instead of stock for our region-level analysis. From a policy perspective, if the US wants to attract more international undergraduate students - either for "brain gain" or to subsidize colleges-our results suggest that easing visa restrictiveness is a path to consider.

Findings from our paper also contribute to the high-skill immigration literature on international students. One million international students study in the US every year, and the number of student visas issued has been larger than the number of work visas and skill-based green cards combined since as early as 1997. Despite its importance, research on international students has been limited and traditionally focused on graduate students before the mid-2000s (e.g., Bound et al., 2009; Shih, 2017). However, there is rising interest in international undergraduates, likely as a result of their swelling numbers and new data efforts. ${ }^{5}$ Bound et al. (2020) find that reductions in state appropriations have led to increases in international undergraduates, who pay full tuition at public universities, and Chen (2020) finds that international undergraduates subsidize in-state students and lead to an increase in domestic college graduates. Chen (2019) finds that US-educated Chinese students face more labor market challenges than those educated in China when they return home. Due to data limitations, previous studies have only been able to provide statistics on enrollment levels and not on the composition of international students based on measures of academic ability.

Our paper differs from prior work by compiling a rich student-level dataset to answer a different line of questions. Using various measures of academic ability, we provide the first evidence that the US has attracted high-achieving international students who provide potential benefits to campuses, such as peer quality, beyond finance. In addition, unlike

\footnotetext{
${ }^{5}$ Between the 2006-07 and 2016-17 academic years, international student enrollment in the US increased 48 percent for graduate students and 84 percent for undergraduates. More than half are undergraduates.
} 
most of the immigration literature-which only observes migrants in the US-we also observe prospective students who have shown some interest in seeking a US education. We show that a large fraction of high-achieving SAT takers do not come, suggesting that there is some low-hanging fruit for US colleges and, perhaps, the labor market as well.

In Section 2, we discuss our data sources and compare our data with the few external data sources on international students. Section 3 presents descriptive statistics on the academic ability for international students in the US and compares them with those for US students. We also discuss why international students have higher scores and document trends in the ability distribution. Section 4 documents our outcomes of interest for the visa policy analysis, and Section 5 describes the relevant institutional backgrounds and variation in visa refusal rates. Section 6 presents our empirical strategy to estimate the impact of visa restrictiveness, and Section 7 presents the results and our discussion. Section 8 concludes.

\section{Data}

\subsection{Data sources}

Our primary data are the universe of over 15 million SAT takers from the 2004-2015 high school graduating cohorts. The SAT is one of two primary standardized tests for US college admissions. Throughout the paper, we consider SAT scores from the math and verbal section, each of which has a minimum of 200 and a maximum of 800 , making the combined score between 400 and $1600 .{ }^{6}$ Along with SAT scores, the data also contain information on where students sent their official score reports ("score sends" hereafter); demographics such as gender, age, parental education, and family income; and other measures of academic ability, such as SAT subject tests, Advanced Placement (AP) exams, and self-reported high school GPA and class rank.

We identify international test takers through the address and high school provided at the time of SAT registration. We define students as international if they had both a foreign mailing address and attended a foreign high school. The College Board does not directly ask about nationality at test registration. We exclude US territories and addresses for foreign US military bases and foreign schools for US armed forces.

We determine whether students enroll in the US by merging SAT-taking data with

${ }^{6}$ The writing section was introduced after 2006. For consistency across years, we do not include the writing section. Our results do not change qualitatively if the writing section is included. 
the National Student Clearinghouse (NSC). NSC data track enrollment for 97 percent of Title IV, degree-granting colleges and universities. We focus on the first college a student enrolls in when considering college characteristics. Detailed information on these colleges, such as college sector and graduation rates, are supplemented by the US Department of Education's Integrated Postsecondary Education Data System (IPEDS). Following previous work, we use the average of the SAT $25^{\text {th }}$ and $75^{\text {th }}$ percentiles of matriculated students as a measure of selectivity (e.g., Loury and Garman, 1995; Dale and Krueger, 2002; Hoxby and Turner, 2013; Pallais, 2015; Mountjoy and Hickman, 2019). In practice, we follow Pallais (2015) and use test scores from a base year, 2003, prior to our sample period so that the analysis is not confounded by changes in selectivity over time.

We obtain annual region-specific refusal rates for student and travel visas through a more than 3-year Freedom of Information Act process with the US Department of State. The refusal rates are for F-1 student visas but also for rourist B visas. We measure visa restrictiveness with refusal rates around the time students make their college application decisions; Section 5.2 provides more details on the measure.

Finally, we use a set of region-year-level controls from a variety of sources. Information on economic conditions such as GDP, exchange rates, and trade are from the Penn World Table 9.1 and the Census Bureau. For each region, the college-age population and postsecondary enrollment in other popular destinations (Australia, Canada, and the UK) are obtained from a combination of the UNESCO Institute for Statistics, manual collections from official local government websites, and information requests to foreign governments.

\subsection{Comparison with external data sources and total enrollment trends}

Although our data contain detailed information on international students, they are not a census of international students in the US. We use two external sources to better understand the advantages and deficiencies of our data. The first primary data source on international students is the Fall Enrollment Survey in IPEDS, which contains the total and new undergraduate international student enrollment each fall at the school level. The other most commonly used data on international students come from an annual college survey conducted by the Institute of International Education (IIE), which covers about 3,000 US institutions. The IIE survey contains the total international enrollment in the US by academic level and region. Appendix Figure A.1 plots the trends of aggregate international enrollment using both IPEDS and IIE data. It is clear that the two datasets closely mirror each other. The total number of international undergraduates enrolled in 
the US was relatively flat before the 2007-08 academic year, and nearly doubled in 9 years to about 450,000 students.

Our SAT data allow us to create aggregate counts of newly enrolled undergraduates, but not the stock of total students. We first compare the trends of new international students in the SAT data with IPEDS in Panel (a) of Appendix Figure A.2. The SAT data account for 59 percent of new international student enrollees at all undergraduate institutions in IPEDS, which suggests that there are alternative paths to the US, such as taking the other college entrance exam, ACT, or enrolling in colleges that do not require college entrance exams. ${ }^{7}$ In Panel (b), we show the same trends for 4-year colleges and 231 selective institutions defined by Barron's rankings that are more likely to require a college entrance exam. We have slightly better coverage at 4-year colleges (63 percent of IPEDS), where most international students enroll. At selective institutions, our coverage is even better ( 82 percent of IPEDS). ${ }^{8}$

Our data also differ from IPEDS and IIE in the definition of international students. Both IPEDS and IIE surveys define international students as temporary visa holders, so that they include international students who went to high school in the US. In 2016, 82,000 international students attended US high schools-triple the number a decade earlier (Farrugia, 2017). The increase is primarily driven by China. Most international students in US high schools seek to pursue a US higher education, which likely contributes to the difference between our data and IPEDS.

Figure 2 shows the trends of new international enrollment in the US by region, which is not reported in IPEDS. China is clearly an outlier. Between 2007 and 2015, the number of new Chinese undergraduates grew from less than 1,000 to about 10,000. Today, Chinese students account for one-third of international students in the US at both the undergraduate and graduate level. There are also sizable increases in the inflow of students from other regions such as India, the United Arab Emirates (UAE), the United Kingdom (UK), and Vietnam. The trends of new international students shown in Figure 2 are similar to the trends of international student stock by region shown in Appendix Figure A.3, which uses the IIE data. China is the primary driving force in international student increases since 2008.

${ }^{7}$ To the best of our knowledge, international ACT takers are only about 10 percent of all international students who take either an SAT or ACT, based on data provided by the ACT in 2014.

${ }^{8}$ The coverages at 4-year and selective institutions are underestimated. We cannot identify college types for 5.4 percent of the international student sample because the NSC blocks their institutional names. 


\section{Academic Ability of International Students in the US}

\subsection{Summary statistics on academic ability and demographics}

Table 1 shows measures of academic ability and demographics for all international students enrolled in the US and compares them with averages for all domestic students for the 2004-15 cohorts. The population average is an interesting statistic, because it sheds light on the overall academic credentials of international undergraduates in the US. Comparison with the average domestic student provides a useful reference point for policymakers who are interested in knowing whether, overall, the US is taking high-quality international students relative to average domestic students. In Section 2.2 we show that China has become the region with the most students in the US, and thus we also separately report the same statistics for Chinese students.

The first section of Table 1 shows statistics related to standardized tests administrated by the College Board, based on data for 267,000 international enrollees and 15 million domestic enrollees in US colleges. International students in the US have higher average academic credentials than US students. Specifically, international students score 0.64 SD (133.3 points) higher on the SAT, and Chinese students score 1 SD (207 points) higher. SAT gaps mostly stem from the math section, in which international students score 0.93 SD higher and Chinese students score 1.74 SD higher. The foreign-domestic verbal gap is $0.26 \mathrm{SD}$ and the China-US verbal gap is $0.1 \mathrm{SD}$. In addition, international students send SAT scores to 2.3 more US colleges than domestic students (conditional on sending to at least one school), and are more than twice as likely to take an SAT subject test. Compared with statistics published by the College Board for all test takers, international students also score higher on SAT subject tests and AP exams. ${ }^{9}$ Chinese students also have stronger than the average international student on these measures.

The second section of Table 1 shows self-reported GPA for both international and US students and high school rankings for international students. The reported GPA for US students is 0.11 lower than international students and 0.38 lower than Chinese students. Of the international student respondents on the survey, about 60 percent reported that they are in the top 10 percent in their high school class, 25 percent in the top 11-20 percent, and

\footnotetext{
${ }^{9}$ In our data, we observe subject test scores and AP information for international students but not for US students. The average AP exam score for all test takers is 2.88 out of 5 between 2004 and 2015 (research.collegeboard.org/programs/ap/data/participation/ap-2018), and the average SAT subject test score for all takers is 655.48 for the 2015 cohort (secure-media.collegeboard.org/digitalServices/pdf/sat/satpercentile-ranks-subject-tests-2015.pdf).
} 
close to 10 percent in the top 21-40 percent. Chinese students reported a similar ranking distribution. One concern is that the non-reporting rates for international students are quite large. We find that international students who did not report their class ranking have SAT scores similar to those ranked in the top 11-20 percent. International students who did not report their GPA scored 20 points lower on the SAT than those who reported, 13.5 points higher than US students who reported, and 191 points higher than US students who did not report.

The third section of Table 1 shows self-reported demographics. While age and gender are required fields, family income and parental education are not. On average, international and domestic students are of similar age. International students are less likely to be female, though the female share of Chinese students is close to that of the US. While international students in the US may have higher family income than their peers at home, the share in the bottom income category is twice as high relative to US students. This suggests that some international families may finance their children's education via loans, savings, or other types of assets such as housing. Lastly, a striking difference is that parents of international (Chinese) students are 26 (16.1) pp more likely to be college-educated than US students.

\subsection{Why do international students in the US have stronger credentials?}

In this section, we provide evidence on potential driving factors for the observed foreigndomestic SAT gap of 0.64 SD. The differences in population averages can be driven by a number of factors, such as preparation in secondary school, selection into college, and missing data.

First, the SAT gap is consistent with students in some large-sending foreign regions being better prepared academically. Based on results from the PISA in the last decade, 15-year-olds in three of the top five sending regions (China, South Korea, and Canada; see Figure 2) did considerably stronger than US students on math and reading. ${ }^{10}$ Figure 3 plots a region's 2012 PISA rank against its mean SAT rank for the 2015 cohort who enrolled in the US. The figure includes the US and 49 foreign regions that participated in the PISA and had the largest US enrollment. US secondary school students ranked the $23^{\text {rd }}$ on the

${ }^{10}$ PISA standards for Programme for International Student Assessment. The OECD funds the PISA to evaluate the educational outcomes of 15 -year-olds worldwide every 3 years based on a common standard. Before the 2015 PISA, China's rank was based on students from Shanghai only. Its rank is stable after adding Beijing, Jiangsu, Guangdong, and Zhejiang in subsequent PISAs. The relative ranks of the US, China, South Korea, and Canada remain similar after correcting for differences in exam effort (Akyol et al., 2019). 
PISA, and domestic college enrollees ranked the $46^{\text {th }}$ on the SAT. Regions in area $Q_{3}$, such as China, South Korea, and Canada, are those to the left of line $l_{1}$ and below line $l_{2}$. While $Q_{3}$ regions send students with higher SAT scores than domestic students to the US, their average secondary school student also performs stronger on the PISA.

Second, selection into who enrolls in US colleges is more positive for some foreign regions than for the US. Hence, the foreign-domestic SAT gap reflects the fact that we are comparing international students from the top of the foreign distribution with domestic students from less than the top of the US distribution. Figure 3 shows that 24 of the 49 top-sending regions are in area $Q_{4}$, meaning that they ranked lower on the PISA relative to the US, but ranked higher on the SAT. Note that 15-year-olds who took the PISA in 2012 are likely the same cohort who graduated from high school in 2015. Taking Brazil as an example, secondary students in Brazil ranked the $43^{r d}$ on PISA but those who later enrolled in a US college ranked the $20^{\text {th }}$ on the SAT. India, while not included in Figure 3 because it did not participate in the 2012 PISA, is most likely in the right-bottom corner of $Q_{4}$ based on its 2009 PISA result. On the other hand, Denmark is the only region in $Q_{2}$. It ranks higher than the US on the PISA but lower on the SAT, implying that the selection of Danish students into US colleges is less positive than that of students.

Both differential preparation in secondary school and selection on student academic ability into US colleges are further evidenced by the fact that international students are more likely sorted to selective institutions than domestic students. In our data, more than 54.5 percent of international and 71 percent of Chinese students are enrolled at selective institutions compared with 21.2 percent of domestic students. The foreign-domestic SAT gap is much smaller within the same school selectivity. We report regression estimates of SAT gaps by school type in Table 2. Column 1 replicates the SAT gap between all international and domestic students we find in Table 1. Columns 2-3 breaks the sample down by institution selectivity. ${ }^{11}$ The gap is $0.22 \mathrm{SD}$ at selective institutions and $0.35 \mathrm{SD}$ at non-selective institutions.

Lastly, as discussed in Section 2.2, our SAT data do not cover all international students in the US, especially at non-selective institutions. If the foreign-domestic difference in academic ability among students without an SAT score were not as large as it is among students with an SAT score, the observed foreign-domestic SAT gap would be overstated.

\footnotetext{
${ }^{11}$ We do not observe school type for about 2 percent of the entire sample because the NSC blocks institution names. Our results are robust when predicting school selectivity type for blocked observations using machine learning/non-parametric models and information on student academic records, score-sending portfolio, demographics, and high school.
} 
While we cannot observe test scores for students who did not take the test, we examine an academic ability measure that is available for everyone at non-selective institutionscollege graduation rate from IPEDS. ${ }^{12}$ We find no evidence that the foreign-domestic gap in academic ability is smaller at non-selective institutions. Panel (a) of Figure 4 shows the trends of graduation rates by college selectivity. At non-selective institutions, international students are about $10 \mathrm{pp}$ more likely to graduate than domestic students in recent cohorts. At selective institutions, students have similar graduation rates, of over 80 percent. Panel (b) breaks down non-selective institutions by college sector. At 2-year colleges, where SAT data coverage is the worst, the gap in graduation rates is no smaller than for 4-year non-selective colleges.

Note that besides the population difference in academic ability, policymakers may also be interested in the foreign-domestic SAT gap within the same college and cohort. Since international and domestic students sort to very different sets of institutions, the within-school SAT gap can be distinct from the population difference. Column 4 of Table 2 shows that there is a smaller SAT gap of 0.03 SD between international and US students within the same college-cohort. However, there is large cross-region variation. Column 5 shows that of the top five sending regions, students from China, India, Canada, and South Korea score $0.15,0.16,0.04$, and 0.29 SD higher on the SAT, respectively, than domestic students in the same college-cohort. Students from the UK and other foreign regions score 0.23 and 0.14 SD lower on the SAT, respectively. Columns 6-7 show that the SAT gap also varies significantly across subjects, with international students scoring $0.42 \mathrm{SD}$ higher on math but $0.38 \mathrm{SD}$ lower on verbal. This is consistent with international students' comparative advantage in choosing STEM majors and are important contributors to the STEM workforce (Bound et al., 2015; Anelli et al., 2019).

\subsection{Trends in the ability of international students}

While the literature has well documented the drastic expansion of international student enrollment in the last decade, we do not know how the distribution of academic ability has changed. Thus far, we have focused on understanding a snapshot of average academic credentials for all international students in the US between 2004 and 2015. In this section, we examine changes in the distribution of international student SAT scores over time.

We first split international students into four groups based on how their SATs compare

\footnotetext{
${ }^{12}$ Research has shown that SAT scores are highly correlated with first-year college GPA and college completion (Shaw, 2015; Westrick et al., 2019).
} 
to SAT quartiles for domestic students. ${ }^{13}$ In Panel (a) of Figure 5, we plot the shares of international students in each quartile over time. In 2015, 57.5 percent of international students have an SAT above the $75^{\text {th }}$ percentile (top quartile), which is a 9 pp increase from 2004. In contrast, the share of every other quartile group decreased by about $3 \mathrm{pp}$, with 6.5 percent of international students in the bottom quartile in 2015. The level difference is more striking, given the increase in total international enrollment. The number of international students in the top quartile is five times that in the bottom quartile in 2004, but nine times that in 2015.

We also create a group for international students with a score above the $90^{\text {th }}$ percentile. The black dotted line shows that 34.5 percent of 2015 international students are in this group, following a trend similar to the top quartile students. Panel (b) of Figure 5 shows the trends of the top two percentile groups by subject, and suggests that the aggregate trends stem primarily, but not exclusively, from international students with extremely high scores on the math section of the SAT.

In Figure 6, we further examine the regional composition of high-scoring international students and how it has changed over time. Panel (a) shows that the five regions with the highest share of top quartile students are China, India, Canada, South Korea, and Singapore. While less than 2 percent of the top quartile of international students are from China in 2004, nearly 40 percent are Chinese in 2015. China's emergence is at the cost of share declines for Canada, Singapore, and other regions, with the exception of India and South Korea, which have only about a 1 percent decline in their shares. Panel (b) shows the same pattern of compositional changes for students above the $90^{\text {th }}$ percentile, with China accounting for 43 percent in 2015.

Overall, the composition of international students has shifted over time during a period of rapid expansion in international enrollment. The US has attracted increasingly more high-scoring international students, with China being the primary driving force. The increase in high-scoring Chinese students is consistent with an increase in Chinese family's wealth and a limited supply of elite colleges-coupled with a boom in demand for college education-in China (Bound et al., 2020; Chen, 2019).

\footnotetext{
${ }^{13}$ All SAT percentiles referred to this paper are computed using data on US test takers in a given high school cohort, and these percentiles are stable over time.
} 


\section{Who Comes to the US (and Who Doesn't)}

In this section, we document which students come to the US and which do not to better understand outcomes of interest in the visa policy analysis. We make use of our unique data that follows students from SAT taking, to score sending, and to enrollment in the US. SAT taking and score sending are measures of interest in US higher education but do not guarantee enrollment. Appendix Figure A.4 shows that over 120,000 international students in the 2015 cohort took the SAT, double the number 8 years earlier. The number of students who send their scores to US colleges and enroll follow trends similar to those of SAT takers, despite becoming a smaller fraction of SAT takers over time.

First, we show that unlike domestic SAT takers, the vast majority of whom send their scores to at least one US college and enroll in the US, only 46.7 percent of international SAT takers are score senders and 27.1 percent are enrollees. Figure 7 shows the shares of SAT takers who are score senders and who are enrollees, both in aggregate and by the 30 regions with the most SAT takers between 2004 and 2015. These shares vary drastically by region. For instance, 74.4 (55.6) percent of Chinese are score senders (enrollees); 52.8 (25.5) percent are Canadian, and less than 25 (15) percent are Thai or Saudi Arabian. ${ }^{14}$ Note that not all enrollees are score senders, since some schools do not require standardized tests. About 5 percent of international SAT takers enroll in US colleges without sending their scores.

Second, we show that international score senders and enrollees are positively selected from SAT takers. Figure 8 shows that among international SAT takers, the number of score sends and US enrollment probability increase in SAT score with some degree of nonlinearity. Panel (a) also shows that the gap in score sends between score senders (triangles) and SAT takers (circles) decreases in SAT score. Since the gap size decreases in the probability of being a score sender, the probability of sending a score increases in SAT score.

The positive selection into score senders and enrollees is not only true on average but also within regions. Figure 9 plots the SAT median for SAT takers, score senders, and enrollees by region. It is evident that SAT takers (diamonds) are always to the left of score senders (squares) and enrollees (circles), which implies positive selection across all regions. While the degree of selection has a large regional variation, international score

\footnotetext{
${ }^{14}$ Lebanon and Egypt have extremely low shares of score senders and enrollees because the SAT is used for college admission at prestigious local universities. In our regression analysis, we include region fixed effects to account for this.
} 
senders and enrollees are more positively selected compared to the US case, on average.

Third, we show that more than half of high-scoring international SAT takers do not end up enrolling in the US. Figure 8 shows that only 30 to 60 percent of international test takers above the $75^{\text {th }}$ SAT percentile enroll in a US college-much less than domestic test takers. This is due to both a low conversion rate from SAT takers to enrollees and the fact that most international SAT takers have high test scores. In fact, Figure 9 shows that the SAT median for international test takers is higher than the median for US score senders. Scores are measured in SD and are rescaled so that the median of US takers in the sample period is zero. In cases such as China and South Korea, the median SAT taker has a score $0.28 \mathrm{SD}$ and $0.75 \mathrm{SD}$ above the $75^{\text {th }}$ percentile, respectively.

In Section 3.2, we show that enrollees from many regions have higher academic ability than each region's average student. ${ }^{15}$ This positive selection could be driven by US college admissions, the selection from secondary students to SAT takers, and the selection from SAT takers to score senders and enrollees. The patterns observed in Figure 8 and 9 suggest that at least in part, selection from SAT takers plays a role. In addition, Appendix Figure A.5 shows that there is a positive selection from secondary students to SAT takers for many regions by plotting PISA rank against SAT rank for test takers.

\section{Institutional Background}

\subsection{The US college application process for international students}

Students typically take the SAT or send test scores in the fall (or earlier) of their graduation year. The SAT test registration fee is about $\$ 47$, plus an extra $\$ 30$ foreign fee, in our sample period. The cost of taking the SAT includes the time and money spent for test preparation and travel to test centers. For example, there is no test center in mainland China and students must travel to places such as Hong Kong to take the SAT.

Students can choose up to four schools to receive their SAT scores at no cost before knowing their scores. After the test, each score send costs around \$10. On average, international score senders send their SAT scores to more than 6 US colleges. To complete a college application, students must obtain information on the schools, fill in forms, write essays, get recommendation letters, and pay an average application fee of $\$ 44$. The fee is more expensive for selective institutions. Typically, students receive offers in the spring of their graduation year. After international students accept an offer, the school registers

\footnotetext{
${ }^{15}$ This assumes that on average, domestic US enrollees with SAT scores are stronger than those without.
} 
them on the Student and Exchange Visitor Information System (SEVIS) and issues Form I-20, which is required for F-1 visa applications. The school must be certified by the Student and Exchange Visitor Program.

\subsection{Nonimmigrant visa application process}

In order to enter the US, foreign citizens are generally required to obtain a visa. The Immigration and Nationality Act (INA) establishes visa types for different travel purposes. A nonimmigrant visa, such as the F-1 (student) visa and B (business/tourism visitor) visa, is for a temporary stay; an immigrant visa, such as Green Card, is for permanent residence. Table 3 shows selected statistics for nonimmigrant visas based on data from the State Department in 2004-15. Panel A lists information for five visa types with the highest issuance and the sum of the remaining 72 types. Average annual issuance for $B$ visas is over 5.4 million and is the highest of all types. The F-1 visa is second, with an annual average close to 400,000 . The issuance for both B and F-1 visas varies over time more than other visas.

Applying for a visa is costly. In addition to filling out lengthy application forms, preparing various supporting documents, and paying an application fee of $\$ 160$ (as of 2019), applicants are generally required by law to be interviewed by a consular officer at a US embassy or consulate. ${ }^{16}$ In addition, before the interview, student visa applicants must pay a fee of $\$ 200$ to be registered on SEVIS. The fee increased to \$350 in June of 2019.

Visa applications can be denied. Under US immigration law section 104(a) of the INA, consular officers have the exclusive authority to approve or deny visa applications. Column 5 of Panel A in Table 3 shows that on average, both F-1 and B visa applications have a denial rate of about 20 percent-much higher than other visa types. Column 6 shows that aggregate F-1 and B visa refusal rates also have larger variation over time.

When a visa application is denied, a US consular officer provides the applicant with the reason, based on ineligibility listed in the INA and other immigration laws. There are more than 60 reasons, and Panel B of Table 3 shows that "INA 214(b): immigrant intent" is given 93 percent of the time. This means that the consular officer determines the visa applicant intends to immigrate. While some visa categories, such as the H-1B temporary worker visa, allow applicants to have immigrant intent, B and F-1 visas do not. There are no official caps on B and F-1 visa issuance. In practice, the Department of State sometimes adjusts visa restrictiveness by imposing different standards on what

\footnotetext{
${ }^{16}$ Official guidelines: travel.state.gov/content/travel/en/us-visas/study/student-visa.html
} 
comprises an immigration intent. For example, in two cables issued in 2004 and 2005, the State Department asked consular officers to be less strict when considering the 214(b) provision for student visa applicants (Kless, 2006). Specifically, they were asked to focus on students' immediate and near-term intent and not expect students to have a detailed long-term plan.

\subsection{Variation in visa refusal rates}

Figure 10 and Appendix Figure A.6 show that the refusal rates for F-1 and B visas follow similar trends and vary significantly across regions and time. In our analysis sample, the F-1 visa refusal rate at the region-year-level has an average of 24.2 percent with a SD of 20.3 percent, a maximum of 86.7 percent, and a minimum of 0.1 percent. The B visa refusal rate has an average of 25.8 percent with a SD of 17.1 percent, a maximum of 73.5 percent, and a minimum of 0.4 percent.

What drives variation in F-1 and B visa refusal rates? First, refusal rates in a given region reflect the restrictiveness of immigration policies on US entry for that region. At one extreme, citizens of 38 regions that are members of the Visa Waiver Program (VWP) can enter the US for business and tourism without obtaining a B visa. The program is a comprehensive security partnership between America and its allies, and about 20 million travelers under this program entered the US in 2014. ${ }^{17}$ Figure 1 shows that the aggregate F-1 visa refusal rate for VWP regions is significantly smaller than for the world overall and the variation is much smaller.

Immigration policies can often target a specific region or a group of regions. For instance, after the $9 / 11$ attacks in 2001, the US largely increased visa restrictiveness for both F-1 and B visas for Islamic regions because some of the terrorists had those visa types (Kless, 2006). It is evident in Figure 10 that visa refusal rates spiked right after 2001 in places such as the UAE, Pakistan, Saudi Arabia, and Qatar.

Another example is China. A sequence of policy changes made it easier for Chinese to obtain visas in 2008-14. The changes include simplifying the visa application procedure, extending the visa validity period, and publicly announcing welcoming visa policies. In a US-China joint statement released in 2009, the US expresses its desire to foster closer US-China relations through cultural exchanges, stating,"The US side will receive more Chinese students and facilitate visa issuance for them."18 Figure 10 shows that the F-1

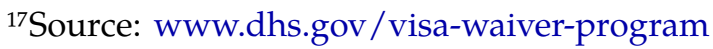

${ }^{18}$ Source: obamawhitehouse.archives.gov/realitycheck/the-press-office/us-china-joint-statement
} 
visa refusal rate for China dropped by 27 pp between 2007 and 2014, coinciding with a period of rapid expansion in Chinese students seeking a US education.

Second, changes in the supply of visa applicants can also alter refusal rates. If the share of qualified applicants increases, the refusal rate can drop even if visa restrictiveness is unchanged. Hence, the F-1 visa refusal rate may not be used to measure visa restrictiveness directly. We describe our empirical strategy to address this issue in the next section.

\section{Empirical Strategy}

We are interested in estimating the effect of expected F-1 visa restrictiveness on international students' decisions throughout the US college application process, as well as the impact on the final enrollment and student composition. In Section 5, we established that before students learn the outcome of their F-1 visa application, they must pay a substantial cost to apply to US colleges and for visas. The cost includes the time and money spent, as well as psychological stress. A lower anticipated chance of obtaining a student visa can therefore decrease the expected benefit of taking the SAT and sending test scores. We refer to this discouragement of actions as the chilling effect. Note that prospective students with different academic ability may respond to the chilling effect differently, perhaps due to different outside options.

We measure expected restrictiveness for US entry with region-year varying F-1 visa refusal rates faced by international students around the time they make SAT taking and score-sending decisions. For example, the visa refusal rate used for students graduating in May 2015 is the average rate between October 2013 and September 2014 (or the 2014 fiscal year). Below, we describe our empirical strategy for estimating the chilling effect and its heterogeneity by academic ability.

We first study how F-1 visa restrictiveness affects SAT taking, measured by the quantity and academic ability of international SAT takers at the region-year-level. Specifically, we employ the following regression model:

$$
Y_{j t}=\alpha \mathrm{FRR}_{j t}+X_{j t} \theta+\omega_{j}+\gamma_{t}+\epsilon_{j t}
$$

where the dependent variables are the number of international SAT takers, the median test score, and the share of takers above the $75^{\text {th }}$ percentile from region $j$ in cohort year $t$. The independent variable of interest, $\mathrm{FRR}_{j t}$, is the F- 1 visa refusal rate faced by students in cohort year $t$ from region $j$ in the time period prior to students' potential visa appointment. 
$X_{j t}$ is a vector of control variables (e.g., real GDP per capita) that vary at the region-year level. The timing of $X_{j t}$ is set to be the calendar year prior to the cohort year $t$. Visa refusal rate and $X_{j t}$ are both measured in natural logs. $\omega_{j}$ and $\gamma_{t}$ represent region and year fixed effects, respectively. Standard errors are clustered at the region level.

We leverage our student-level data to study how F-1 visa restrictiveness affects individual decisions in score sending. We use the following empirical framework:

$$
P_{i j t}=\beta_{1} \mathrm{FRR}_{j t}+W_{i j t} \delta+X_{j t} \rho+\mu_{j}+\tau_{t}+\eta_{i j t},
$$

where the dependent variables are an indicator for student $i$ from region $j$ in cohort year $t$ sending their SAT scores to at least one US undergraduate institution, the number of score sends, and the selectivity of schools receiving scores. $W_{i}$ is a vector of student-level controls, including SAT score and demographics (gender, age, parental education, and family income). $\mu_{j}$ and $\tau_{t}$ represent region and year fixed effects, respectively.

Furthermore, we estimate whether the impact of F-1 visa restrictiveness varies by student academic ability using the following econometric model:

$$
P_{i j t}=\beta_{1} \mathrm{FRR}_{j t}+\beta_{2} \mathrm{FRR}_{j t} \times \mathrm{AA}_{i}+W_{i j t} \delta+X_{j t} \rho+\mu_{j}+\tau_{t}+\eta_{i j t}
$$

For our main results, we measure student academic ability, $\mathrm{AA}_{i}$, using an indicator of high SAT score, $\mathbb{1}_{\mathrm{SAT}_{i} \geq 75^{\text {th }} \mathrm{pctl}}$. In this case, coefficient $\beta_{2}$ is the impact of F- 1 visa refusal rate on the outcome for students with SAT scores above the $75^{\text {th }}$ percentile relative to those below. We have also tried other measures of $\mathrm{AA}_{i}$, such as a quadratic term for SAT scores, and obtained qualitatively similar results. In some specifications, region-year fixed effects are also included to focus on the estimation of $\beta_{2}$.

If changes in expected F-1 visa restrictiveness have an impact on SAT taking and score sending, international enrollment is also likely influenced. We use model (2) to assess the effect of $\mathrm{FRR}_{j t}$ on student $i$ 's US enrollment probability conditional on taking the SAT or sending test scores, as well as the selectivity of the school attended by $i$. We use model (1) to quantify the impact of $\mathrm{FRR}_{j t}$ on the aggregate enrollment level and the academic ability composition. While our timing of the visa refusal rate aims to capture the chilling effect on enrollment via SAT taking and score sending, a higher refusal rate may reduce enrollment mechanically, conditional on college acceptances. In Section 7.5, we discuss how the mechanical effect may influence our results on enrollment outcomes.

We address two potential biases that can prevent a causal interpretation of the co- 
efficient of the F-1 visa refusal rate. First, simultaneity bias can arise if the supply of international students applying for visas affects the F-1 visa refusal rate. For example, if there are more qualified student visa applicants, the refusal rate will be lower and does not reflect changes in visa restrictiveness. In fact, we see in Section 3.3 that the composition of international students has changed, which may be correlated with changes in the quality composition of visa applicants. To address this issue, we instrument the F-1 visa refusal rate with the $B$ visa refusal rate for the same region in the same period.

The $\mathrm{B}$ visa refusal rate has attractive features that render it a good instrument. For instance, it satisfies the relevance assumption. As described in Section 5.2, B and F-1 visas share many administrative features. Their refusal rates have similar magnitudes and strong comovement within regions. Other major nonimmigrant visa types have much lower refusal rates, with little variation over time. We formally test for the relevance assumption whenever we report IV estimates. Furthermore, while the refusal rate for B visas reflects policy restrictiveness on US entry, B visas are not for international students. Hence, the $B$ visa refusal rate isolates the variation in visa restrictiveness and likely satisfies the exclusion restriction (conditional on additional controls).

Second, omitted variable bias (OVB) can arise if F-1 or B visa refusal rates are correlated with unobservables that also influence international students' decision to invest in a US education. In Section 5.3, we described several factors that potentially drive the variation in refusal rates other than the supply of student visa applicants. Motivated by the spirit of those factors, we first include region and year fixed effects to control for any regionspecific identifies (e.g., being an US ally) and general time trends (e.g., the globalization of education). In addition, we include a rich set of region-time varying characteristics, including economic growth, trade with the US, demand for college education, enrollment abroad but not in the US, and work visa condition in the US. ${ }^{19}$ Both trade and work visa condition are specific to a region's network with the US. In our student-level analysis, we further include region-year fixed effects to test the sensitivity of the coefficient for the interaction between F-1 visa refusal rate and academic ability, which removes concern about region-year unobservables.

In the rest of the paper, our estimation sample includes data from 101 regions with the highest number of SAT takers in 2004-15. We start with a sample of 124 regions with complete data on visa refusal rates, which cover more than 99 percent of all international

\footnotetext{
${ }^{19}$ We use goods imports from the US and exports to the US. We have also tried non-US-specific trade measures and found nearly identical results. The measure of economic growth is real GDP per capita in USD, which embeds the variation in exchange rates.
} 
SAT takers in the sample period. We exclude 22 regions that are members of the VWP, since we do not have valid B visa refusal rates for them. During our sample period, 10 regions joined the VWP at different times, but all have at least 5 years when they are not in the VWP. We exclude the time periods when these 10 regions are in the VWP. Our results are robust when we exclude the 10 regions entirely (see Section 7.4). We further exclude Canada, as Canadians need neither B visas nor F visas. Regions in our analysis cover 75 percent of all international SAT takers in the sample period.

\section{$7 \quad$ Visa Policy Results}

\subsection{Impact on SAT taking}

Table 4 shows estimates for the impact of the expected F- 1 visa refusal rate on international SAT taking using model (1). The outcome variable in columns 1-3 is log of the number of new SAT takers at the region-year-level. Column 1 shows OLS estimate with year and region fixed effects, and suggests that a higher F-1 visa refusal rate is associated with a lower number of international takers. The negative coefficient for the F-1 visa refusal rate persists after adding a set of region-year-varying covariates to control for factors potentially correlated with the refusal rate in column 2 , and instrumenting with the $B$ visa refusal rate in column 3 . The 2SLS estimate in column 3 is statistically significant at 5 percent and suggests that on average, a 10 pp increase in the F- 1 visa refusal rate leads to a 7.4 percent (or 7.1 log points) decrease in international SAT takers. This is larger than the OLS estimate in column 2. The F-statistic for the excluded instrument in the first stage is 90.7 , passing the test of a weak instrument. ${ }^{20}$

Columns 4-7 of Table 4 report estimates with the full set of controls for two outcomes on the academic ability of international SAT takers: the median SAT in the unit of SD and the share of takers with a score above the $75^{\text {th }}$ percentile ("high-scoring takers" hereafter). ${ }^{21}$ The 2SLS estimates are much larger than the OLS estimates. A 10 pp increase in the F-1 visa refusal rate leads to a 0.04 SD decrease in the median SAT among SAT takers and about 2 pp decrease in the share of high-scoring takers.

\footnotetext{
${ }^{20}$ See Appendix Table A.1 for complete estimates from the first stage.

${ }^{21}$ For the median and share to make sense, we require that a data point has at least three students.
} 


\subsection{Impact on score sending}

Next, we move to the student-level analysis that examines the impact of F-1 visa restrictiveness on score-sending. Appendix Table A.2 provides summary statistics for outcome variables, visa refusal rates, and student-level controls for the analysis sample. Table 5 shows estimates from models (2) and (3), in which the outcome is an indicator for sending SAT scores to at least one US college. Panel A reports OLS estimates and Panel B reports 2SLS estimates. For both panels, column 1 includes the F-1 visa refusal rate and region and year fixed effects. Column 2 adds a set of student-level controls, including SAT quadratic and demographics (gender, age, parental education, family income). Column 3 further adds a set of region-year-level covariates, which are the same as those included in Table 4. The estimated coefficient for the visa refusal rate changes little after adding various controls. The 2SLS estimates are much larger than the OLS estimates and are statistically significant. The F-statistics for the excluded instruments in the first stage pass the weak instrument test. Column 3 of Panel B indicates that a 10 pp increase in the F-1 visa refusal rate decreases the probability of score sending by $1.7 \mathrm{pp}$, or about 3.7 percent of the average score-sending probability.

To study whether the impact on score sending varies by student ability, columns 4-5 of Table 5 add an interaction between the visa refusal rate and an indicator for being a high-scoring taker. Estimates from column 4 show that high-scoring test takers are nearly twice as responsive to a more restrictive visa policy than low-scoring takers. A $10 \mathrm{pp}$ increase in the F-1 visa refusal rate decreases the probability of score sending by $1.3 \mathrm{pp}$ for low-scoring students and and $2.3 \mathrm{pp}$ for high-scoring students. Column 5 includes region-year fixed effects to control for unobservables at the same level as visa refusal rates. The interaction coefficient estimate changes little from column 4.

We further study the impact on score sending by examining the composition of score sends conditional on sending scores to at least one US college. We focus on 2SLS estimates in Table 6 and report OLS estimates in Appendix Table A.3. While Panel A of Table 6 shows that a more restrictive F-1 visa policy does not affect the number of score sends, column 3 of Panel B shows that on average, a $10 \mathrm{pp}$ increase in the F-1 visa refusal rate increases the average selectivity of schools receiving scores by 4 SAT points (or 0.03 SD). When using the maximum SAT among schools receiving scores, columns 4-5 of Panel C suggest that the effect on score-sending selectivity is larger for low-scoring students than high-scoring students. Hence, conditional on sending test scores, SAT takers send scores to slightly more selective US colleges in response to a higher refusal rate without changing 
the number of score sends.

\subsection{Impact on enrollment}

Because a higher expected F-1 visa refusal rate decreases the number of international SAT takers and discourages sending test scores to US colleges, it may also affect international enrollment. Assuming the marginal SAT taker has the same probability of enrolling in the US as the average SAT taker, the effect on SAT taking translates directly to enrollment. For example, in response to a $10 \mathrm{pp}$ increase in the F-1 visa refusal rate, a 7.4 percent decrease in SAT takers implies an 7.4 percent decrease in international enrollment on average.

We estimate the impact of the F-1 visa refusal rate on US enrollment through score sending by using models (2) and (3), in which the outcome is an indicator for enrolling in the US conditional on taking the SAT. Table 7 presents 2SLS estimates. Columns 3-5 from Panel A show that on average, a $10 \mathrm{pp}$ increase in the refusal rate decreases the enrollment probability at a US college by 4.5 percent (or $1.2 \mathrm{pp}$ ) among SAT takers, which implies a 4.5 percent decrease in the aggregate enrollment. High-scoring takers are slightly less influenced, but statistically indistinguishable from low-scoring takers. We report OLS estimates in Appendix Table A.4.

Although the impact on US enrollment probability conditional on taking the SAT is similar by academic ability group, there is a nuance. Panel B shows that conditional on enrolling in the US, a higher expected F-1 visa refusal rate increases the selectivity of the enrolled school slightly for high-scoring students but not for low-scoring students. Hence, despite sending scores to more selective schools (see Section 7.2), high-scoring students end up at more selective schools while low-scoring students do not.

We assess the impact of expected visa restrictiveness on aggregate international enrollment and academic ability using model (1). Table 8 has the same structure as Table 4 . The pattern for the visa refusal rate coefficient is similar to the case of SAT takers. The 2SLS estimates indicate that on average, a $10 \mathrm{pp}$ increase in F-1 visa refusal rate leads to a 12.2 percent (or 11.6 log points) decrease in new international enrollment. It also decreases the median SAT by 0.05 SD and the share of high-scoring students by $2.8 \mathrm{pp}$. Based on our earlier estimates and assuming that the enrollment probability for the marginal SAT taker is the same as the average SAT taker, about 60 percent of the impact on aggregate enrollment is through SAT taking, and about 40 percent is through influencing score-sending decisions.

Although coefficients for the region-year controls are not the focus of our paper, they 
are of interest in the literature on macro determinants of migration. Our estimates show that higher ability to pay for a US education (measured by real GDP per capita in USD), more imports from the US, greater trends of studying abroad (measured by enrollment in other popular destinations), and better chances of obtaining a work visa (measured by $\mathrm{H}-1 \mathrm{~B}$ visa issuance) are associated with higher international student enrollment and more SAT takers. There is no consistent evidence that these factors are associated with the composition of international students to a large extent. We do not emphasize these results, because some of the measures can be quite noisy. For example, H-1B visa issuance may also reflect the number of $\mathrm{H}-1 \mathrm{~B}$ applicants and the desire to stay in the US for employment.

\subsection{Robustness checks}

One potential concern about our results on the aggregate enrollment and enrollment effect through score sending is that estimates may partially reflect a mechanical effect of the visa refusal rate. That is, fewer students enroll because they are rejected by visa consular officers. While we use the refusal rate around the time students make scoresending decisions, the concern persists if visa refusal rates are highly serially correlated. To address this concern, we directly add the visa refusal rate in the period when potential visa appointments occur to our existing empirical framework. We also include a specification in which the average refusal rate for the previous 3 years is used instead of the rate for the previous year. Appendix Tables A.5, A.6, and A.7 show that the impact of the visa refusal rate on enrollment outcomes is primarily driven by the refusal rate prior to a student's high school graduation year. In addition, because our instrument for the F-1 visa refusal rate is not driven by student visa applicants and isolates the variation in visa restrictiveness, the 2SLS estimates help to tease out the mechanical effect. ${ }^{22}$

Our results are robust to a number of alternative measures and sample selection. First, Appendix Table A.8 reports student-level estimates using a more flexible measure of academic ability, and it shows qualitatively the same results when using the SAT quadratic instead of an indicator for high-scoring students. Second, Appendix Table A.9 shows consistent results when using the number of high-scoring SAT takers/enrollees instead of the share in our region-level analysis. Third, because the number of score sends is count data in nature, we also report estimates from Poisson regressions in Appendix Table A.10, and find no difference. Last, our results are robust when excluding 10 regions entirely

\footnotetext{
${ }^{22}$ Estimating the mechanical effect of F-1 visa restrictiveness on international enrollment requires data on visa applications, which is beyond the scope of our paper.
} 
that become VWP members during our sample period. The main results presented in the paper are mostly conservative compared with estimates that exclude the 10 regions entirely, which are reported in Tables A.11-A.12.

\subsection{Discussion of the heterogeneity in academic ability}

Because the college application process is costly, an increase in the F-1 visa refusal rate decreases the expected value of pursuing a US education. We find that an increase in expected F-1 visa restrictiveness decreases foreign investment in a US college education prior to visa appointments. Specifically, there are fewer SAT takers, and SAT takers are less likely to send scores to US schools; both lead to a decrease in international enrollment in the US. Prospective students who send scores also send to more selective institutions, presumably to increase the expected value of studying in the US.

Notably, high-scoring students are more responsive to changes in visa restrictiveness than low-scoring students in terms of taking the SAT and sending scores to any US college. There are at least five possible reasons. First, high-scoring students may have better options elsewhere. Hence when the expected value of US college applications decreases, they are more likely to invest their time in other options. Major competitors with the US for international students include Canada, the UK, and Australia, where the risk of not obtaining a student visa is much lower. For example, the success rate in obtaining a student visa to study in the UK is over 98 percent in 2018. ${ }^{23}$ In addition, many high-quality universities in these regions have made themselves more accessible to international students. For instance, the University of Cambridge and the majority of Australian universities have started to accept China's college entrance exam score in their admissions process.

Second, Rosenzweig et al. (2006) argue that international students take degrees as a passage to work for higher wages in the US. Higher F-1 visa refusal rates may signal a lower chance of working in the US after graduation. In fact, US colleges receive fewer score sends from international students in the top SAT quintile after a reduction in the probability of staying in the US to work (Kato and Sparber, 2013). Furthermore, we assume that highscoring students would attend more selective institutions than low-scoring students in either the US or their home region. Results from Chen (2019) suggest that in the case of China, relative to low-scoring students, high-scoring students have lower job callback rates after returning home than if they had stayed. In other words, when the expected

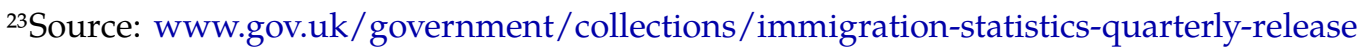


chance of staying in the US decreases, high-scoring students have a stronger labor market incentive to stay in their home region than low-scoring students.

Third, while sending scores to slightly more selective US institutions increases the expected benefit of college applications, we show in Section 7.2 that high-scoring students are less responsive on this dimension, especially for the most selective school they send scores to. This is likely because high-scoring students already send scores to selective US colleges and are limited in the scope of changing their application portfolio. While the $99^{\text {th }}$ percentile of school selectivity (i.e., SAT score) is 1420, the maximum SAT of score sends is 1392 for high-scoring students. In contrast, the maximum SAT of score sends for low-scoring students is only 1272.

Fourth, we are interested in the impact of the region-level anticipated uncertainty in obtaining a visa, which reflects US policy toward a certain region. Theoretically, F-1 visa refusal rates may vary by student type. A particular concern is whether school selectivity is correlated with the chances of getting a visa. While we cannot obtain access to refusal data at the individual level, it is unclear how school selectivity would be correlated with the refusal rate. Visa officers may suspect the intention of a student who is going to a non-selective school, but they may also suspect that students going to a selective school are more likely to stay after graduation. In practice, prospective students form an expectation of overall visa restrictiveness from various online platforms, on which previous applicants share their experiences; news reporting on policy shifts; and paid college consulting services. To the best of our knowledge, these sources do not offer information on visa restrictiveness by school selectivity. Our empirical strategy also isolates the variation in visa restrictiveness that is not driven by the composition of students.

Fifth, high-scoring students may use information on visas restrictiveness differently from low-scoring students. For example, they may have better access to the information and are better at calculating the expected benefit of completing the college application and visa process. It could also be that high-scoring students are more risk-averse, so that they particularly dislike a higher level of uncertainty. Future work may further explore why high-scoring students are more responsive to visa restrictiveness.

\section{Conclusion}

International students not only benefit local institutions and supply skilled labor (Kerr, 2018); they are also important for cultural and political exchange. Student visa programs are a common policy tool for bringing global talent. Understanding how people make 
decisions to invest in global human capital is essential when designing relevant immigration and education policies. Our paper finds that the F-1 visa in the US has brought international students with academic ability higher than the average domestic student for college education. In addition, the anticipated chances of obtaining a visa affect international students' decisions on investing in a US education. A higher F-1 visa refusal rate decreases the quantity and academic ability of international students coming to the US, by discouraging students from taking the SAT and sending test scores, especially high-scoring students.

Results from our paper suggest that F-1 visa restrictiveness has important welfare implications for students, institutions, and the US labor market. Policymakers who claim that their goal is to attract the best international migrants may especially want to take our results into consideration. Given that variation in the visa refusal rate go up and down over time, a different way to read our results is that a more welcoming entrance visa policy will not only attract more international students with higher SAT scores than the average domestic student, but also disproportionately more high-scoring international students.

Our results suggest that a more relaxed F-1 visa policy can stimulate the inflow of international students, which can be important in light of studies showing that many US public universities have relied on recruiting international students to offset state funding cuts and subsidizing domestic students (Shih, 2016; Bound et al., 2020; Chen, 2020). A back-of-the-envelope calculation indicates that a $10 \mathrm{pp}$ decrease in the F-1 visa refusal rate would increase international undergraduate enrollment by about 13,807 students each year. ${ }^{24}$ This implies a $\$ 559$ million increase in tuition revenue and living expenses from international undergraduate students in each cohort for each year. ${ }^{25}$ This accumulates to $\$ 9$ billion in tuition revenue every 4 years.

Finally, note that the visa refusal rate is not the only measure of policy restrictiveness. Recent media have reported an increase in visa processing time and policies that decrease student visa duration and increase the SEVIS fee. In addition, our data do not observe a student's college outcome outside the US. Future work may want to take other types of immigration frictions into consideration and explore student outcomes if they do not come to the US.

\footnotetext{
${ }^{24}$ We multiply 12.2 percent by the average of IIE's new international undergraduate enrollment in 2013-14 to $2017-18$ academic years, which is 113,178 .

${ }^{25} \mathrm{We}$ compute the net expense as the cost of tuition and fees and living expenses minus funding support from US institutions using administrative data on all F-1 visa holders who started an undergraduate degree program in 2017. The average net expense is $\$ 40,474$ for 2017.
} 


\section{References}

1. Abramitzky, Ran and Victor Lavy (2014). "How Responsive is Investment in Schooling to Changes in Redistributive Policies and in Returns?" Econometrica 82.4, pp. 12411272.

2. Akyol, Ş. Pelin, Kala Krishna, and Jinwen Wang (2019). “Taking PISA Seriously: How Accurate are Low Stakes Exams?" NBER Working Paper No. 24930.

3. Anelli, Massimo, Kevin Shih, and Kevin Williams (2019). "Foreign Peers in College and the STEM Careers of Domestic Students." IZA Working Paper 10743.

4. Bound, John, Breno Braga, Gaurav Khanna, and Sarah Turner (2020). "A Passage to America: University Funding and International Students." American Economic Journal: Economic Policy 12.1, pp. 97-126.

5. Bound, John, Murat Demirci, Gaurav Khanna, and Sarah Turner (2015). "Finishing Degrees and Finding Jobs: US Higher Education and the Flow of Foreign IT Workers." Innovation Policy and the Economy 15.1, pp. 27-72.

6. Bound, John, Sarah Turner, and Patrick Walsh (2009). "Internationalization of US Doctorate Education." NBER Working Paper No. 14792.

7. Card, David and Alan B Krueger (2005). "Would the Elimination of Affirmative Action Affect Highly Qualified Minority Applicants? Evidence from California and Texas." Industrial and Labor Relations Review 58.3, pp. 416-434.

8. Charles, Kerwin Kofi, Erik Hurst, and Matthew J Notowidigdo (2018). "Housing Booms and Busts, Labor Market Opportunities, and College Attendance." American Economic Review 108.10, pp. 2947-94.

9. Chen, Mingyu (2019). "The Value of US College Education in Global Labor Markets: Experimental Evidence from China." Industrial Relations Section Working Papers No. 627.

10. Chen, Mingyu (2020). "Are Public Universities Still Public? The Impact of Service Exports on the US Higher Education Market." Mimeo.

11. Dale, Stacy Berg and Alan B Krueger (2002). "Estimating the Payoff to Attending a More Selective College: An Application of Selection on Observables and Unobservables." The Quarterly Journal of Economics 117.4, pp. 1491-1527.

12. Deming, David and Susan Dynarski (2010). Into College, Out of Poverty? Policies to Increase the Postsecondary Attainment of the Poor; Targeting Investments in Children: Fighting Poverty When Resources are Limited. University of Chicago Press.

13. DOS (2019). Report of the Visa Office 2018. The US Department of State. 
14. Dynarski, Susan, CJ Libassi, Katherine Michelmore, and Stephanie Owen (2018). "Closing the Gap: The Effect of a Targeted, Tuition-Free Promise on College Choices of High-Achieving, Low-Income Students." NBER Working Paper No. 25349.

15. Farrugia, Christine (2017). Trends in International Secondary Students in the United States, 2013-2016. Institute of International Education.

16. Hoxby, Caroline and Sarah Turner (2013). "Expanding College Opportunities for High-Achieving, Low Income Students." Stanford Institute for Economic Policy Research Discussion Paper 12-014.

17. IIE (2019). Open Doors Report on International Educational Exchange. Institute of International Education.

18. Jensen, Robert (2010). "The (Perceived) Returns to Education and the Demand for Schooling." The Quarterly Journal of Economics 125.2, pp. 515-548.

19. Kato, Takao and Chad Sparber (2013). "Quotas and Quality: The Effect of H-1B Visa Restrictions on the Pool of Prospective Undergraduate Students from Abroad." Review of Economics and Statistics 95.1, pp. 109-126.

20. Kerr, William R (2018). The Gift of Global Talent: How Migration Shapes Business, Economy \& Society. Stanford University Press.

21. Kless, Sylvia H. (2006). "Impact of Changing Immigration Policies on Higher Education Institutions and Their International Students and Scholars." 27th National Conference on Law and Higher Education.

22. Kuka, Elira, Na'ama Shenhav, and Kevin Shih (2020). "Do Human Capital Decisions Respond to the Returns to Education? Evidence from DACA." American Economic Journal: Economic Policy 12.1, pp. 293-324.

23. Loury, Linda Datcher and David Garman (1995). "College Selectivity and Earnings". Journal of Labor Economics 13.2, pp. 289-308.

24. Mountjoy, Jack and Brent Hickman (2019). "The Returns to College(s): Estimating Value-Added and Match Effects in Higher Education". Working Paper.

25. Pallais, Amanda (2015). "Small Differences that Matter: Mistakes in Applying to College." Journal of Labor Economics 33.2, pp. 493-520.

26. Redden, Elizabeth (2019). "China Issues Warning to U.S.-Bound Students". Inside Higher Ed.

27. Rosenzweig, Mark R, Douglas A Irwin, and Jaffrey G Williamson (2006). "Global Wage Differences and International Student Flows [with Comments and Discussion]." Brookings Trade Forum, pp. 57-96. 
28. Shah, Manisha and Bryce Millett Steinberg (2017). "Drought of Opportunities: Contemporaneous and Long-Term Impacts of Rainfall Shocks on Human Capital." Journal of Political Economy 125.2, pp. 527-561.

29. Shaw, Emily J (2015). "An SAT® Validity Primer." College Board Research Paper.

30. Shih, Kevin (2016). "Labor Market Openness, H-1B Visa Policy, and the Scale of International Student Enrollment in the United States." Economic Inquiry 54.1, pp. 121138.

31. Shih, Kevin (2017). “Do International Students Crowd-Out or Cross-Subsidize Americans in Higher Education?" Journal of Public Economics 156, pp. 170-184.

32. Smith, Jonathan (2018). "The Sequential College Application Process." Education Finance and Policy 13.4, pp. 545-575.

33. UNCESCO (2020). United Nations Educational, Scientific and Cultural Organization. URL: http://uis . unesco.org.

34. Westrick, Paul A., Jessica P. Marini, Linda Young, Helen Ng, Doron Shmueli, and Emily J. Shaw (2019). "Validity of the SAT® for Predicting First-Year Grades and Retention to the Second Year." College Board Research Paper.

35. Wiswall, Matthew and Basit Zafar (2014). "Determinants of College Major Choice: Identification using an Information Experiment." Review of Economic Studies 82.2, pp. 791-824. 
Figures and tables 
Figure 1: Aggregate F-1 visa refusal rates

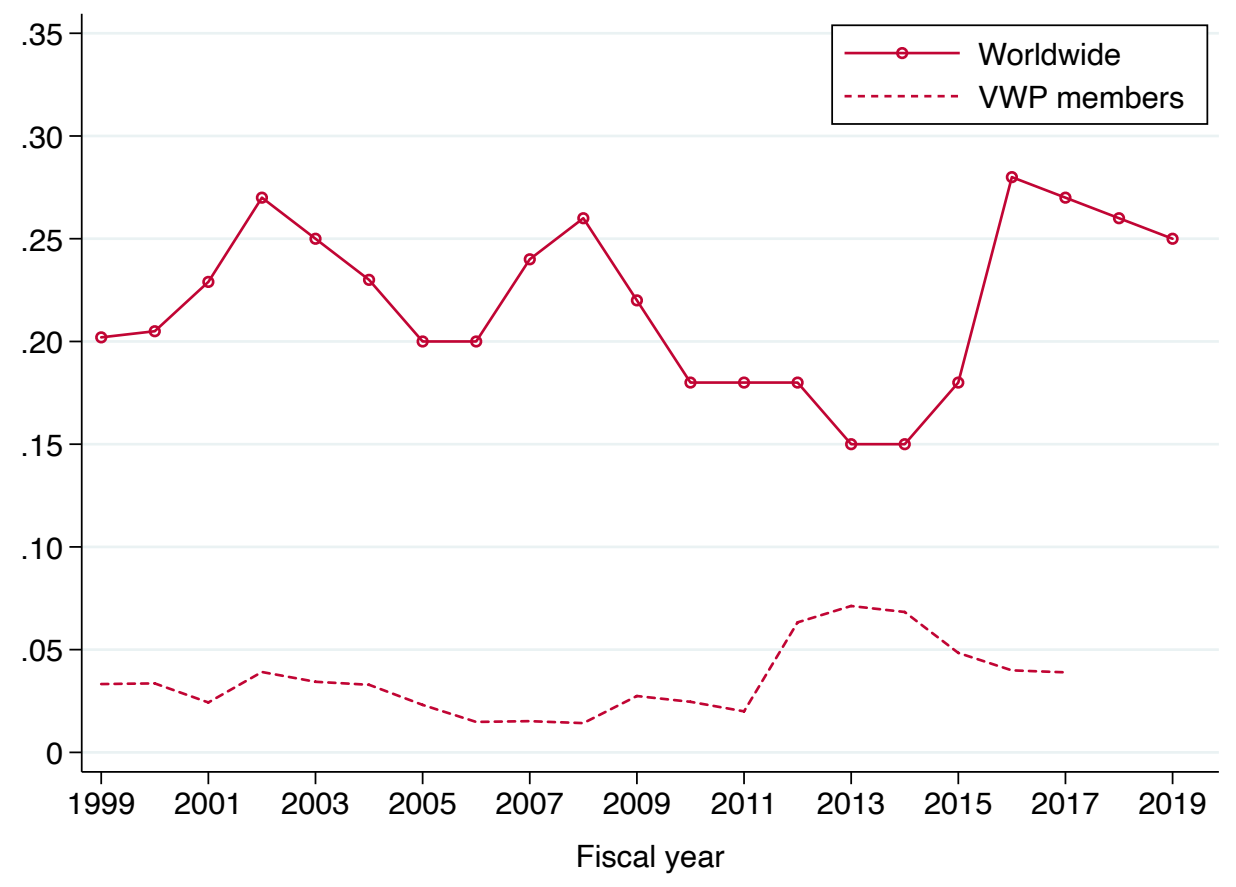

(a) F-1 student visa refusal rates over time

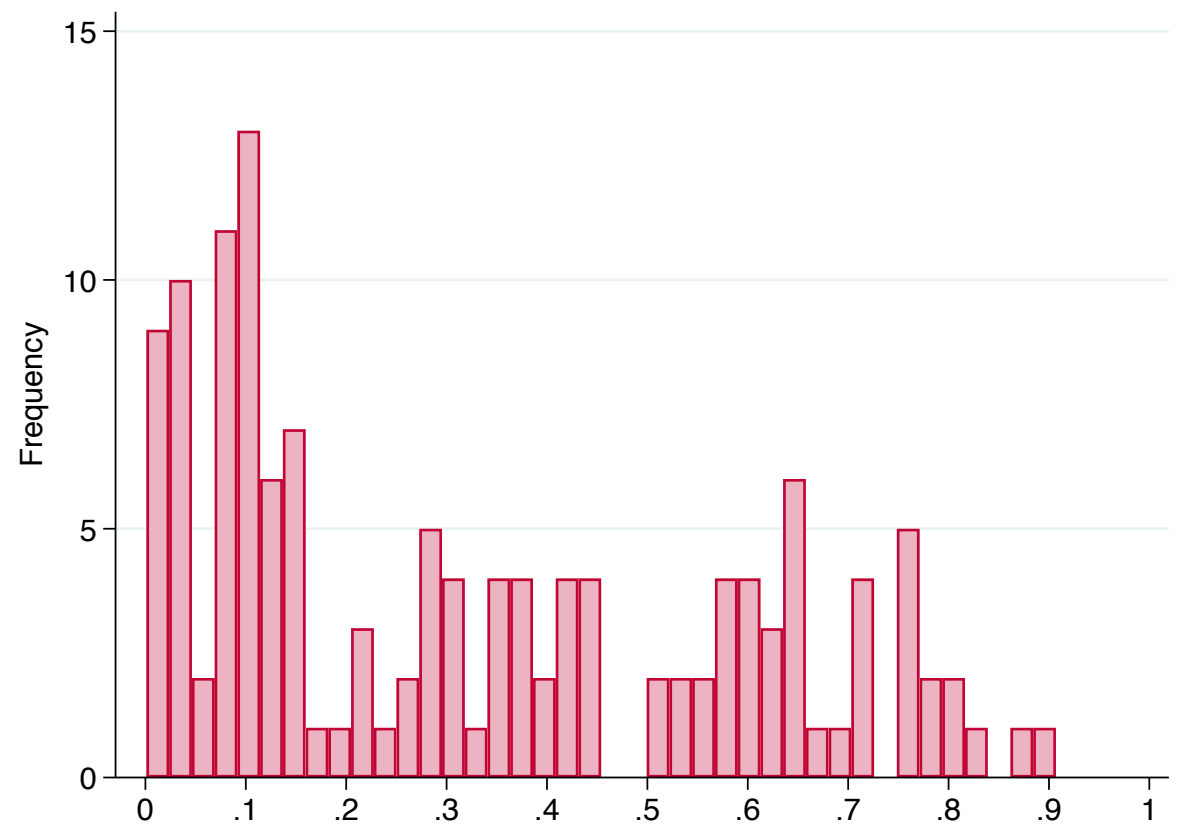

(b) F-1 student visa refusal rates across regions in 2017

Note: Data are obtained from the US Department of State via Freedom of Information Act requests. The refusal rates are adjusted for denials that are later overcome or waived. VWP members are regions in the Visa Waiver Program (for B visas). Figure (b) includes data for 135 regions not covered by the VWP in 2017. 
Figure 2: New international students in the US by region

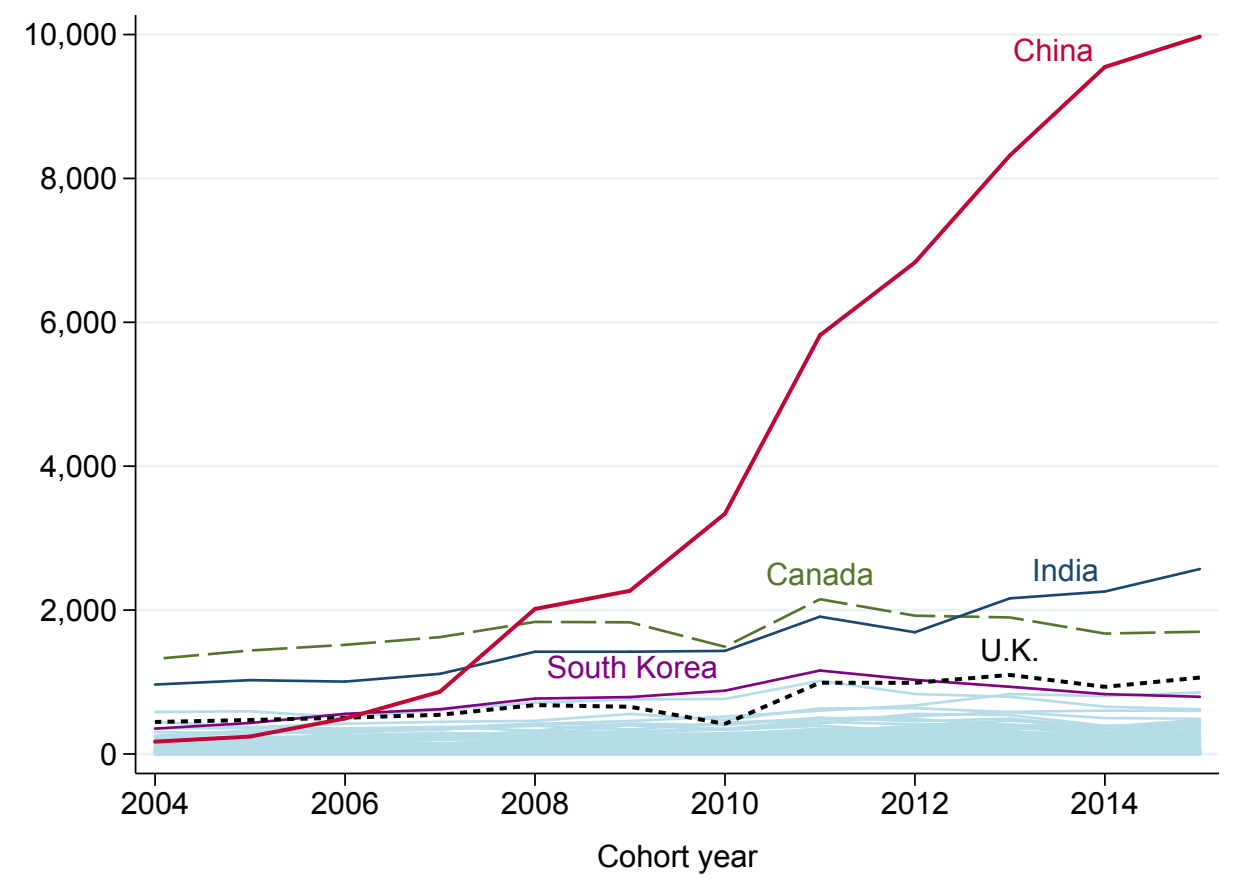

(a) With China

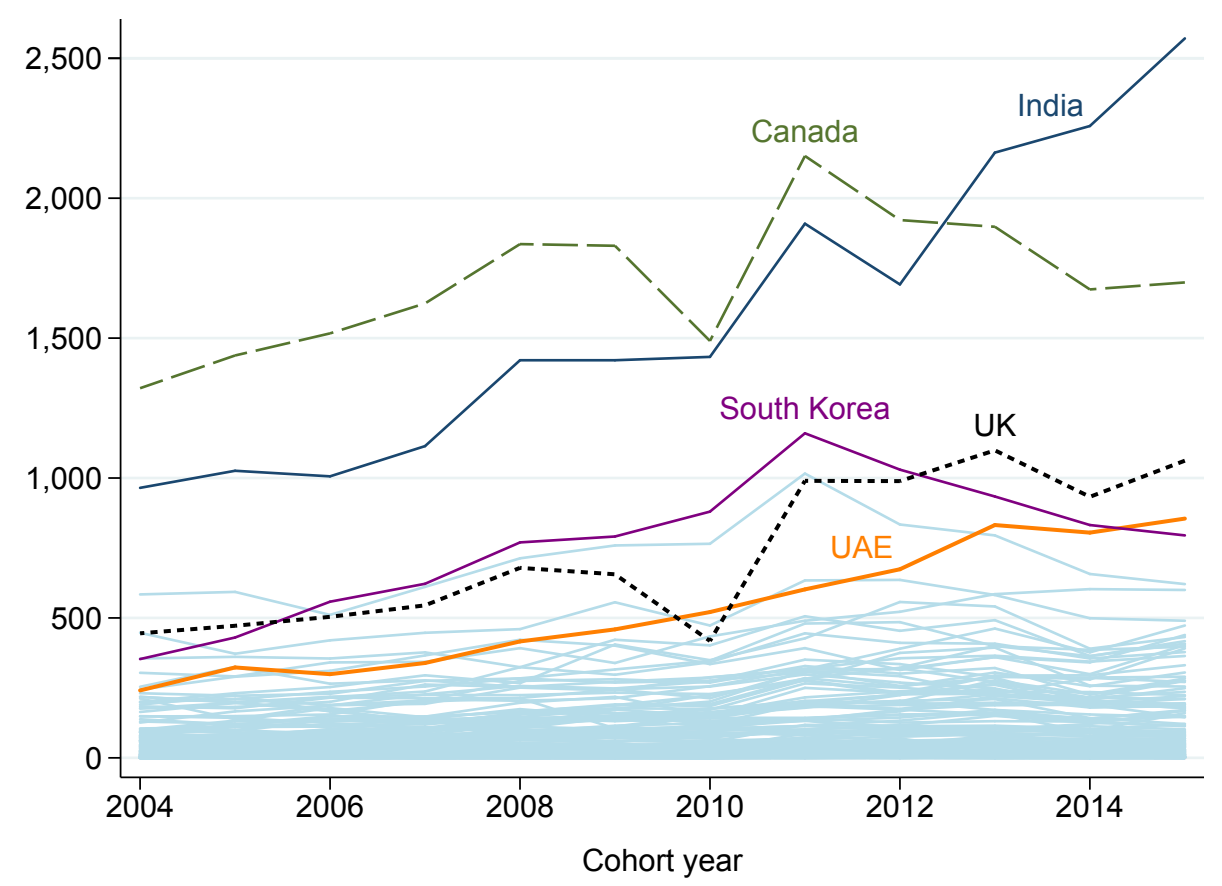

(b) Without China

Note: Data are from the College Board and the National Student Clearinghouse. Data include 2004-15 high school graduating cohorts who enrolled in the US and had an SAT score from 180 regions. 
Figure 3: Rank of 2012 PISA versus mean SAT rank in 3 years

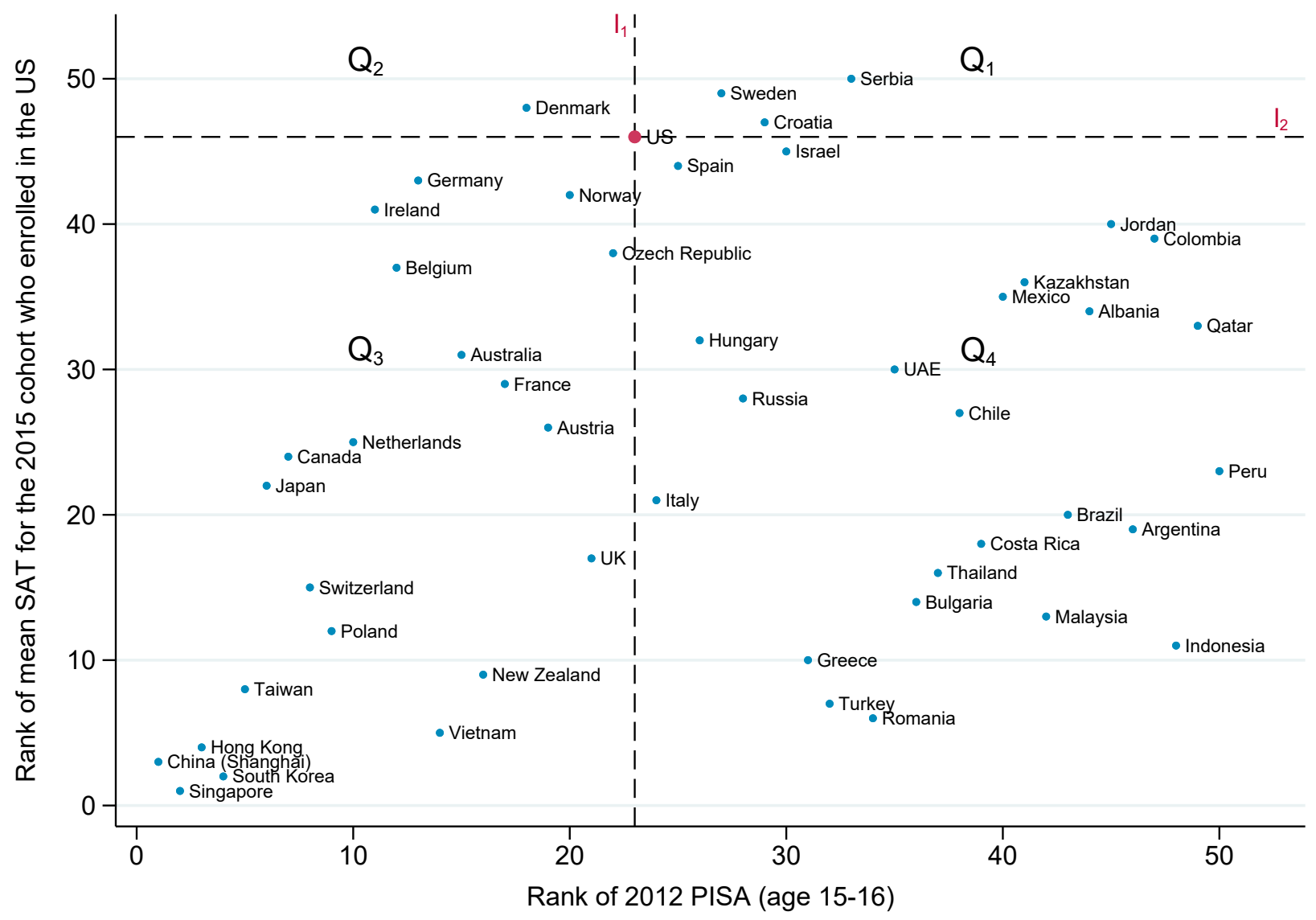

Note: PISA data are from OECD, and SAT data are from the College Board. Ranks are based on math and verbal sections for both PISA and SAT. A total of 50 regions that have both 2012 PISA scores and at least 30 US enrollment in the 2015 high school graduating cohort are included. The SAT ranks are computed based on scores of students enrolled in the US. 
Figure 4: College graduation rate by residency

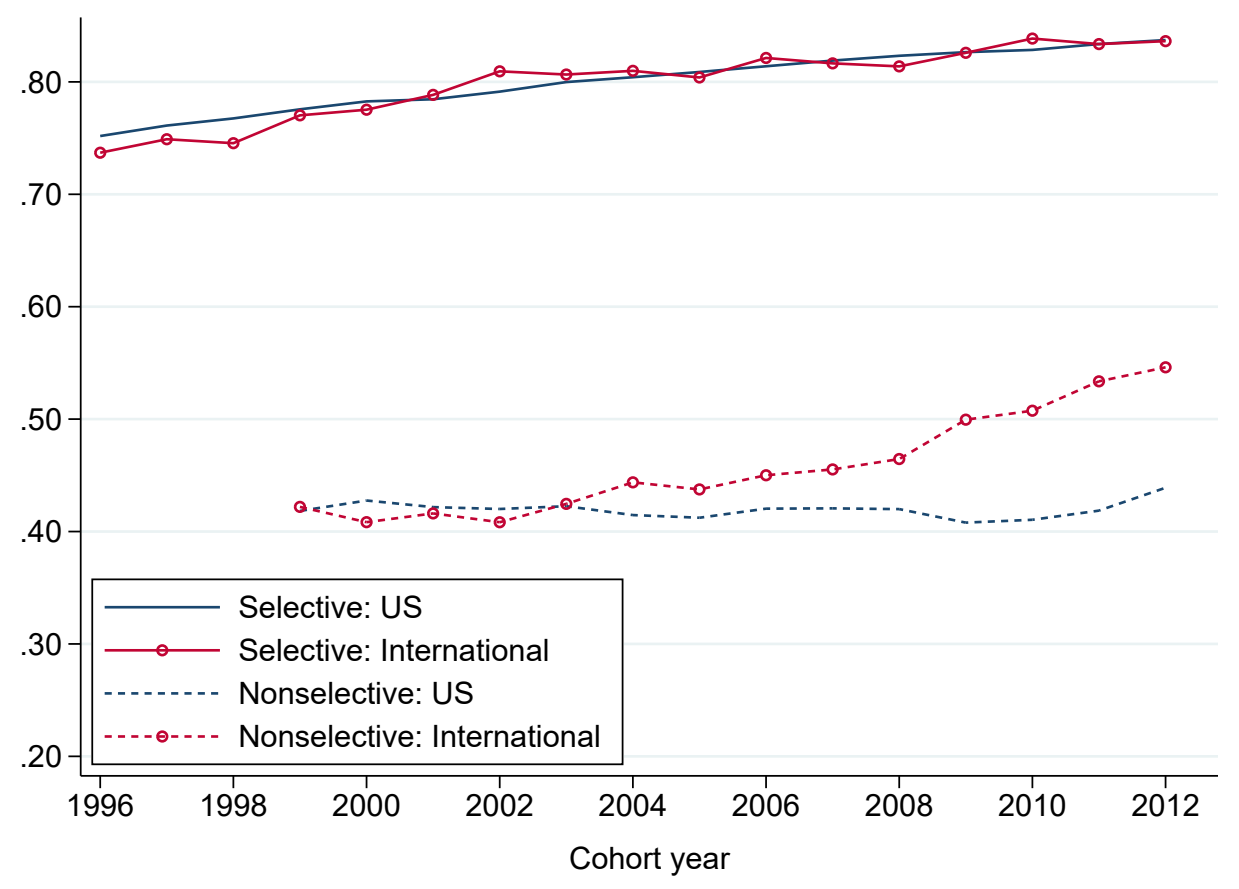

(a) By school selectivity

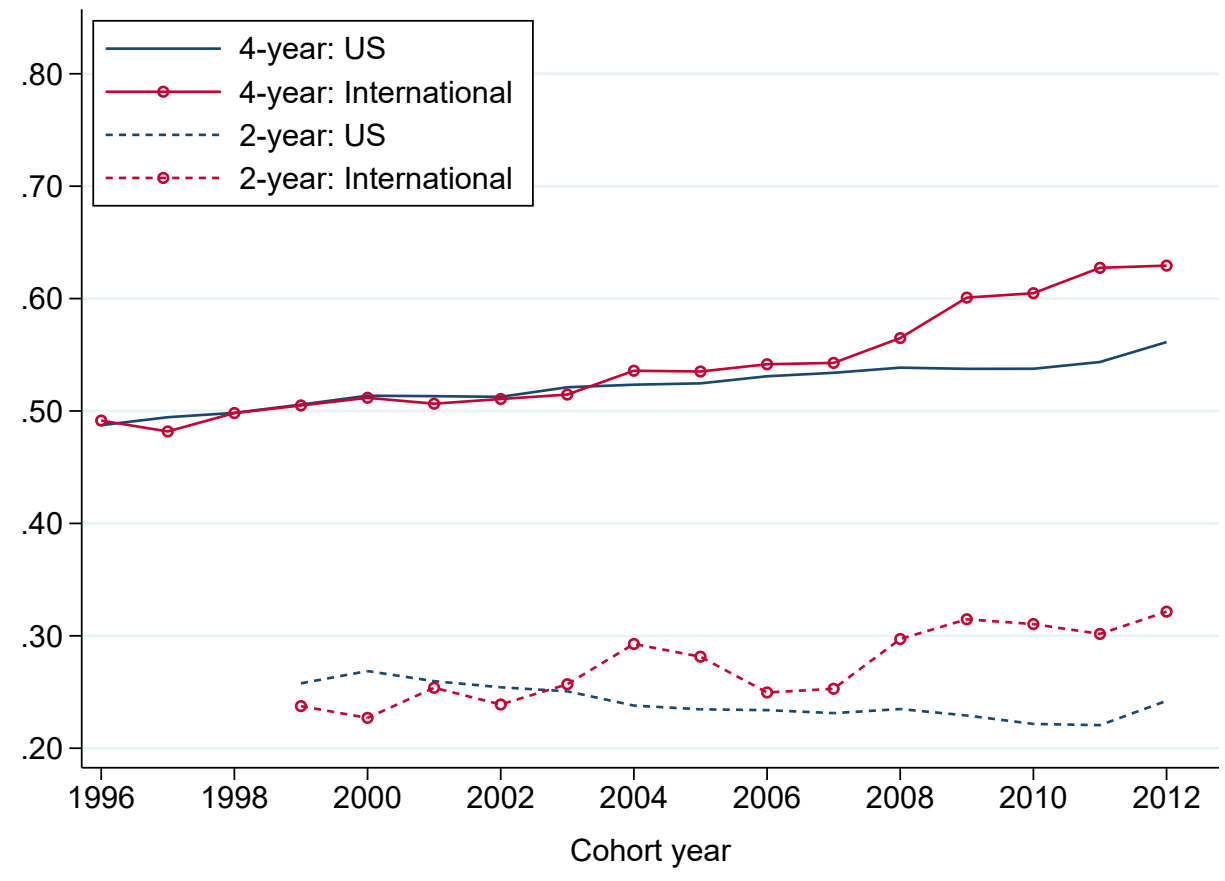

(b) By sector (non-selective school only)

Note: Data are from IPEDS and for Title-VI, degree-granting, non-online, and always-reporting US institutions. Graduation rates are refer to students receiving degrees within 6 years at 4-year colleges and 3 years at 2-year colleges from their initial institutions of attendance. Selective schools are defined as those categorized by Barron's rankings. 
Figure 5: Composition of new international students in the US by SAT percentile

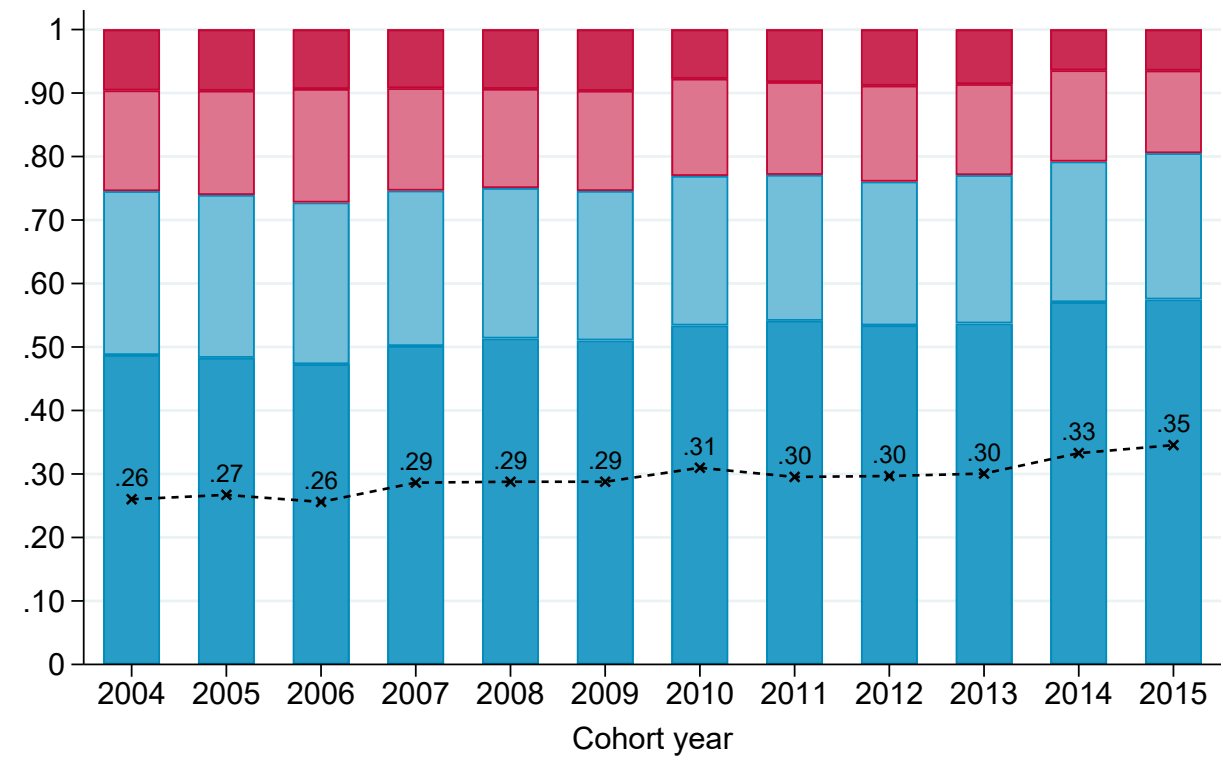

\begin{tabular}{|lll|}
\hline Above $75^{\text {th }}$ pctl & $\square 0^{\text {th }}-75^{\text {th }}$ pctl $\square 25^{\text {th }}-50^{\text {th }}$ pctl \\
Below $25^{\text {th }}$ pctl & $-\cdots \times---$ Above $90^{\text {th }}$ pctl \\
\hline
\end{tabular}

(a) Shares by quartile and the $90^{\text {th }}$ percentile

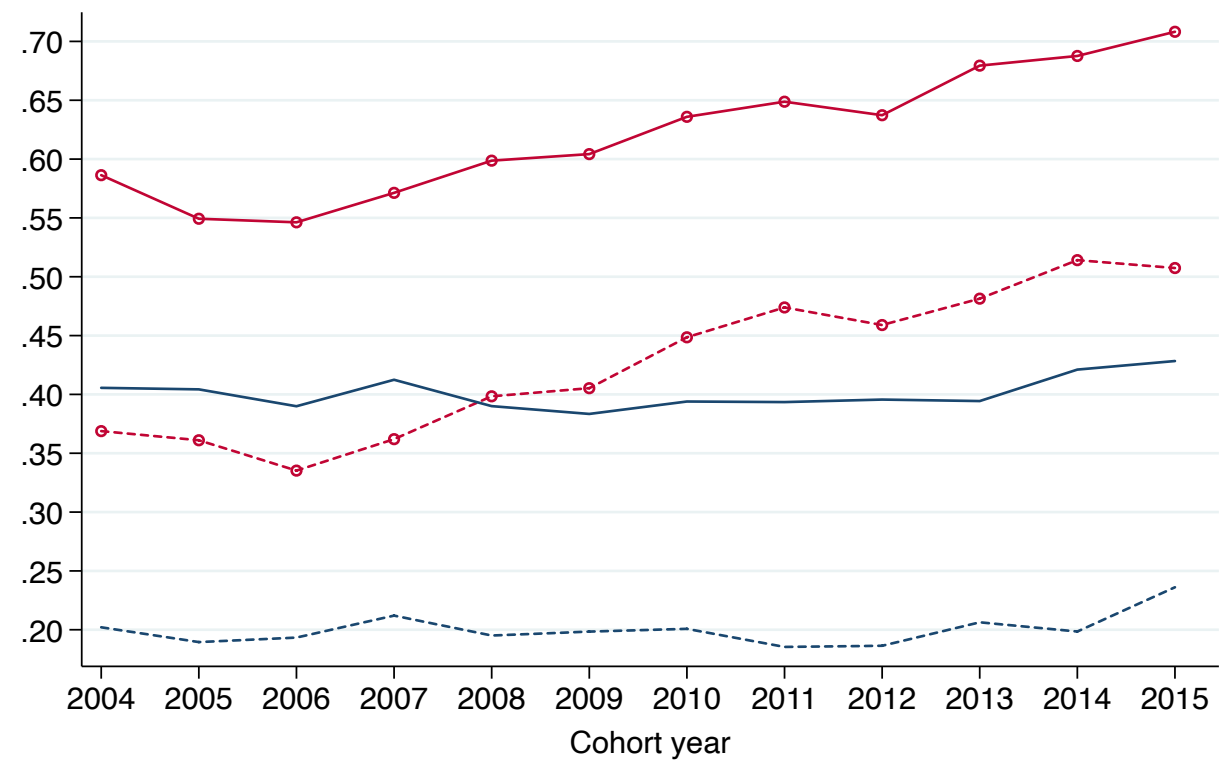

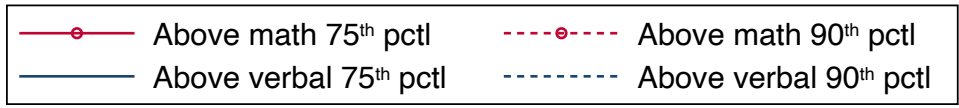

(b) Shares by top percentile by math and verbal

Note: Figures are based on data from the College Board. SAT percentiles are computed from data of US test takers in the same high school graduation cohort. 
Figure 6: Regional shares of new international students in the US by top SAT percentile

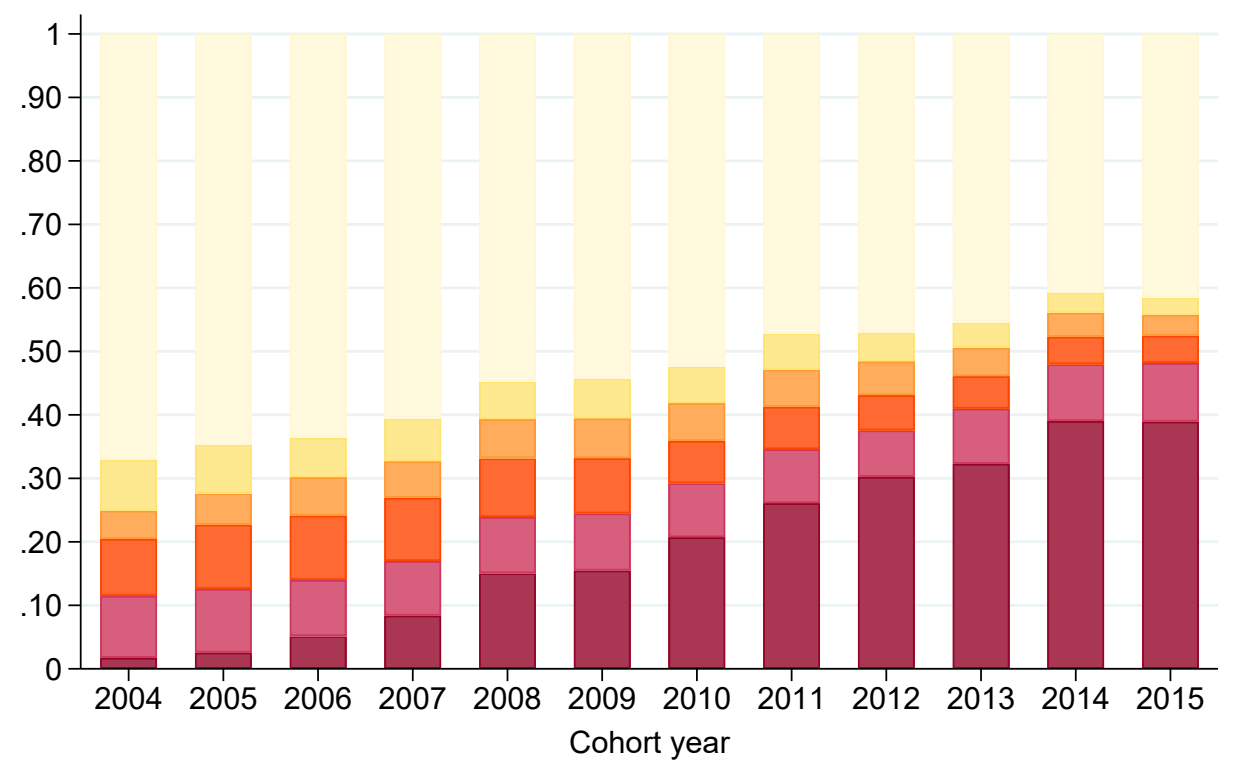

\begin{tabular}{|l|l|l|}
\hline China & India & Canada \\
South Korea & Singapore & Others \\
\hline
\end{tabular}

(a) Enrollees above $75^{\text {th }}$ percentile

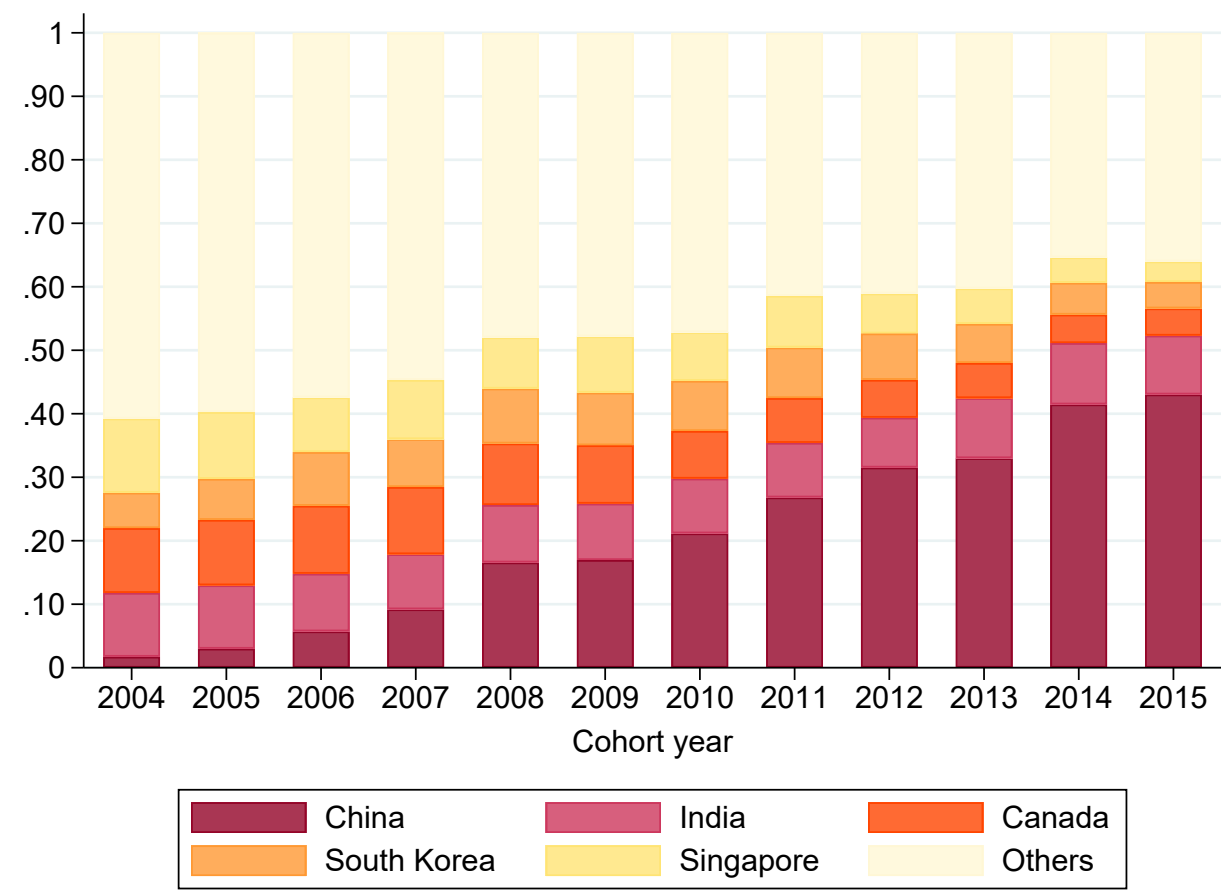

(b) Enrollees above $90^{\text {th }}$ percentile

Note: Figures are based on data from the College Board. SAT percentiles are computed from data on US test takers in the same high school graduation cohort. The five regions with the most top-percentile enrollees in the last 5 years are labeled and "Others" includes data from 175 regions. 
Figure 7: Share of SAT takers who send scores to at least one US college and enroll by region, 2004-15 cohorts

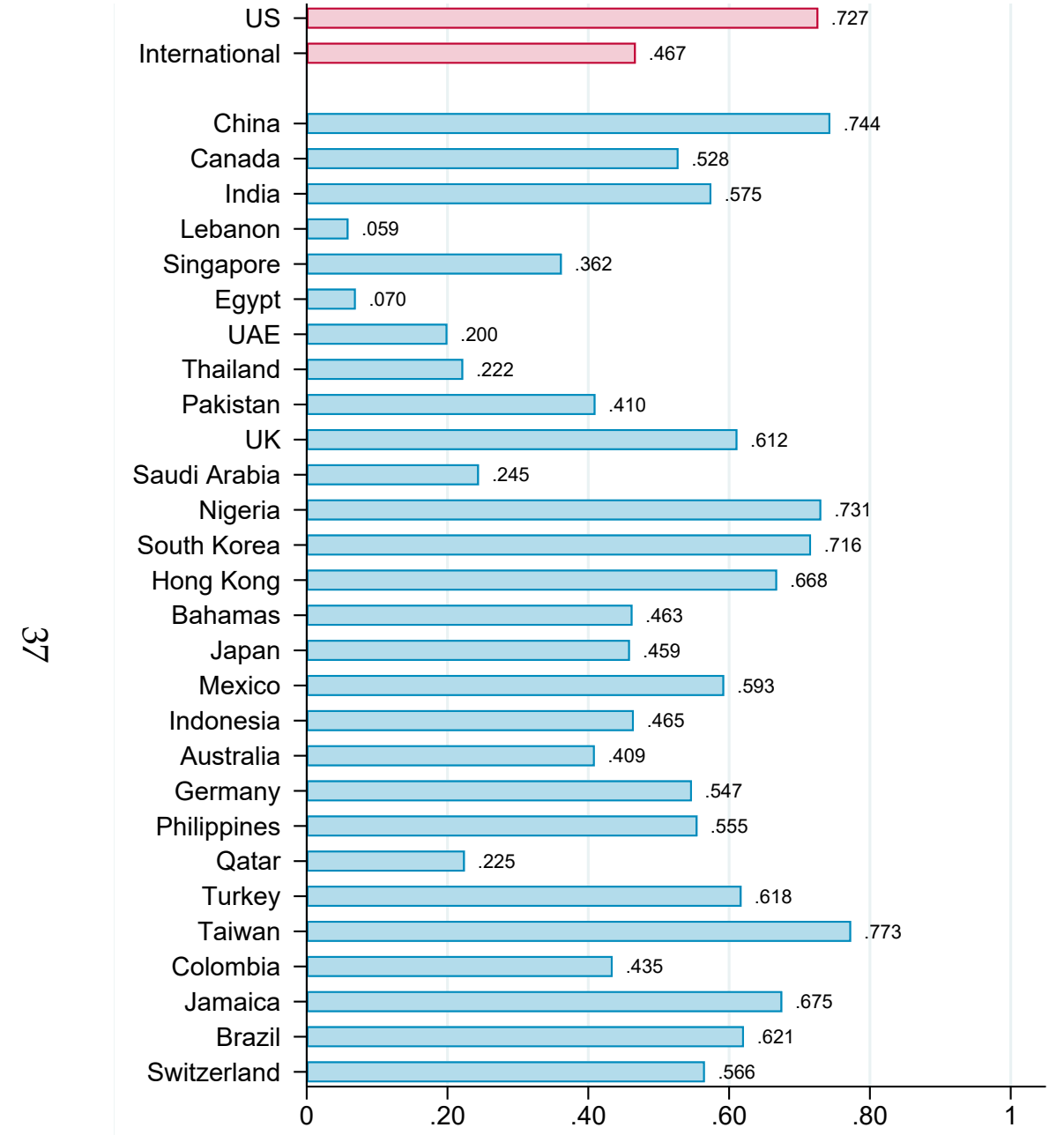

(a) Share of takers who send scores to at least one US college

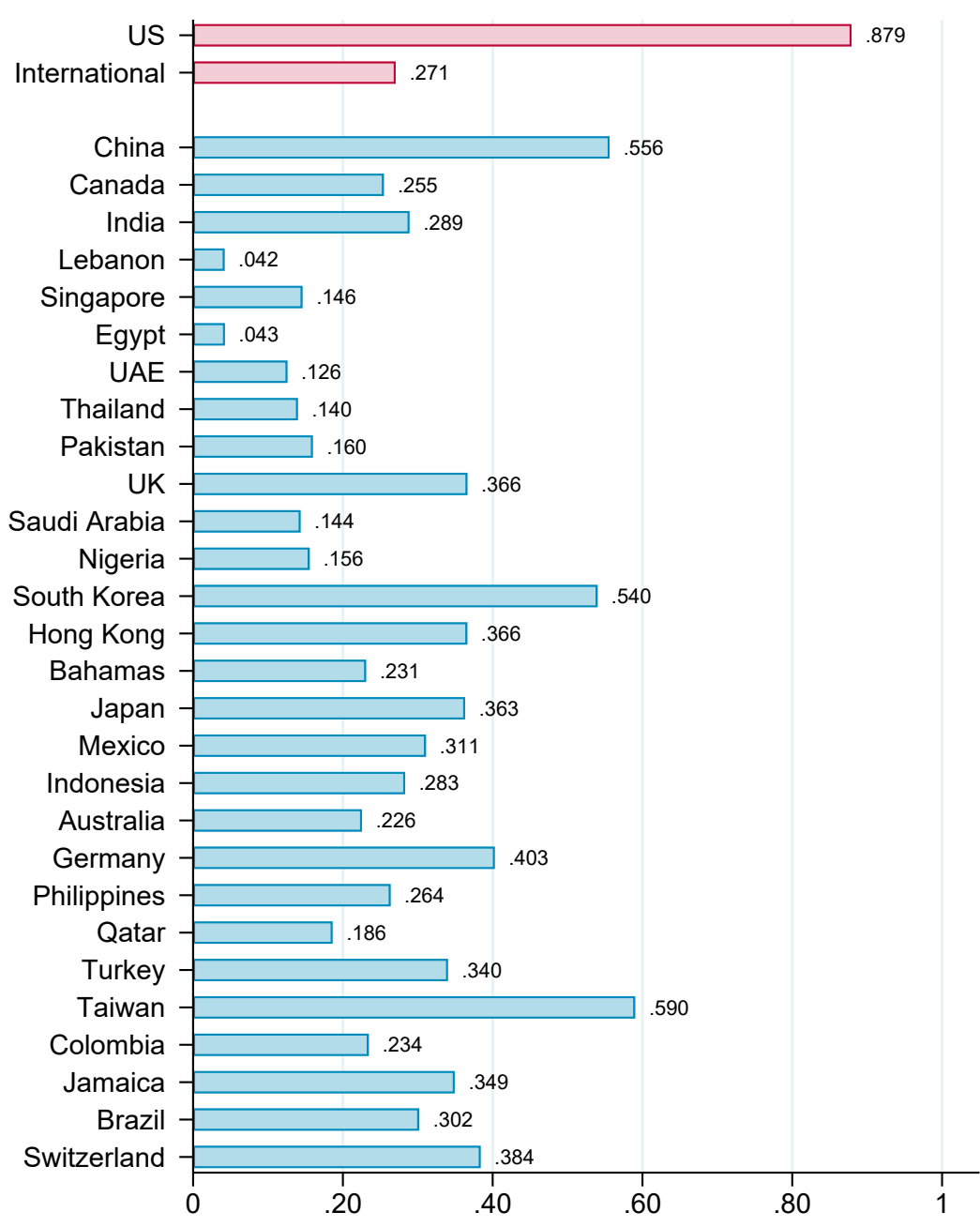

(b) Share of takers who enroll

Note: Figures are based on data from the College Board for 2004-15 high school graduation cohorts. A score sender is an SAT taker who sent scores to at least one US college, and an enrollee is a taker who is matched to a US college enrollment record at the National Student Clearinghouse. In addition to the US and international total, 30 regions with the most SAT takers in the time period are listed. 
Figure 8: Enrollment probability and score-sending decisions by SAT score

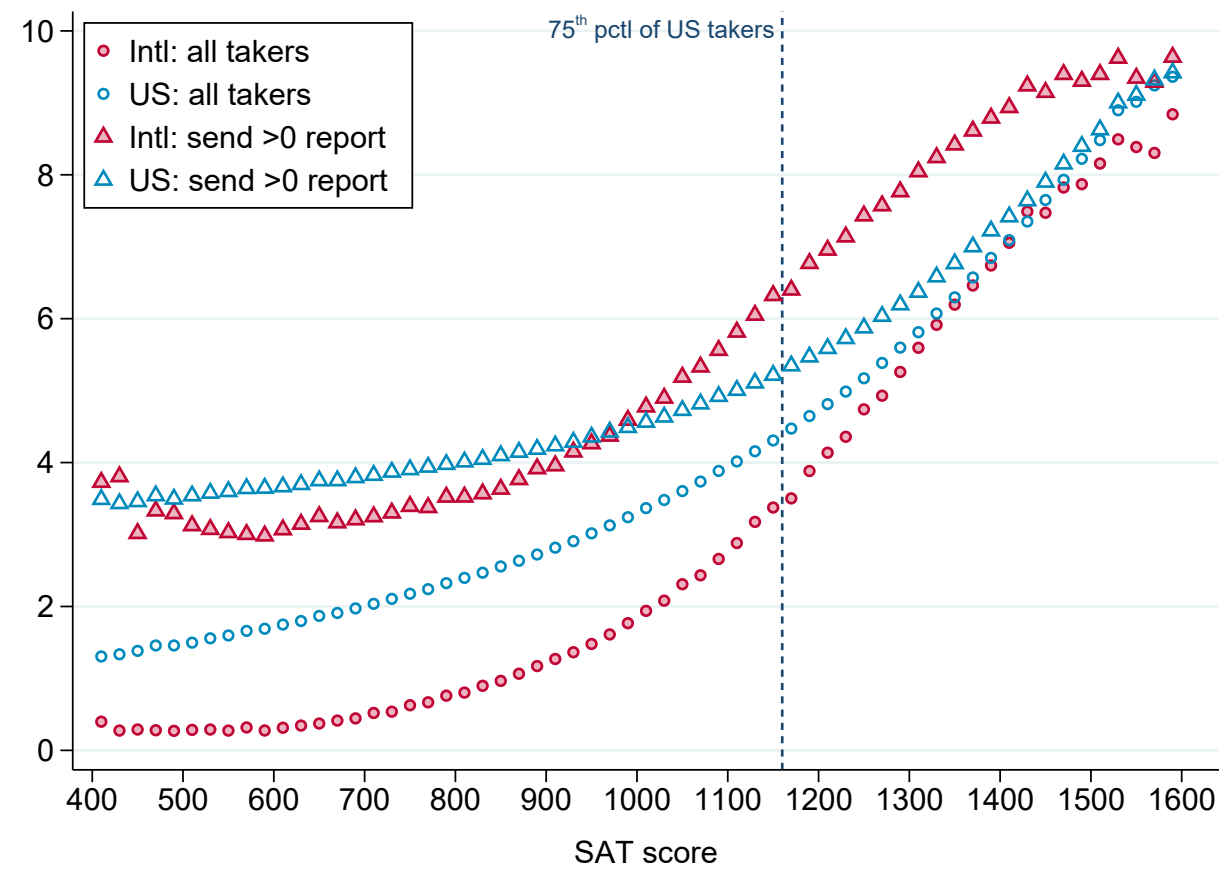

(a) Number of score sends

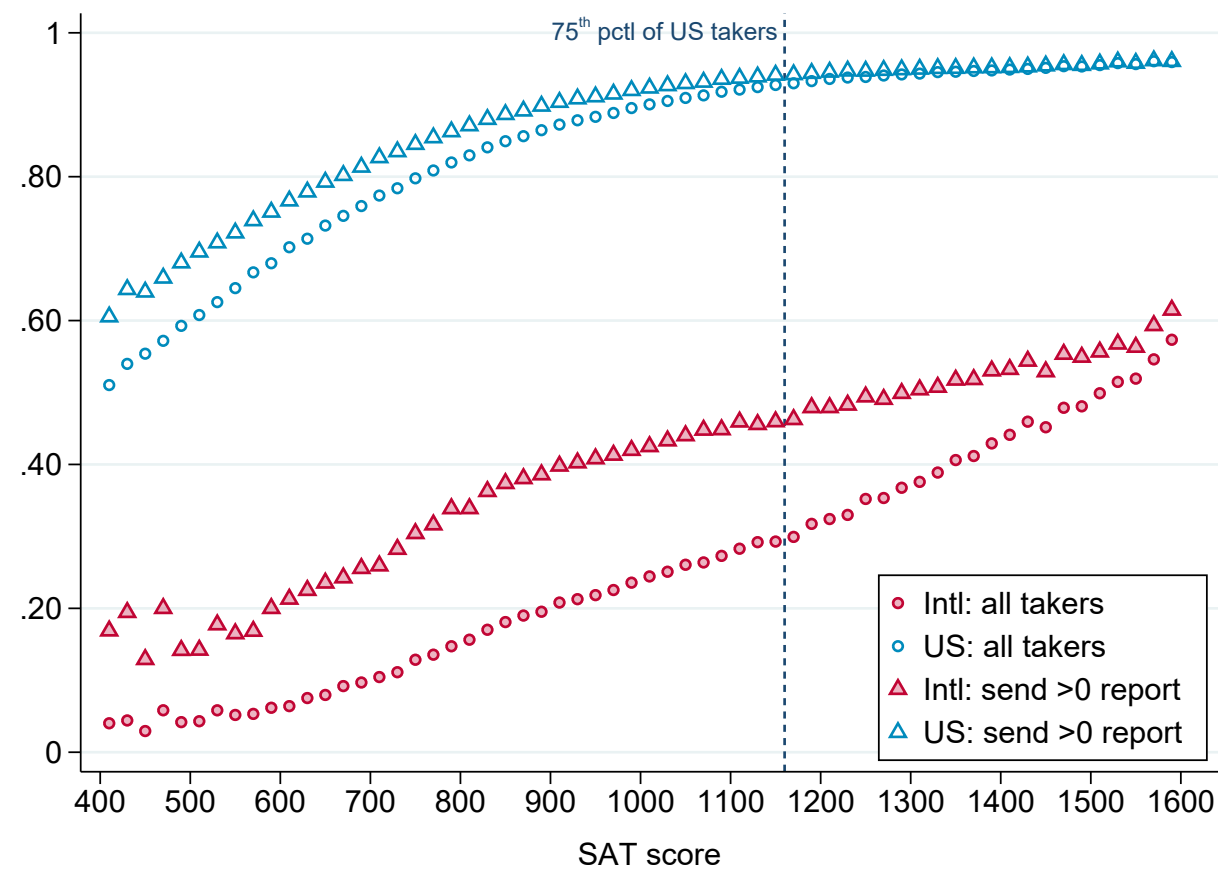

(b) Enrollment probability

Note: Figures are based on SAT data from the College Board for 2004-15 high school graduation cohorts. Enrollment probability and number of score sends are computed as the average for takers with SAT scores in the same 20-point bin. 
Figure 9: SAT median in standard deviations for test takers, score senders, and enrollees

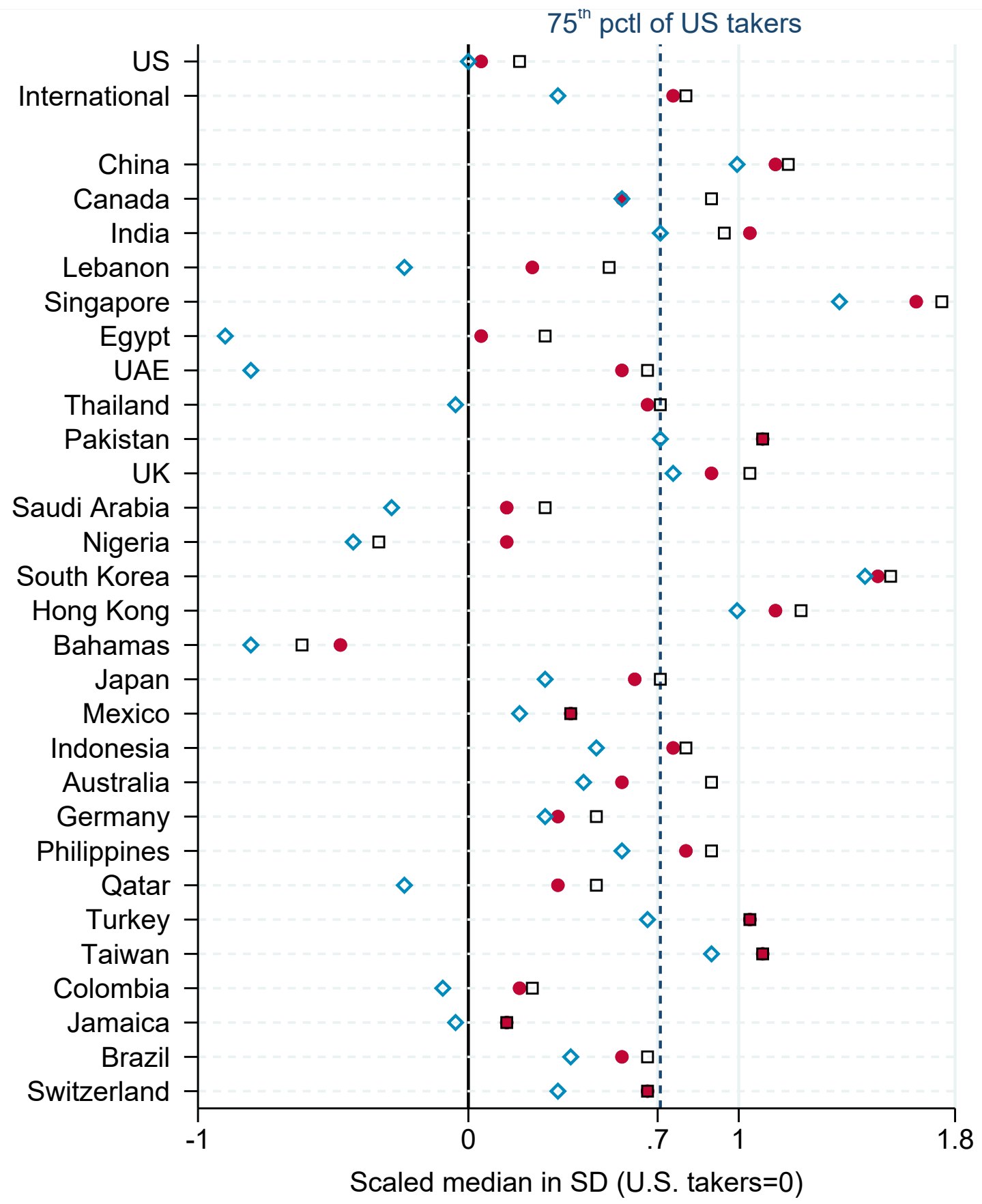

\section{$\diamond$ SAT takers $\quad$ S Score senders $\bullet$ Enrollees}

Note: Figures are based on SAT data from the College Board for 2004-15 high school graduation cohorts. A score sender is an SAT taker who sent scores to at least one US college, and an enrollee is a taker who is matched to a US enrollment record at the National Student Clearinghouse. The SAT median for US takers is 1010 (4.78 SD) in this period, and 30 regions with the most SAT takers are listed. 
Figure 10: Visa refusal rates by type and region, 1999-2018 fiscal years

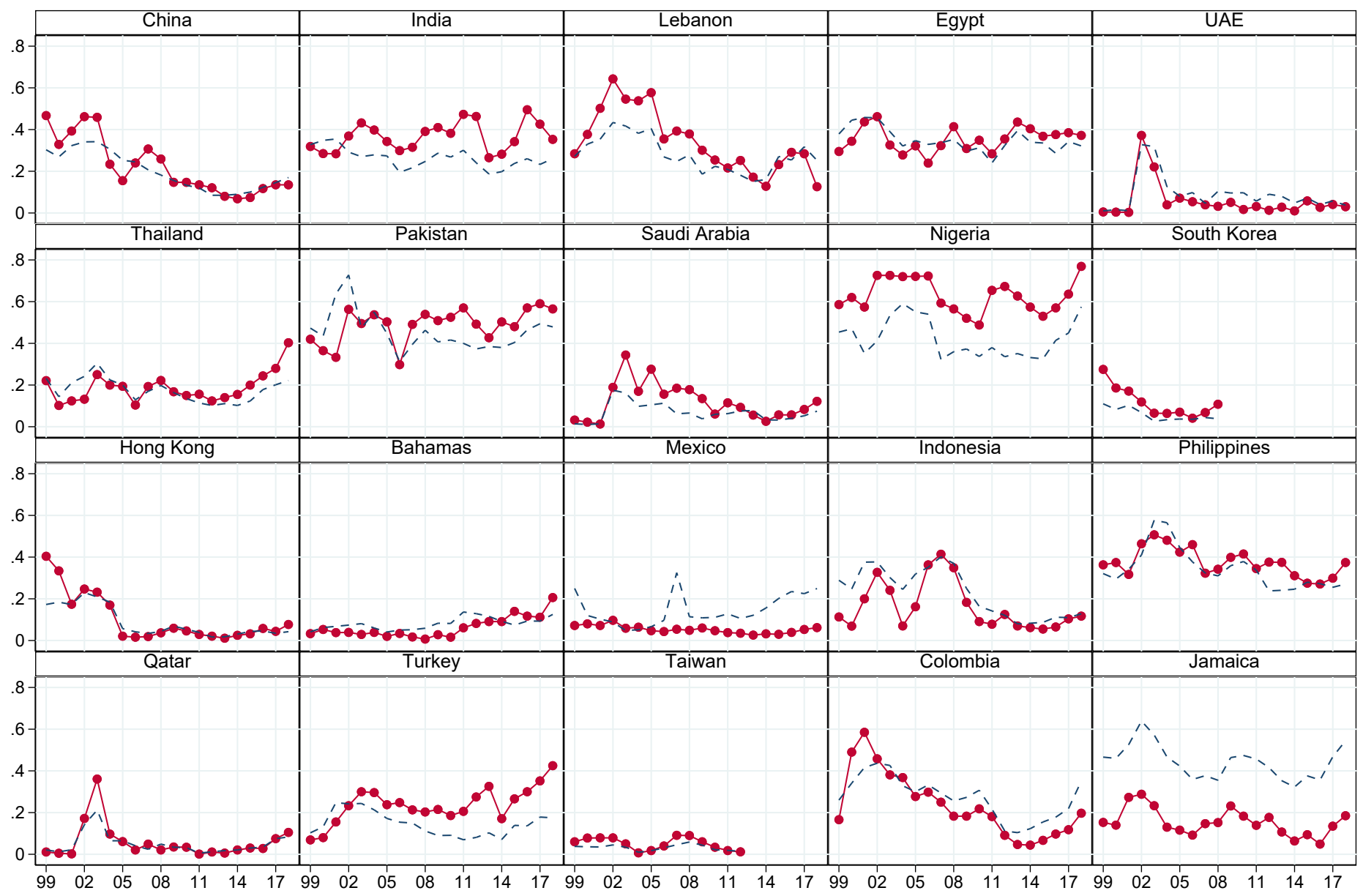

$$
\longrightarrow \text { Student }(\mathrm{F}-1) \text { visa } \ldots \ldots-\ldots \text { Visitor }(\mathrm{B}) \text { visa }
$$

Note: Data are obtained from the US Department of State via Freedom of Information Act requests. The figure shows refusal rates for the top 25 regions with the most SAT takers in 1999-2018 when they are not covered by the US Visa Waiver Program. 
Table 1: Summary statistics of SAT enrollees, 2004-2015 cohorts

\begin{tabular}{|c|c|c|c|c|c|c|}
\hline & \multicolumn{2}{|c|}{ US } & \multicolumn{2}{|c|}{ International } & \multicolumn{2}{|c|}{ China } \\
\hline & $\begin{array}{l}\text { mean } \\
(1)\end{array}$ & $\begin{array}{l}\mathrm{sd} \\
(2)\end{array}$ & $\begin{array}{c}\text { mean } \\
(3)\end{array}$ & $\begin{array}{l}\text { sd } \\
(4)\end{array}$ & $\begin{array}{c}\text { mean } \\
(5)\end{array}$ & $\begin{array}{l}\mathrm{sd} \\
(6)\end{array}$ \\
\hline \multicolumn{7}{|l|}{ Standardized tests } \\
\hline SAT & 1026.6 & 207.1 & 1159.9 & 208.9 & 1233.6 & 178.5 \\
\hline SAT math & 518.0 & 112.2 & 622.9 & 118.7 & 713.7 & 77.3 \\
\hline SAT verbal & 508.6 & 109.7 & 537.0 & 120.0 & 519.9 & 126.4 \\
\hline No. of score sends & 3.832 & 3.619 & 6.171 & 5.588 & 9.377 & 6.497 \\
\hline Take a subject test & 0.168 & 0.374 & 0.444 & 0.497 & 0.543 & 0.498 \\
\hline No. of subject tests taken & 2.679 & 0.973 & 2.704 & 0.827 & 2.674 & 0.649 \\
\hline Subject test average & $\mathrm{n} / \mathrm{a}$ & $\mathrm{n} / \mathrm{a}$ & 690.9 & 85.1 & 730.5 & 68.5 \\
\hline Take an AP exam & $\mathrm{n} / \mathrm{a}$ & $\mathrm{n} / \mathrm{a}$ & 0.222 & 0.416 & 0.313 & 0.464 \\
\hline No. of AP exams taken & $\mathrm{n} / \mathrm{a}$ & $\mathrm{n} / \mathrm{a}$ & 3.634 & 2.410 & 3.936 & 2.388 \\
\hline AP exam average & $\mathrm{n} / \mathrm{a}$ & $\mathrm{n} / \mathrm{a}$ & 3.444 & 1.154 & 3.512 & 1.251 \\
\hline \multicolumn{7}{|l|}{ High school performance } \\
\hline GPA & 3.347 & 0.583 & 3.455 & 0.603 & 3.724 & 0.439 \\
\hline GPA not reported & 0.035 & 0.185 & 0.210 & 0.407 & 0.319 & 0.466 \\
\hline Ranked $1^{\text {st }}-10^{\text {th }}$ & $\mathrm{n} / \mathrm{a}$ & $\mathrm{n} / \mathrm{a}$ & 0.600 & 0.490 & 0.606 & 0.489 \\
\hline Ranked $11^{\text {th }}-20^{\text {th }}$ & $\mathrm{n} / \mathrm{a}$ & $\mathrm{n} / \mathrm{a}$ & 0.242 & 0.428 & 0.268 & 0.443 \\
\hline Ranked $21^{\text {st }}-40^{\text {th }}$ & $\mathrm{n} / \mathrm{a}$ & $\mathrm{n} / \mathrm{a}$ & 0.090 & 0.287 & 0.082 & 0.274 \\
\hline Ranked $41^{\text {st }}-60^{\text {th }}$ & $\mathrm{n} / \mathrm{a}$ & $\mathrm{n} / \mathrm{a}$ & 0.056 & 0.230 & 0.037 & 0.189 \\
\hline Ranked $61^{\text {st }}-100^{\text {th }}$ & $\mathrm{n} / \mathrm{a}$ & $\mathrm{n} / \mathrm{a}$ & 0.011 & 0.106 & 0.007 & 0.085 \\
\hline Rank not reported & $\mathrm{n} / \mathrm{a}$ & $\mathrm{n} / \mathrm{a}$ & 0.504 & 0.500 & 0.561 & 0.496 \\
\hline \multicolumn{7}{|l|}{ Demographics } \\
\hline Age & 18.310 & 0.534 & 18.418 & 0.790 & 18.488 & 0.724 \\
\hline Female & 0.544 & 0.498 & 0.486 & 0.500 & 0.531 & 0.499 \\
\hline Family income $<\$ 20 \mathrm{k}$ & 0.097 & 0.296 & 0.190 & 0.392 & 0.209 & 0.406 \\
\hline Family income $\$ 20-60 \mathrm{k}$ & 0.265 & 0.441 & 0.279 & 0.449 & 0.399 & 0.490 \\
\hline Family income $\$ 60-120 \mathrm{k}$ & 0.353 & 0.478 & 0.259 & 0.438 & 0.239 & 0.426 \\
\hline Family income $>\$ 120 \mathrm{k}$ & 0.285 & 0.452 & 0.271 & 0.445 & 0.153 & 0.360 \\
\hline Family income not reported & 0.395 & 0.489 & 0.517 & 0.500 & 0.521 & 0.500 \\
\hline $\begin{array}{l}\text { At least one parent has } \\
\text { college education }\end{array}$ & 0.562 & 0.496 & 0.822 & 0.382 & 0.723 & 0.448 \\
\hline Parental educ. not reported & 0.101 & 0.302 & 0.187 & 0.390 & 0.261 & 0.439 \\
\hline Enroll at a 4-year college & \multicolumn{2}{|c|}{0.756} & \multicolumn{2}{|c|}{0.885} & \multicolumn{2}{|c|}{0.932} \\
\hline Observations & \multicolumn{2}{|c|}{$15,132,119$} & \multicolumn{2}{|c|}{267,533} & \multicolumn{2}{|c|}{49,886} \\
\hline
\end{tabular}

Notes: Data include SAT takers who have enrollment records at a US college in the National Student Clearinghouse. Information on parental education, family income, and high school performance are collected as a part of test registration, though they are not required fields. 
Table 2: Regression estimates for SAT difference among enrollees, 2004-15 cohorts

\begin{tabular}{|c|c|c|c|c|c|c|c|}
\hline & \multicolumn{5}{|c|}{ SAT (math+verbal) } & \multirow{2}{*}{$\begin{array}{c}\text { SAT math } \\
\text { All } \\
\text { data } \\
(6)\end{array}$} & \multirow{2}{*}{$\begin{array}{c}\text { SAT verbal } \\
\text { All } \\
\text { data } \\
\text { (7) }\end{array}$} \\
\hline & $\begin{array}{c}\text { All } \\
\text { data } \\
(1)\end{array}$ & $\begin{array}{c}\text { Selective } \\
\text { colleges } \\
(2)\end{array}$ & $\begin{array}{c}\text { Not } \\
\text { selective } \\
\text { (3) }\end{array}$ & $\begin{array}{c}\text { All } \\
\text { data } \\
(4)\end{array}$ & $\begin{array}{c}\text { All } \\
\text { data } \\
(5)\end{array}$ & & \\
\hline International student & $\begin{array}{c}133.276^{* * *} \\
(0.407)\end{array}$ & $\begin{array}{c}36.003^{* * *} \\
(0.476)\end{array}$ & $\begin{array}{l}64.038^{* * *} \\
(0.532)\end{array}$ & $\begin{array}{l}5.495^{* * *} \\
(0.724)\end{array}$ & & $\begin{array}{l}46.950^{* * *} \\
(0.418)\end{array}$ & $\begin{array}{c}-41.455^{* * *} \\
(0.468)\end{array}$ \\
\hline China & & & & & $\begin{array}{l}31.544^{* * *} \\
(1.068)\end{array}$ & & \\
\hline India & & & & & $\begin{array}{l}33.828^{* * *} \\
(2.003)\end{array}$ & & \\
\hline Canada & & & & & $\begin{array}{l}9.019^{* * *} \\
(2.929)\end{array}$ & & \\
\hline UK & & & & & $\begin{array}{c}-47.901^{* * *} \\
(3.969)\end{array}$ & & \\
\hline South Korea & & & & & $\begin{array}{l}59.550^{* * *} \\
(2.926)\end{array}$ & & \\
\hline Other International & & & & & $\begin{array}{c}-28.617^{* * *} \\
(1.069)\end{array}$ & & \\
\hline US mean & 1027 & 1226 & 976 & 1029 & 1029 & 519 & 510 \\
\hline US SD & 207.1 & 165.0 & 183.0 & 206.4 & 206.4 & 111.9 & 109.5 \\
\hline Intl share & 0.017 & 0.042 & 0.010 & 0.017 & 0.017 & 0.017 & 0.017 \\
\hline Observations & $15,399,652$ & $3,281,877$ & $11,826,636$ & $15,108,513$ & $15,108,513$ & $15,108,513$ & $15,108,513$ \\
\hline School-cohort FE & No & No & No & Yes & Yes & Yes & Yes \\
\hline
\end{tabular}

Notes: The dependent variables are SAT scores. Domestic students is the omitted group. Data include SAT takers who have enrollment records at a US college in the National Student Clearinghouse (NSC) from the 2004-15 cohorts. For columns 2-7, only students with school name not blocked by the NSC are included. Columns 4-7 include school-cohort fixed effects and are weighted by the share of international students times the number of international students in each school-year. Robust standard errors are in parentheses. ${ }^{* * *}=\mathrm{p}<0.01,{ }^{* *}=\mathrm{p}<0.05$, and ${ }^{*}=\mathrm{p}<0.1$. 
Table 3: Nonimmigrant visa statistics, 2004-15

\begin{tabular}{|c|c|c|c|c|c|c|}
\hline & \multicolumn{6}{|c|}{ A. Annual visa issuance and refusal rates } \\
\hline & \multicolumn{2}{|c|}{$\begin{array}{l}\text { No. of } \\
\text { Issuance }\end{array}$} & \multicolumn{2}{|c|}{$\begin{array}{c}\text { Share of all } \\
\text { visa issuance }\end{array}$} & \multicolumn{2}{|c|}{$\begin{array}{l}\text { Refusal } \\
\text { rate }\end{array}$} \\
\hline & $\begin{array}{c}\text { mean } \\
(1)\end{array}$ & $\begin{array}{l}\mathrm{sd} \\
(2)\end{array}$ & $\begin{array}{c}\text { mean } \\
(3)\end{array}$ & $\begin{array}{l}\text { sd } \\
(4)\end{array}$ & $\begin{array}{c}\text { mean } \\
(5)\end{array}$ & $\begin{array}{l}\text { sd } \\
(6)\end{array}$ \\
\hline B visitor visa & $5,421,550$ & $1,708,764$ & 0.731 & 0.038 & 0.213 & 0.047 \\
\hline F-1 student visa & 399,551 & 141,265 & 0.053 & 0.007 & 0.198 & 0.034 \\
\hline $\mathrm{J}-1$ exchange visitor visa & 315,939 & 28,239 & 0.045 & 0.009 & 0.061 & 0.012 \\
\hline C1/D crewmen visa & 237,686 & 25,199 & 0.034 & 0.006 & 0.038 & 0.016 \\
\hline $\mathrm{H}-1 \mathrm{~B}$ temporary worker visa & 138,481 & 18,552 & 0.020 & 0.004 & 0.032 & 0.015 \\
\hline \multirow[t]{3}{*}{ Other 72 visa categories } & 818,014 & 69,529 & 0.117 & 0.026 & 0.064 & 0.007 \\
\hline & \multicolumn{6}{|c|}{ B. Share of reasons assigned to annual visa refusals } \\
\hline & $\begin{array}{c}\text { mean } \\
(1)\end{array}$ & $\begin{array}{l}\mathrm{sd} \\
(2)\end{array}$ & & & & \\
\hline INA 214(b): immigrant intent & 0.929 & 0.014 & & & & \\
\hline $\begin{array}{l}\text { INA } 221(\mathrm{~g}) \text { : incomplete app. } \\
\text { or admin. processing }\end{array}$ & 0.050 & 0.012 & & & & \\
\hline Other 61 reasons & 0.021 & 0.007 & & & & \\
\hline
\end{tabular}

Notes: Data are obtained from the US Department of State. Panel A lists five visa categories that have the highest issuance and combines the rest categories. Refusal rates and reasons for refuals are adjusted after accounting for overcome and waived cases. INA is the Immigration and Nationality Act. Note that $\mathrm{H}-1 \mathrm{~B}$ visa issuance is subject to an annual quota, and applicants are allowed to have immigrant intent. 
Table 4: Regression of the number and academic ability of new international SAT takers

\begin{tabular}{|c|c|c|c|c|c|c|c|}
\hline & \multicolumn{3}{|c|}{$\log$ (no. of takers) } & \multicolumn{2}{|c|}{ Median SAT in SD } & \multicolumn{2}{|c|}{$\%$ above $75^{\text {th }}$ pctl } \\
\hline & $\begin{array}{c}\text { OLS } \\
(1)\end{array}$ & $\begin{array}{c}\text { OLS } \\
(2)\end{array}$ & $\begin{array}{c}\text { 2SLS } \\
(3)\end{array}$ & $\begin{array}{c}\text { OLS } \\
(4)\end{array}$ & $\begin{array}{c}\text { 2SLS } \\
(5)\end{array}$ & $\begin{array}{c}\text { OLS } \\
(6)\end{array}$ & $\begin{array}{c}\text { 2SLS } \\
(7)\end{array}$ \\
\hline F-1 visa refusal rate & $\begin{array}{c}-0.546^{* * *} \\
(0.181)\end{array}$ & $\begin{array}{c}-0.363^{* *} \\
(0.168)\end{array}$ & $\begin{array}{c}-0.712^{* *} \\
(0.283)\end{array}$ & $\begin{array}{c}-0.109 \\
(0.076)\end{array}$ & $\begin{array}{c}-0.390^{* *} \\
(0.165)\end{array}$ & $\begin{array}{c}-0.024 \\
(0.027)\end{array}$ & $\begin{array}{c}-0.197^{* * *} \\
(0.066)\end{array}$ \\
\hline Real GDP PC in USD & & $\begin{array}{l}0.373^{* * *} \\
(0.071)\end{array}$ & $\begin{array}{l}0.368^{* * *} \\
(0.070)\end{array}$ & $\begin{array}{c}0.009 \\
(0.038)\end{array}$ & $\begin{array}{c}0.004 \\
(0.039)\end{array}$ & $\begin{array}{c}-0.010 \\
(0.014)\end{array}$ & $\begin{array}{c}-0.013 \\
(0.015)\end{array}$ \\
\hline Imports from the US & & $\begin{array}{c}0.165^{* * *} \\
(0.042)\end{array}$ & $\begin{array}{l}0.151^{* * *} \\
(0.043)\end{array}$ & $\begin{array}{c}0.022 \\
(0.021)\end{array}$ & $\begin{array}{c}0.010 \\
(0.022)\end{array}$ & $\begin{array}{c}0.015^{*} \\
(0.008)\end{array}$ & $\begin{array}{c}0.007 \\
(0.008)\end{array}$ \\
\hline Exports to the US & & $\begin{array}{c}-0.004 \\
(0.041)\end{array}$ & $\begin{array}{c}-0.003 \\
(0.041)\end{array}$ & $\begin{array}{c}0.034^{* *} \\
(0.016)\end{array}$ & $\begin{array}{c}0.035^{* *} \\
(0.016)\end{array}$ & $\begin{array}{c}0.009 \\
(0.007)\end{array}$ & $\begin{array}{c}0.009 \\
(0.007)\end{array}$ \\
\hline College-aged pop. & & $\begin{array}{c}0.184 \\
(0.175)\end{array}$ & $\begin{array}{c}0.184 \\
(0.173)\end{array}$ & $\begin{array}{c}-0.131 \\
(0.081)\end{array}$ & $\begin{array}{c}-0.131 \\
(0.081)\end{array}$ & $\begin{array}{c}-0.066^{* *} \\
(0.026)\end{array}$ & $\begin{array}{c}-0.066^{* *} \\
(0.027)\end{array}$ \\
\hline $\begin{array}{l}\text { Enrollment in other } \\
\text { popular destinations } \\
\text { H-1B issuance }\end{array}$ & & $\begin{array}{l}0.116^{* *} \\
(0.047) \\
0.201^{* * *} \\
(0.049)\end{array}$ & $\begin{array}{c}0.116^{* *} \\
(0.048) \\
0.202^{* * *} \\
(0.049)\end{array}$ & $\begin{array}{c}0.008 \\
(0.017) \\
0.008 \\
(0.019)\end{array}$ & $\begin{array}{c}0.009 \\
(0.017) \\
0.009 \\
(0.019)\end{array}$ & $\begin{array}{c}0.009 \\
(0.006) \\
0.004 \\
(0.009)\end{array}$ & $\begin{array}{c}0.009 \\
(0.007) \\
0.005 \\
(0.009)\end{array}$ \\
\hline Outcome mean & 5.361 & 5.361 & 5.361 & 4.933 & 4.933 & 0.303 & 0.303 \\
\hline F-stat on IV in $1^{\text {st }}$-stg & - & - & 90.70 & - & 90.70 & - & 90.70 \\
\hline Observations & 1,097 & 1,097 & 1,097 & 1,097 & 1,097 & 1,097 & 1,097 \\
\hline Year FE & Yes & Yes & Yes & Yes & Yes & Yes & Yes \\
\hline Region FE & Yes & Yes & Yes & Yes & Yes & Yes & Yes \\
\hline
\end{tabular}

Notes: The dependent variables are, at the region-year-level, the number of SAT takers in natural $\log$, median SAT score among SAT takers in SD unit, and the share of SAT takers above the $75^{\text {th }}$ percentile. All independent variables are measured in the time period prior to a student's high school graduation year, and all except the visa refusal rate are in natural log. A region's enrollment in other popular destinations includes its higher education enrollment in Australia, Canada, and the UK. Data include 101 regions with the most test takers in 2004-15 and in periods that are not covered by the US Visa Waiver Program. Minimum enrollment of three students is required. Clustered standard errors at the regionlevel are in parentheses. ${ }^{* *}=\mathrm{p}<0.01,{ }^{* *}=\mathrm{p}<0.05$, and ${ }^{*}=\mathrm{p}<0.1$. 
Table 5: Regression of the probability of sending scores

\begin{tabular}{|c|c|c|c|c|c|}
\hline & \multicolumn{5}{|c|}{ A. OLS estimates } \\
\hline & (1) & (2) & (3) & (4) & (5) \\
\hline F-1 visa refusal rate & $\begin{array}{c}-0.058 \\
(0.046)\end{array}$ & $\begin{array}{c}-0.075^{* *} \\
(0.036)\end{array}$ & $\begin{array}{r}-0.066^{*} \\
(0.038)\end{array}$ & $\begin{array}{c}-0.027 \\
(0.037)\end{array}$ & \\
\hline \multirow[t]{3}{*}{$\times$ Above $75^{\text {th }}$ pctl } & & & & $\begin{array}{c}-0.126^{* * *} \\
(0.035)\end{array}$ & $\begin{array}{c}-0.125^{* * *} \\
(0.036)\end{array}$ \\
\hline & \multicolumn{5}{|c|}{ B. 2SLS estimates } \\
\hline & (1) & $(2)$ & (3) & $(4)$ & (5) \\
\hline F-1 visa refusal rate & $\begin{array}{c}-0.174^{* *} \\
(0.069)\end{array}$ & $\begin{array}{c}-0.167^{* * *} \\
(0.060)\end{array}$ & $\begin{array}{c}-0.166^{* * *} \\
(0.061)\end{array}$ & $\begin{array}{c}-0.128^{* *} \\
(0.062)\end{array}$ & \\
\hline$\times$ Above $75^{\text {th }}$ pctl & & & & $\begin{array}{c}-0.101^{* *} \\
(0.042)\end{array}$ & $\begin{array}{c}-0.110^{* * *} \\
(0.042)\end{array}$ \\
\hline Outcome mean & 0.451 & 0.451 & 0.451 & 0.451 & 0.451 \\
\hline F-stat on IV in $1^{\text {st }}$-stg & 60.76 & 61.04 & 61.11 & 30.40 & 313.49 \\
\hline Observations & 709,213 & 709,213 & 709,213 & 709,213 & 709,213 \\
\hline Student-level controls & No & Yes & Yes & Yes & Yes \\
\hline Region-year controls & No & No & Yes & Yes & No \\
\hline Year FE & Yes & Yes & Yes & Yes & No \\
\hline Region FE & Yes & Yes & Yes & Yes & No \\
\hline Region-year FE & No & No & No & No & Yes \\
\hline
\end{tabular}

Notes: The dependent variable is an indicator for sending scores to at least one US college. All region-year-level variables are measured in the time period prior to a student's high school graduation year, and all except the visa refusal rate are in natural log. Region-year-level controls are the same as the those included in Table 4. Student-level controls include SAT quadratic, gender, age, parental education, and family income and in columns $4-5$ an indicator for being above the $75^{\text {th }}$ percentile. Data include SAT takers from 101 regions with the most takers in 2004-15 and in periods that are not covered by the US Visa Waiver Program. Clustered standard errors at the region-level are in parentheses. ${ }^{* *}=\mathrm{p}<0.01,{ }^{* *}=\mathrm{p}<0.05$, and ${ }^{*}=\mathrm{p}<0.1$. 
Table 6: IV regression of the composition of score sends

\begin{tabular}{|c|c|c|c|c|c|}
\hline & \multicolumn{5}{|c|}{ A. Number of score sends } \\
\hline & $(1)$ & $(2)$ & (3) & $(4)$ & (5) \\
\hline F-1 visa refusal rate & $\begin{array}{c}-0.647 \\
(0.647)\end{array}$ & $\begin{array}{c}-0.281 \\
(0.651)\end{array}$ & $\begin{array}{r}-0.597 \\
(0.560)\end{array}$ & $\begin{array}{c}-0.369 \\
(0.634)\end{array}$ & \\
\hline$\times$ Above $75^{\text {th }}$ pctl & & & & $\begin{array}{c}-0.394 \\
(0.768)\end{array}$ & $\begin{array}{c}-0.345 \\
(0.774)\end{array}$ \\
\hline Observations & 319,881 & 319,881 & 319,881 & 319,881 & 319,881 \\
\hline Outcome mean & 6.958 & 6.958 & 6.958 & 6.958 & 6.958 \\
\hline \multirow[t]{3}{*}{ F-stat on IV in $1^{\text {st }}$-stg } & 71.27 & 71.34 & 73.86 & 37.07 & 311.45 \\
\hline & \multicolumn{5}{|c|}{ B. Selectivity: school SAT average } \\
\hline & (1) & $(2)$ & (3) & (4) & (5) \\
\hline F-1 visa refusal rate & $\begin{array}{c}22.983 \\
(18.250)\end{array}$ & $\begin{array}{c}37.183^{* *} \\
(15.953)\end{array}$ & $\begin{array}{c}40.177^{* *} \\
(15.634)\end{array}$ & $\begin{array}{c}42.168^{* *} \\
(16.689)\end{array}$ & \\
\hline$\times$ Above $75^{\text {th }}$ pctl & & & & $\begin{array}{c}-3.283 \\
(12.246)\end{array}$ & $\begin{array}{c}-8.474 \\
(12.499)\end{array}$ \\
\hline Observations & 315,876 & 315,876 & 315,876 & 315,876 & 315,876 \\
\hline Outcome mean & 1241 & 1241 & 1241 & 1241 & 1241 \\
\hline \multirow[t]{3}{*}{ F-stat on IV in $1^{\text {st }}$-stg } & 70.72 & 70.78 & 73.54 & 36.91 & 310.19 \\
\hline & \multicolumn{5}{|c|}{ C. Selectivity: school SAT maximum } \\
\hline & (1) & (2) & (3) & (4) & (5) \\
\hline F-1 visa refusal rate & $\begin{array}{c}27.411 \\
(22.446)\end{array}$ & $\begin{array}{c}41.389^{* *} \\
(19.385)\end{array}$ & $\begin{array}{c}38.567^{* *} \\
(17.977)\end{array}$ & $\begin{array}{c}47.006^{* *} \\
(18.605)\end{array}$ & \\
\hline$\times$ Above $75^{\text {th }}$ pctl & & & & $\begin{array}{r}-14.411 \\
(9.747)\end{array}$ & $\begin{array}{r}-20.627^{* *} \\
(9.882)\end{array}$ \\
\hline Observations & 315,876 & 315,876 & 315,876 & 315,876 & 315,876 \\
\hline Outcome mean & 1337 & 1337 & 1337 & 1337 & 1337 \\
\hline F-stat on IV in $1^{\text {st }}$-stg & 70.72 & 70.78 & 73.54 & 36.91 & 310.19 \\
\hline Student-level controls & No & Yes & Yes & Yes & Yes \\
\hline Region-year controls & No & No & Yes & Yes & No \\
\hline Year FE & Yes & Yes & Yes & Yes & No \\
\hline Region FE & Yes & Yes & Yes & Yes & No \\
\hline Region-year FE & No & No & No & No & Yes \\
\hline
\end{tabular}

Notes: The dependent variables are the number of score sends to a US college (Panel A), average SAT (Panel B), and maximum SAT (Panel C) of the 2003 entering class at schools receiving scores. Data include only students who sent scores to at least one US college. See Table 5 for notes on controls and sample inclusion. Clustered standard errors at the region-level are in parentheses. ${ }^{* * *}=\mathrm{p}<0.01,{ }^{* *}=$ $\mathrm{p}<0.05$, and ${ }^{*}=\mathrm{p}<0.1$. 
Table 7: IV regression of enrollment outcomes in the US

\begin{tabular}{|c|c|c|c|c|c|}
\hline & \multicolumn{5}{|c|}{ A. Probability of enrolling a US college } \\
\hline & (1) & $(2)$ & (3) & $(4)$ & (5) \\
\hline F-1 visa refusal rate & $\begin{array}{c}-0.144^{* * *} \\
(0.050)\end{array}$ & $\begin{array}{c}-0.123^{* * *} \\
(0.046)\end{array}$ & $\begin{array}{c}-0.118^{* * *} \\
(0.045)\end{array}$ & $\begin{array}{c}-0.125^{* * *} \\
(0.046)\end{array}$ & \\
\hline$\times$ Above $75^{\text {th }}$ pctl & & & & $\begin{array}{c}0.021 \\
(0.025)\end{array}$ & $\begin{array}{c}0.035 \\
(0.026)\end{array}$ \\
\hline Observations & 709,213 & 709,213 & 709,213 & 709,213 & 709,213 \\
\hline Outcome mean & 0.263 & 0.263 & 0.263 & 0.263 & 0.263 \\
\hline \multirow[t]{3}{*}{ F-stat on IV in $1^{\text {st }}$-stg } & 60.76 & 61.04 & 61.11 & 30.40 & 313.49 \\
\hline & \multicolumn{5}{|c|}{ B. Selectivity (average SAT) of the enrolled school } \\
\hline & (1) & (2) & (3) & (4) & (5) \\
\hline F-1 visa refusal rate & $\begin{array}{c}8.611 \\
(17.472)\end{array}$ & $\begin{array}{c}12.124 \\
(13.699)\end{array}$ & $\begin{array}{c}13.305 \\
(12.970)\end{array}$ & $\begin{array}{c}-18.068 \\
(16.416)\end{array}$ & \\
\hline$\times$ Above $75^{\text {th }}$ pctl & & & & $\begin{array}{l}50.989^{* * *} \\
(19.357)\end{array}$ & $\begin{array}{l}52.522^{* * *} \\
(19.584)\end{array}$ \\
\hline Observations & 156,093 & 156,093 & 156,093 & 156,093 & 156,073 \\
\hline Outcome mean & 1,213 & 1,213 & 1,213 & 1,213 & 1,213 \\
\hline F-stat on IV in $1^{\text {st }}$-stg & 66.63 & 66.93 & 69.13 & 34.61 & 266.35 \\
\hline Student-level controls & No & Yes & Yes & Yes & Yes \\
\hline Region-year controls & No & No & Yes & Yes & No \\
\hline Year FE & Yes & Yes & Yes & Yes & No \\
\hline Region FE & Yes & Yes & Yes & Yes & No \\
\hline Region-year FE & No & No & No & No & Yes \\
\hline
\end{tabular}

Notes: The dependent variables are an indicator for enrolling at a US college (Panel A) and average SAT score for the 2003 entering class at the US college enrolled (Panel B). See Table 5 for notes on controls and sample inclusion. Clustered standard errors at the region-level are in parentheses. ${ }^{* * *}=\mathrm{p}<0.01,{ }^{* *}=\mathrm{p}<0.05$, and ${ }^{*}=\mathrm{p}<0.1$. 
Table 8: Regression of the number and academic ability of new international students

\begin{tabular}{|c|c|c|c|c|c|c|c|}
\hline & \multicolumn{3}{|c|}{ Log(no. of enrollees) } & \multicolumn{2}{|c|}{ Median SAT in SD } & \multicolumn{2}{|c|}{$\%$ above $75^{\text {th }}$ pctl } \\
\hline & $\begin{array}{l}\text { OLS } \\
(1)\end{array}$ & $\begin{array}{l}\text { OLS } \\
(2)\end{array}$ & $\begin{array}{c}\text { 2SLS } \\
(3)\end{array}$ & $\begin{array}{l}\text { OLS } \\
(4)\end{array}$ & $\begin{array}{l}\text { 2SLS } \\
(5)\end{array}$ & $\begin{array}{l}\text { OLS } \\
(6)\end{array}$ & $\begin{array}{c}\text { 2SLS } \\
(7)\end{array}$ \\
\hline F-1 visa refusal rate & $\begin{array}{c}-0.622^{* * *} \\
(0.196)\end{array}$ & $\begin{array}{c}-0.434^{* *} \\
(0.180)\end{array}$ & $\begin{array}{c}-1.155^{* * *} \\
(0.323)\end{array}$ & $\begin{array}{c}0.013 \\
(0.115)\end{array}$ & $\begin{array}{c}-0.537^{* *} \\
(0.227)\end{array}$ & $\begin{array}{r}-0.084^{*} \\
(0.051)\end{array}$ & $\begin{array}{c}-0.284^{* * *} \\
(0.096)\end{array}$ \\
\hline Real GDP PC in USD & & $\begin{array}{l}0.205^{* * *} \\
(0.073)\end{array}$ & $\begin{array}{l}0.194^{* * *} \\
(0.065)\end{array}$ & $\begin{array}{c}-0.065 \\
(0.050)\end{array}$ & $\begin{array}{c}-0.074 \\
(0.053)\end{array}$ & $\begin{array}{c}-0.015 \\
(0.021)\end{array}$ & $\begin{array}{c}-0.018 \\
(0.020)\end{array}$ \\
\hline Imports from the US & & $\begin{array}{l}0.178^{* * *} \\
(0.044)\end{array}$ & $\begin{array}{l}0.148^{* * *} \\
(0.043)\end{array}$ & $\begin{array}{c}0.015 \\
(0.032)\end{array}$ & $\begin{array}{c}-0.008 \\
(0.033)\end{array}$ & $\begin{array}{c}0.011 \\
(0.012)\end{array}$ & $\begin{array}{c}0.003 \\
(0.012)\end{array}$ \\
\hline Exports to the US & & $\begin{array}{c}0.050 \\
(0.032)\end{array}$ & $\begin{array}{c}0.052^{*} \\
(0.030)\end{array}$ & $\begin{array}{c}0.008 \\
(0.024)\end{array}$ & $\begin{array}{c}0.009 \\
(0.023)\end{array}$ & $\begin{array}{c}-0.003 \\
(0.011)\end{array}$ & $\begin{array}{c}-0.003 \\
(0.010)\end{array}$ \\
\hline College-aged pop. & & $\begin{array}{c}0.215 \\
(0.181)\end{array}$ & $\begin{array}{c}0.216 \\
(0.144)\end{array}$ & $\begin{array}{c}-0.161 \\
(0.100)\end{array}$ & $\begin{array}{r}-0.160^{*} \\
(0.091)\end{array}$ & $\begin{array}{c}-0.048 \\
(0.043)\end{array}$ & $\begin{array}{c}-0.048 \\
(0.037)\end{array}$ \\
\hline $\begin{array}{l}\text { Enrollment in other } \\
\text { popular destinations } \\
\text { H-1B issuance }\end{array}$ & & $\begin{array}{c}0.076 \\
(0.050) \\
0.130^{* *} \\
(0.055)\end{array}$ & $\begin{array}{c}0.077^{*} \\
(0.041) \\
0.133^{* * *} \\
(0.047)\end{array}$ & $\begin{array}{c}0.002 \\
(0.026) \\
0.058^{*} \\
(0.033)\end{array}$ & $\begin{array}{c}0.003 \\
(0.026) \\
0.060^{*} \\
(0.032)\end{array}$ & $\begin{array}{c}0.007 \\
(0.011) \\
0.032^{* *} \\
(0.016)\end{array}$ & $\begin{array}{c}0.007 \\
(0.011) \\
0.032^{* *} \\
(0.015)\end{array}$ \\
\hline $\begin{array}{l}\text { Outcome mean } \\
\text { F-stat on IV in } 1^{\text {st }} \text {-stg } \\
\text { Observations }\end{array}$ & $\begin{array}{c}4.081 \\
- \\
1,097\end{array}$ & $\begin{array}{c}4.081 \\
- \\
1,097\end{array}$ & $\begin{array}{c}4.081 \\
104.25 \\
1,097\end{array}$ & $\begin{array}{c}5.226 \\
- \\
1,097\end{array}$ & $\begin{array}{c}5.226 \\
104.25 \\
1,097\end{array}$ & $\begin{array}{c}0.409 \\
- \\
1,097\end{array}$ & $\begin{array}{c}0.409 \\
104.25 \\
1,097\end{array}$ \\
\hline $\begin{array}{l}\text { Year FE } \\
\text { Region FE }\end{array}$ & $\begin{array}{l}\text { Yes } \\
\text { Yes }\end{array}$ & $\begin{array}{l}\text { Yes } \\
\text { Yes }\end{array}$ & $\begin{array}{l}\text { Yes } \\
\text { Yes }\end{array}$ & $\begin{array}{l}\text { Yes } \\
\text { Yes }\end{array}$ & $\begin{array}{l}\text { Yes } \\
\text { Yes }\end{array}$ & $\begin{array}{l}\text { Yes } \\
\text { Yes }\end{array}$ & $\begin{array}{l}\text { Yes } \\
\text { Yes }\end{array}$ \\
\hline
\end{tabular}

Notes: The dependent variables are, at the region-year-level, the number of SAT takers enrolled in the US in natural log, median SAT score among enrollees in SD unit, and the share of enrollees above the $75^{\text {th }}$ percentile. All independent variables are measured in the time period prior to a student's high school graduation year, and all except the visa refusal rate are in natural log. A region's enrollment in other popular destinations includes its higher education enrollment in Australia, Canada, and the UK. Data include 101 regions with the most test takers in 2004-15 and in periods that are not covered by the US Visa Waiver Program. Minimum enrollment of three students is required. Clustered standard errors at the region-level are in parentheses. ${ }^{* * *}=\mathrm{p}<0.01,{ }^{* *}=\mathrm{p}<0.05$, and ${ }^{*}=\mathrm{p}<0.1$. 


\section{A Appendix figures and tables}

Figure A.1: International undergraduate enrollment in the US

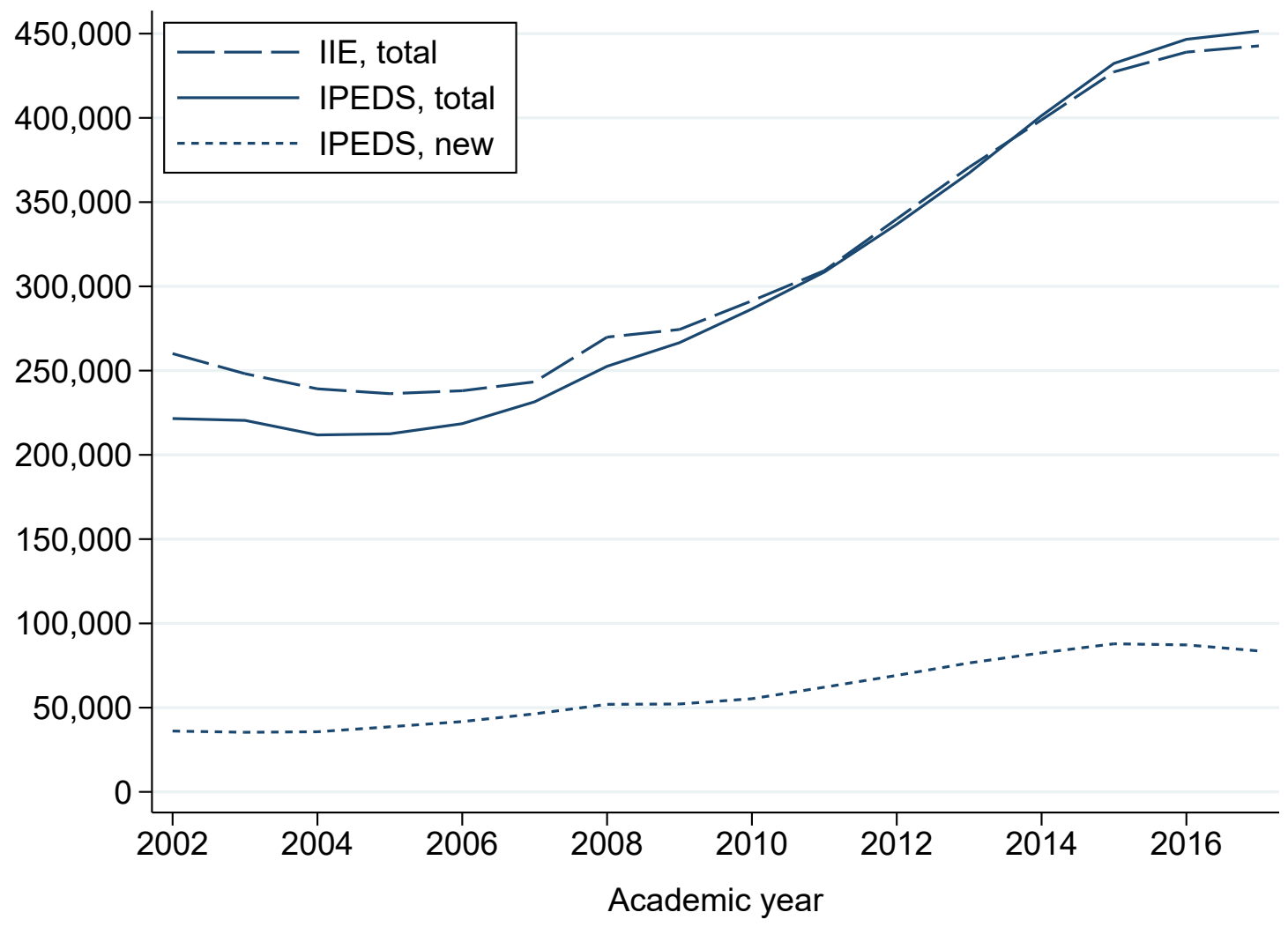

Note: IPEDS data cover approximately 3,000 US institutions that are Title VI, degree-granting, non-online, and always-reporting for the period of 2002-03 to 2017-18 academic years. Both total (stock) and new enrollment numbers are for full-time degree-seeking nonresident students from the Fall Enrollment Survey. Data from the Institute of International Education (IIE) also cover about 3,000 US institutions and can be obtained at https://www.iie.org/Research-and-Insights/Open-Doors/Data. 
Figure A.2: SAT and IPEDS data comparison for new international students in the US

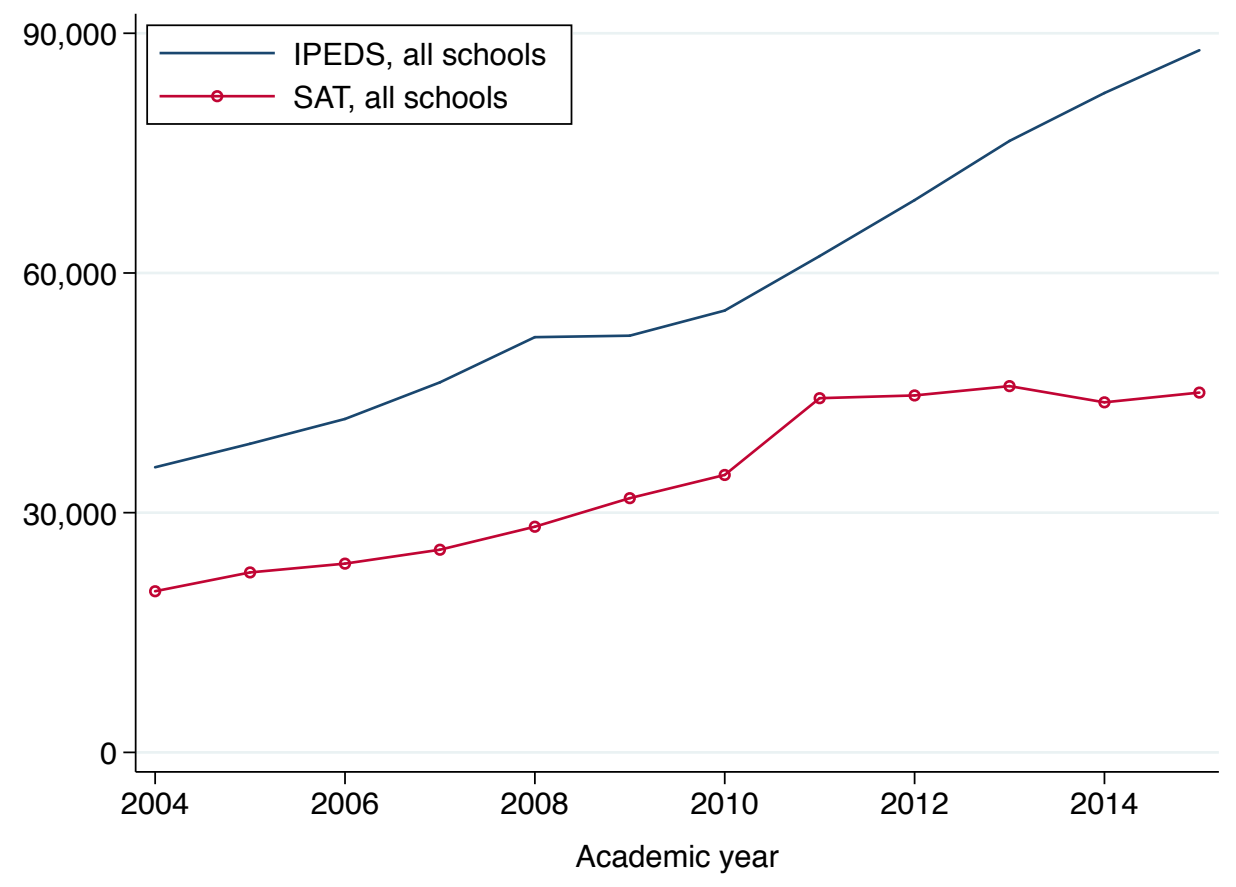

(a) All undergraduate institutions

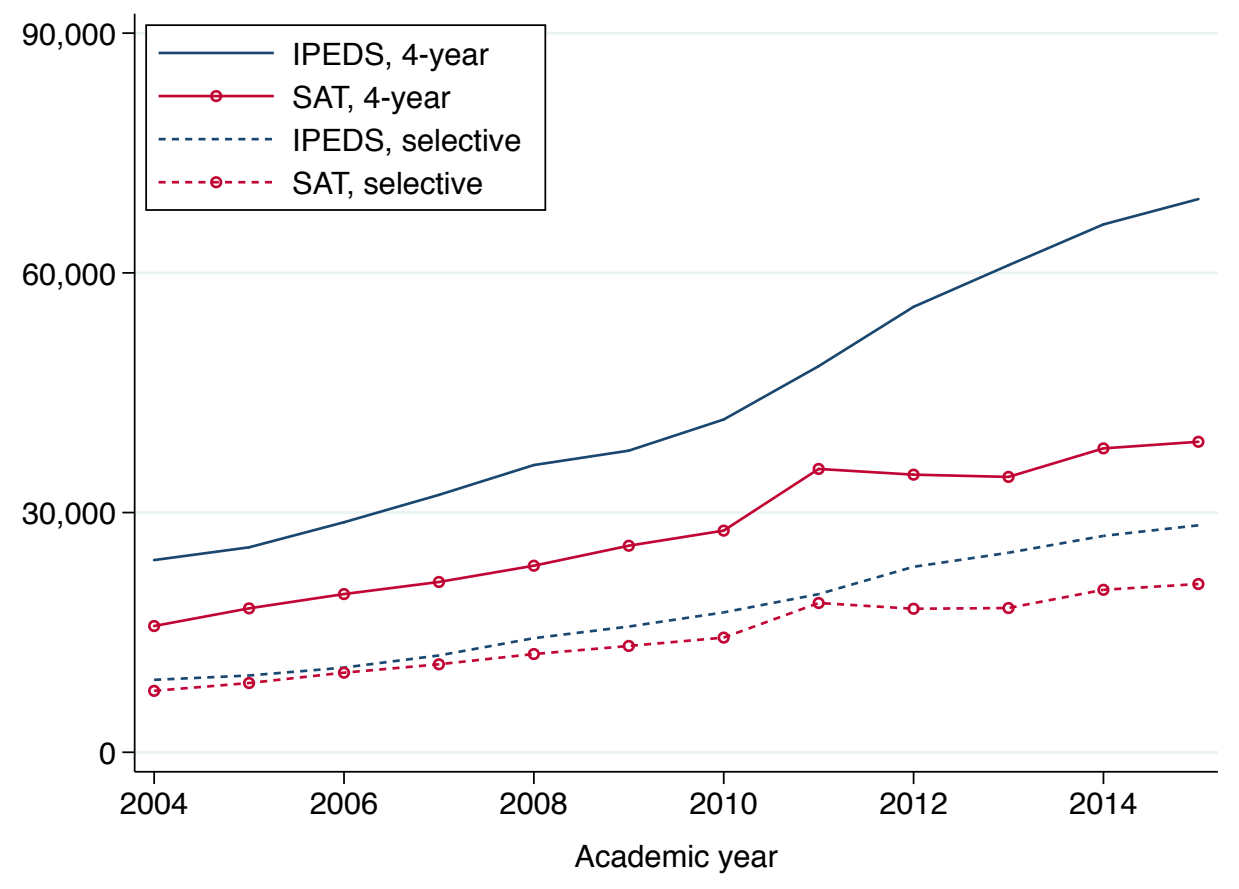

(b) Four-year, non-profit, and selective institutions

Note: Selective schools are defined as those categorized by Barron's rankings. Data cover US institutions that are Title VI, degree-granting, non-online, and always-reporting. IPEDS data are for full-time degree-seeking nonresident students from the Fall Enrollment Survey. SAT data are from the College Board. 
Figure A.3: International undergraduate enrollment in the US by region

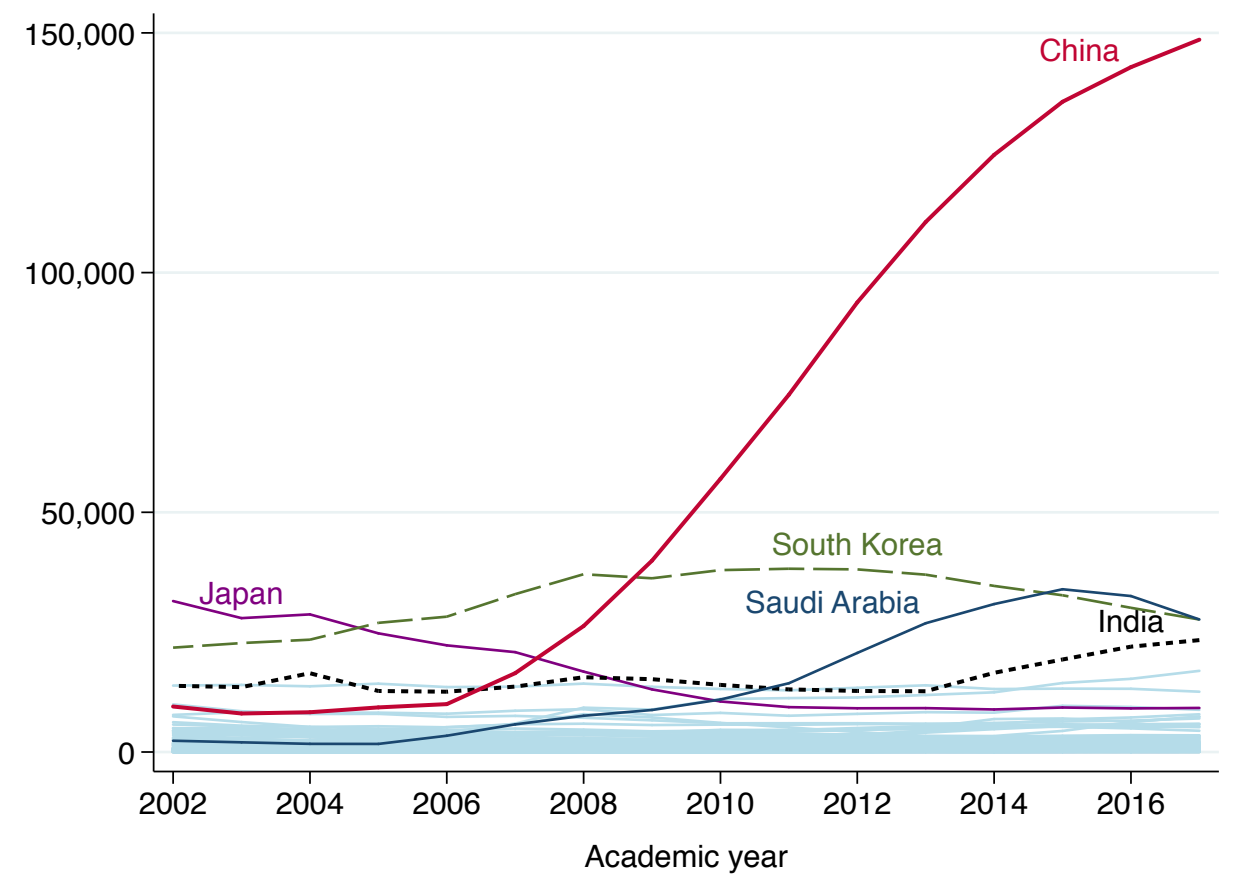

(a) With China

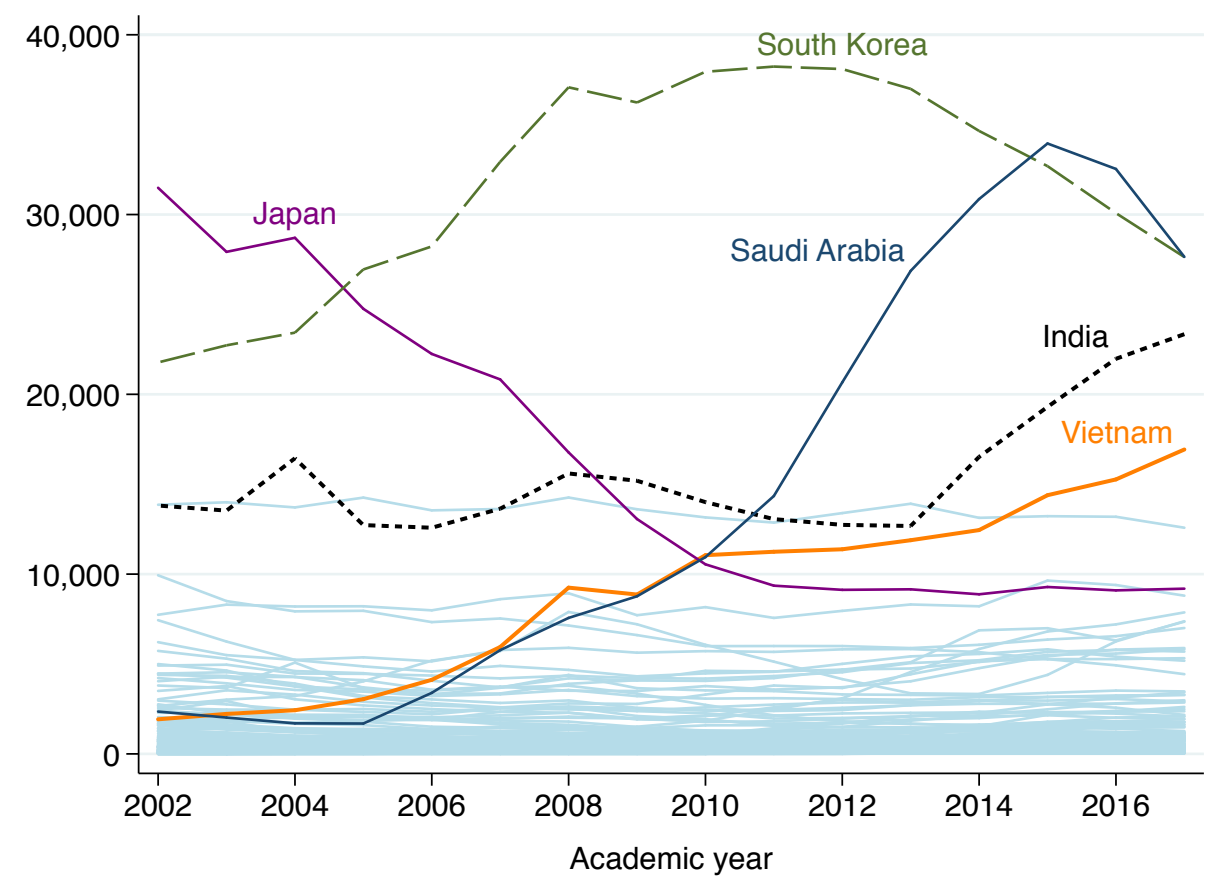

(b) Without China

Note: Data include 176 regions for the period of 2002-03 to 2017-18 academic years and are obtained from the Institute of International Education at https: / /www.iie.org/Research-and-Insights/Open-Doors/Data. 
Figure A.4: Aggregate trends of international SAT takers, score senders, and enrollees

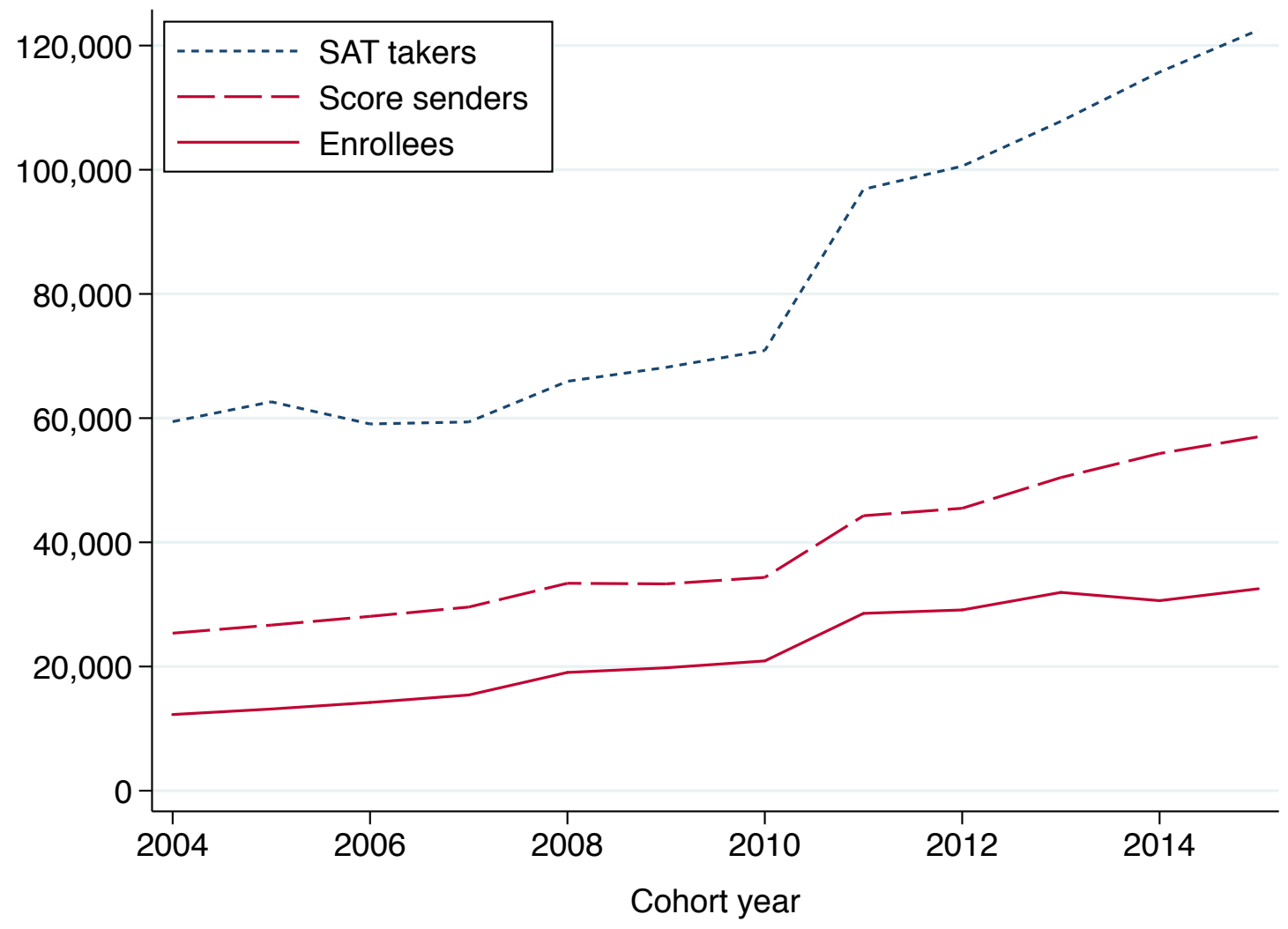

Note: The figure is based on data from the College Board. A score sender is an SAT taker who sent scores to at least one US college, and an enrollee is a taker who is matched to a US college enrollment record at the National Student Clearinghouse. 
Figure A.5: Rank of 2012 PISA versus mean SAT rank of test takers in 3 years

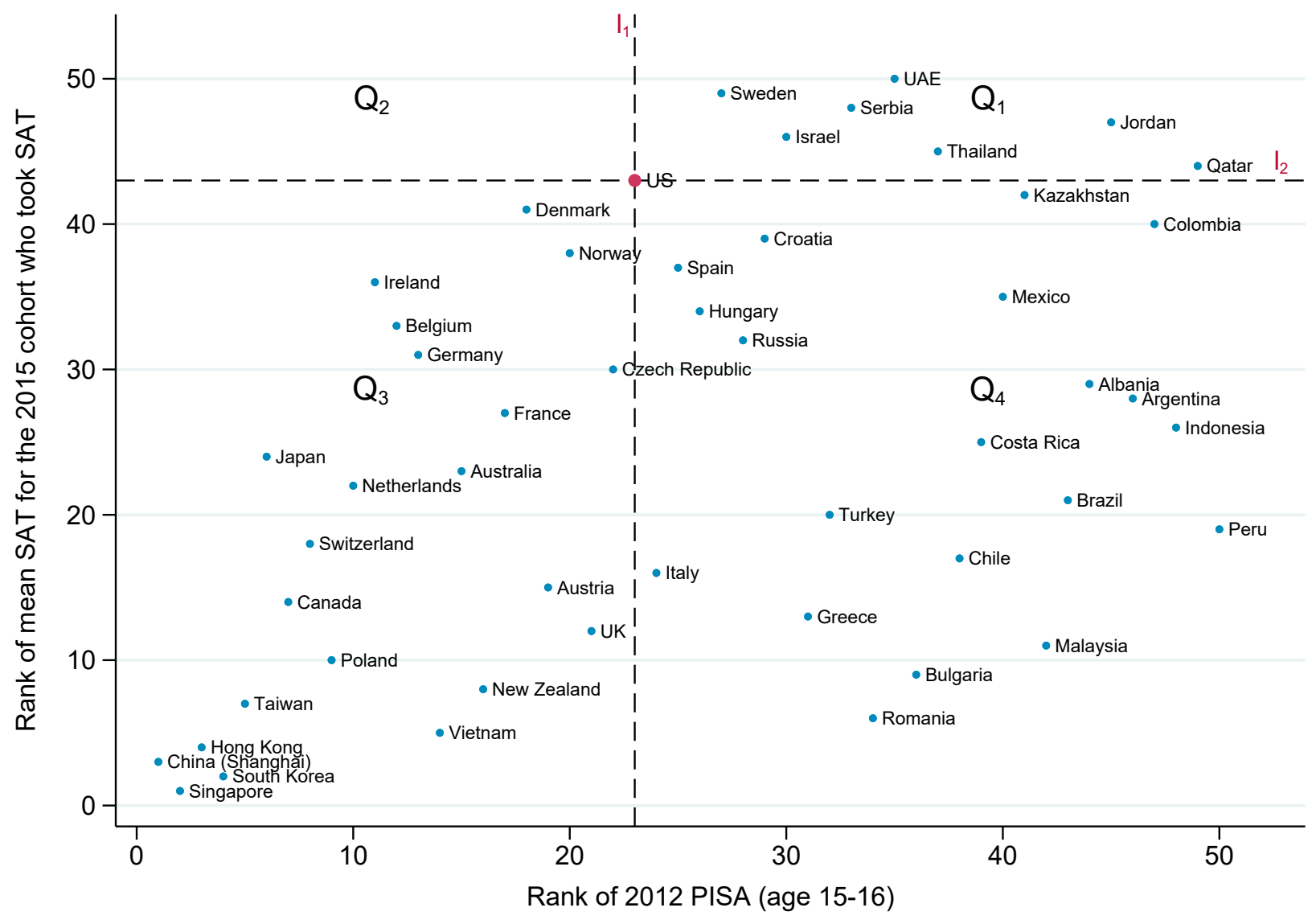

Note: PISA data are from OECD, and SAT data are from the College Board. Ranks are based on math and verbal sections for both PISA and SAT. A total of 50 regions that have both 2012 PISA scores and at least 30 US enrollment in the 2015 high school graduating cohort are included. The SAT ranks are computed based on scores of SAT takers. 
Figure A.6: Visa refusal rates by type and region, 1999-2018 fiscal year

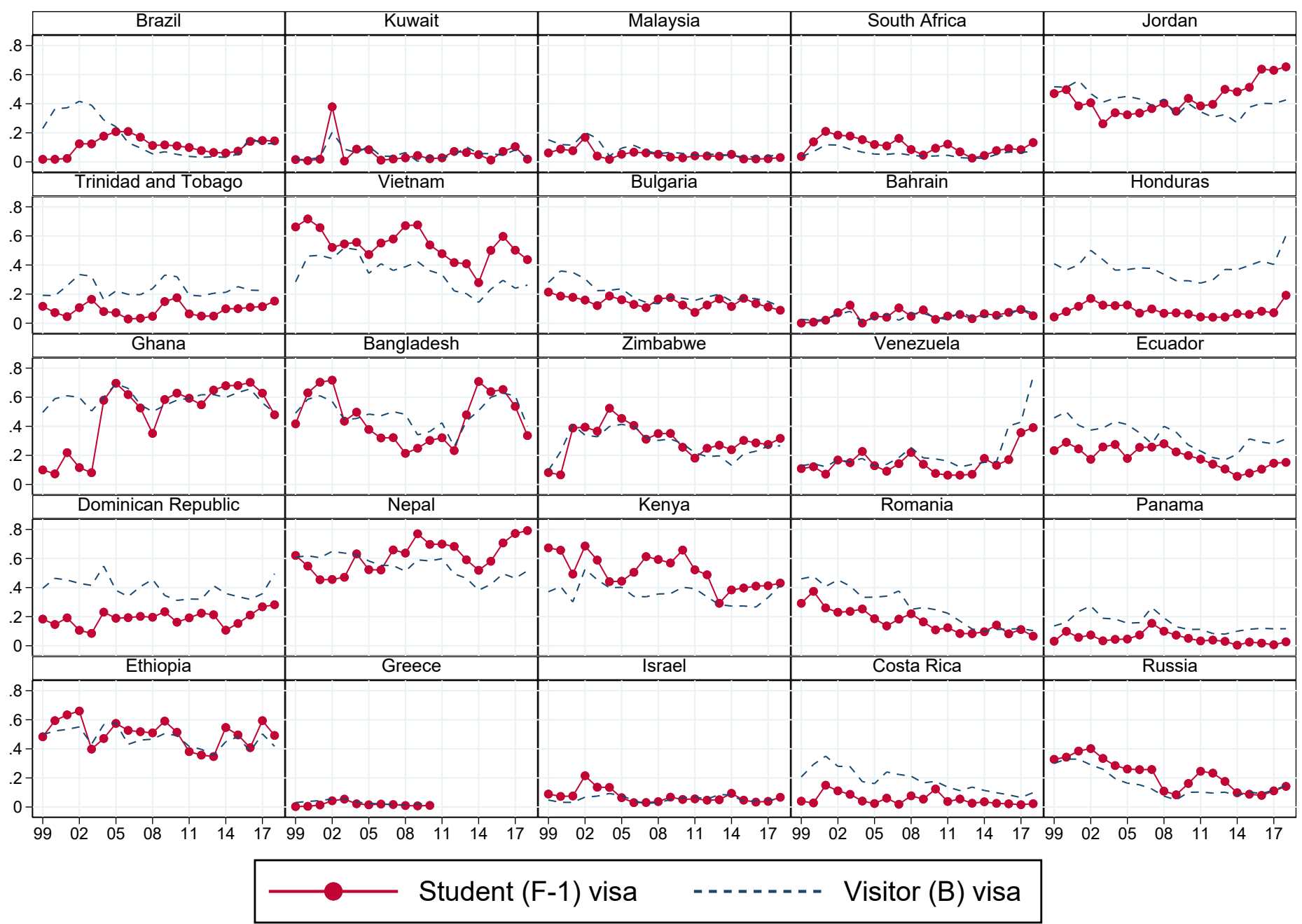

Note: Data are obtained from the US Department of State via Freedom of Information Act requests. The figure shows refusal rates for the top 26-50 regions with the most SAT takers in 1999-2018 when they are not covered by the US Visa Waiver Program. 
Table A.1: First-stage regression of the F-1 visa refusal rate

\begin{tabular}{lccccc}
\hline & $\begin{array}{c}\text { Region } \\
\text { level } \\
(1)\end{array}$ & $\begin{array}{c}\text { SAT } \\
\text { takers } \\
(2)\end{array}$ & $\begin{array}{c}\text { Score } \\
\text { senders } \\
(3)\end{array}$ & $\begin{array}{c}\text { Score } \\
\text { senders } \\
(4)\end{array}$ & $\begin{array}{c}\text { Enrollees } \\
(5)\end{array}$ \\
\hline B visa refusal rate & $0.091^{* * *}$ & $0.114^{* * *}$ & $0.107^{* * *}$ & $0.107^{* * *}$ & $0.102^{* * *}$ \\
& $(0.010)$ & $(0.015)$ & $(0.012)$ & $(0.012)$ & $(0.012)$ \\
Real GDP PC in USD & -0.020 & 0.012 & 0.011 & 0.011 & 0.006 \\
& $(0.020)$ & $(0.027)$ & $(0.023)$ & $(0.023)$ & $(0.022)$ \\
Imports from the US & $-0.024^{* * *}$ & -0.022 & -0.011 & -0.011 & -0.014 \\
& $(0.008)$ & $(0.017)$ & $(0.012)$ & $(0.012)$ & $(0.013)$ \\
Exports to the US & -0.001 & 0.008 & -0.006 & -0.007 & -0.008 \\
& $(0.006)$ & $(0.013)$ & $(0.009)$ & $(0.009)$ & $(0.009)$ \\
College-aged pop. & 0.002 & -0.075 & 0.022 & 0.023 & 0.039 \\
& $(0.031)$ & $(0.056)$ & $(0.036)$ & $(0.036)$ & $(0.037)$ \\
Enrollment in other & 0.008 & 0.024 & -0.003 & -0.003 & -0.003 \\
popular destinations & $(0.008)$ & $(0.016)$ & $(0.010)$ & $(0.010)$ & $(0.010)$ \\
H-1B issuance & -0.005 & $-0.024^{* *}$ & $-0.027^{* *}$ & $-0.027^{* *}$ & $-0.026^{* *}$ \\
& $(0.008)$ & $(0.010)$ & $(0.011)$ & $(0.011)$ & $(0.010)$ \\
Outcome mean & & & & & \\
Observations & 0.242 & 0.224 & 0.221 & 0.221 & 0.192 \\
\hline Student-level controls & 1,097 & 709,213 & 319,881 & 315,876 & 156,073 \\
Year FE & No & Yes & Yes & Yes & Yes \\
Region FE & Yes & Yes & Yes & Yes & Yes \\
\hline Yes & Yes & Yes & Yes & Yes \\
\hline
\end{tabular}

Notes: The dependent variable is the F-1 visa refusal rate that varies at region-year level. Column 1 reports the first-stage regression for region-year-level regressions in Tables 4 and 8. Columns 2-5 report first-stage regressions for student-level regressions in column 3 of Table 5 and 7. Data include 101 regions with the most test takers in 2004-15 and in periods that are not covered by the US Visa Waiver Program. Minimum enrollment of three students is required. Clustered standard errors at the region-level are in parentheses. ${ }^{* * *}=\mathrm{p}<0.01,{ }^{* *}=\mathrm{p}<0.05$, and ${ }^{*}=\mathrm{p}<0.1$. 
Table A.2: Summary statistics of the sample for student-level analysis

\begin{tabular}{|c|c|c|c|c|c|c|}
\hline & \multicolumn{2}{|c|}{ SAT takers } & \multicolumn{2}{|c|}{ Score senders } & \multicolumn{2}{|c|}{ Enrollees } \\
\hline & $\begin{array}{c}\text { mean } \\
(1)\end{array}$ & $\begin{array}{l}\mathrm{sd} \\
(2)\end{array}$ & $\begin{array}{c}\text { mean } \\
(3)\end{array}$ & $\begin{array}{l}\text { sd } \\
(4)\end{array}$ & $\begin{array}{c}\text { mean } \\
(5)\end{array}$ & $\begin{array}{l}s d \\
(6)\end{array}$ \\
\hline \multicolumn{7}{|l|}{ Outcomes } \\
\hline Send scores to $\geq 1$ school & 0.451 & 0.498 & - & - & 0.807 & 0.394 \\
\hline No. of score sends & 3.138 & 4.828 & 6.958 & 5.010 & 6.686 & 5.766 \\
\hline Avg. school selectivity sent & - & - & 1241 & 116 & 1238 & 105 \\
\hline Enroll in a US college & 0.263 & 0.440 & 0.471 & 0.499 & - & - \\
\hline Selectivity of enrolled school & - & - & - & - & 1213 & 123 \\
\hline \multicolumn{7}{|l|}{ Visa restrictiveness } \\
\hline F-1 visa refusal rate & 0.224 & 0.177 & 0.221 & 0.184 & 0.198 & 0.168 \\
\hline$B$ visa refusal rate & 0.208 & 0.140 & 0.207 & 0.147 & 0.192 & 0.142 \\
\hline \multicolumn{7}{|l|}{ Standardized tests } \\
\hline SAT & 1041 & 227 & 1157 & 200 & 1157 & 205 \\
\hline SAT above the $75^{\text {th }}$ pctl & 0.332 & 0.471 & 0.534 & 0.499 & 0.533 & 0.499 \\
\hline \multicolumn{7}{|l|}{ Demographics } \\
\hline Age & 18.300 & 0.969 & 18.406 & 0.947 & 18.386 & 0.799 \\
\hline Female & 0.464 & 0.499 & 0.463 & 0.499 & 0.478 & 0.500 \\
\hline Family income & 0.169 & 0.375 & 0.184 & 0.387 & 0.205 & 0.404 \\
\hline Family income $\$ 60-120 \mathrm{k}$ & 0.213 & 0.409 & 0.215 & 0.411 & 0.238 & 0.426 \\
\hline Family income $\$ 20-60 \mathrm{k}$ & 0.308 & 0.462 & 0.307 & 0.461 & 0.324 & 0.468 \\
\hline Family income $<\$ 20 \mathrm{k}$ & 0.309 & 0.462 & 0.294 & 0.456 & 0.233 & 0.423 \\
\hline Family income not reported & 0.570 & 0.495 & 0.481 & 0.500 & 0.509 & 0.500 \\
\hline $\begin{array}{l}\text { At least one parent has } \\
\text { college education }\end{array}$ & 0.795 & 0.403 & 0.821 & 0.383 & 0.825 & 0.380 \\
\hline Parental educ. not reported & 0.288 & 0.453 & 0.174 & 0.379 & 0.193 & 0.395 \\
\hline Observations & \multicolumn{2}{|c|}{709,213} & \multicolumn{2}{|c|}{319,881} & \multicolumn{2}{|c|}{186,453} \\
\hline with data on sch. selectivity & \multicolumn{2}{|c|}{ 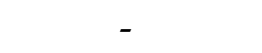 } & \multicolumn{2}{|c|}{315,876} & \multicolumn{2}{|c|}{156,073} \\
\hline
\end{tabular}

Notes: Data include SAT takers and score senders from 101 regions not covered by the US Visa Waiver Program and have the most number of test takers in 2004-15. School selectivity is defined as the average SAT score for the 2003 entering class. Information on parental education and family income are collected as a part of test registration, though they are not required fields. 
Table A.3: OLS regression of the composition of score sends

\begin{tabular}{|c|c|c|c|c|c|}
\hline & \multicolumn{5}{|c|}{ A. Number of score sends } \\
\hline & $(1)$ & (2) & (3) & $(4)$ & (5) \\
\hline F-1 visa refusal rate & $\begin{array}{c}-0.023 \\
(0.297)\end{array}$ & $\begin{array}{c}0.034 \\
(0.246)\end{array}$ & $\begin{array}{c}0.051 \\
(0.222)\end{array}$ & $\begin{array}{c}0.413 \\
(0.374)\end{array}$ & \\
\hline$\times$ Above $75^{\text {th }}$ pctl & & & & $\begin{array}{c}-0.722 \\
(0.641)\end{array}$ & $\begin{array}{c}-0.717 \\
(0.653)\end{array}$ \\
\hline Observations & 319,881 & 319,881 & 319,881 & 319,881 & 319,881 \\
\hline \multirow[t]{3}{*}{ Outcome mean } & 6.958 & 6.958 & 6.958 & 6.958 & 6.958 \\
\hline & \multicolumn{5}{|c|}{ B. Selectivity: school SAT average } \\
\hline & (1) & (2) & (3) & (4) & (5) \\
\hline F-1 visa refusal rate & $\begin{array}{l}11.739 \\
(12.434)\end{array}$ & $\begin{array}{l}15.439 \\
(9.911)\end{array}$ & $\begin{array}{l}14.852 \\
(9.562)\end{array}$ & $\begin{array}{c}17.601^{*} \\
(10.406)\end{array}$ & \\
\hline$\times$ Above $75^{\text {th }}$ pctl & & & & $\begin{array}{c}-5.299 \\
(9.768)\end{array}$ & $\begin{array}{c}-9.624 \\
(10.055)\end{array}$ \\
\hline Observations & 315,876 & 315,876 & 315,876 & 315,876 & 315,876 \\
\hline \multirow[t]{3}{*}{ Outcome mean } & 1,241 & 1,241 & 1,241 & 1,241 & 1,241 \\
\hline & \multicolumn{5}{|c|}{ C. Selectivity: school SAT maximum } \\
\hline & (1) & (2) & (3) & (4) & (5) \\
\hline $\begin{array}{l}\text { F-1 visa refusal rate } \\
\times \text { Above } 75^{\text {th }} \text { pctl }\end{array}$ & $\begin{array}{c}21.247 \\
(15.437)\end{array}$ & $\begin{array}{c}24.506^{*} \\
(12.949)\end{array}$ & $\begin{array}{r}20.810^{*} \\
(10.896)\end{array}$ & $\begin{array}{c}30.350^{* * * *} \\
(11.239) \\
-18.686^{* * *} \\
(6.960)\end{array}$ & $\begin{array}{l}-24.470^{* * *} \\
(7.110)\end{array}$ \\
\hline $\begin{array}{l}\text { Observations } \\
\text { Outcome mean }\end{array}$ & $\begin{array}{c}315,876 \\
1,337\end{array}$ & $\begin{array}{c}315,876 \\
1,337\end{array}$ & $\begin{array}{c}315,876 \\
1,337\end{array}$ & $\begin{array}{c}315,876 \\
1,337\end{array}$ & $\begin{array}{c}315,876 \\
1,337\end{array}$ \\
\hline Student-level controls & No & Yes & Yes & Yes & Yes \\
\hline Region-year controls & No & No & Yes & Yes & No \\
\hline Year FE & Yes & Yes & Yes & Yes & No \\
\hline Region FE & Yes & Yes & Yes & Yes & No \\
\hline Region-year FE & No & No & No & No & Yes \\
\hline
\end{tabular}

Notes: The dependent variables are the number of score sends to a US college (Panel A), average SAT (Panel B), and maximum SAT (Panel C) of the 2003 entering class at schools receiving scores. Data include only students who sent scores to at least one US college. See Table 5 for notes on controls and sample inclusion. Clustered standard errors at the region-level are in parentheses. ${ }^{* * *}=\mathrm{p}<0.01,{ }^{* *}=$ $\mathrm{p}<0.05$, and ${ }^{*}=\mathrm{p}<0.1$. 
Table A.4: OLS regression of enrollment outcomes in the US

\begin{tabular}{|c|c|c|c|c|c|}
\hline & \multicolumn{5}{|c|}{ A. Probability of enrolling a US college } \\
\hline & $(1)$ & $(2)$ & (3) & $(4)$ & (5) \\
\hline F-1 visa refusal rate & $\begin{array}{c}-0.047 \\
(0.030)\end{array}$ & $\begin{array}{r}-0.050^{*} \\
(0.027)\end{array}$ & $\begin{array}{r}-0.050^{*} \\
(0.027)\end{array}$ & $\begin{array}{r}-0.052^{*} \\
(0.028)\end{array}$ & \\
\hline$\times$ Above $75^{\text {th }}$ pctl & & & & $\begin{array}{c}0.006 \\
(0.020)\end{array}$ & $\begin{array}{c}0.019 \\
(0.021)\end{array}$ \\
\hline Observations & 709,213 & 709,213 & 709,213 & 709,213 & 709,213 \\
\hline \multirow[t]{3}{*}{ Outcome mean } & 1.000 & 1.000 & 1.000 & 1.000 & 1.000 \\
\hline & \multicolumn{5}{|c|}{ B. Selectivity (average SAT) of the enrolled school } \\
\hline & $(1)$ & $(2)$ & (3) & (4) & (5) \\
\hline F-1 visa refusal rate & $\begin{array}{l}18.896^{* *} \\
(9.351)\end{array}$ & $\begin{array}{l}14.938^{* *} \\
(5.956)\end{array}$ & $\begin{array}{c}10.954^{* *} \\
(5.336)\end{array}$ & $\begin{array}{l}-8.132 \\
(10.409)\end{array}$ & \\
\hline$\times$ Above $75^{\text {th }}$ pctl & & & & $\begin{array}{r}33.388^{*} \\
(17.415)\end{array}$ & $\begin{array}{c}33.376^{*} \\
(17.759)\end{array}$ \\
\hline \multirow{3}{*}{$\begin{array}{l}\text { Observations } \\
\text { Outcome mean }\end{array}$} & 156,073 & 156,073 & 156,073 & 156,073 & 156,073 \\
\hline & \multicolumn{5}{|c|}{ C. US enrollment probability for score senders } \\
\hline & (1) & $(2)$ & (3) & $(4)$ & (5) \\
\hline F-1 visa refusal rate & $\begin{array}{c}-0.083^{* *} \\
(0.036)\end{array}$ & $\begin{array}{c}-0.073^{* *} \\
(0.033)\end{array}$ & $\begin{array}{c}-0.057^{* *} \\
(0.026)\end{array}$ & $\begin{array}{l}-0.111^{* * *} \\
(0.029)\end{array}$ & \\
\hline$\times$ Above $75^{\text {th }}$ pctl & & & & $\begin{array}{l}0.107^{* * *} \\
(0.021)\end{array}$ & $\begin{array}{l}0.120^{* * *} \\
(0.022)\end{array}$ \\
\hline Observations & 319,881 & 319,881 & 319,881 & 319,881 & 319,881 \\
\hline Outcome mean & 0.471 & 0.471 & 0.471 & 0.471 & 0.471 \\
\hline Student-level controls & No & Yes & Yes & Yes & Yes \\
\hline Region-year controls & No & No & Yes & Yes & No \\
\hline Year FE & Yes & Yes & Yes & Yes & No \\
\hline Region FE & Yes & Yes & Yes & Yes & No \\
\hline Region-year FE & No & No & No & No & Yes \\
\hline
\end{tabular}

Notes: The dependent variables are an indicator for enrolling at a US college (Panel A), average SAT score for the 2003 entering class at the US college enrolled (Panel B), and an indicator for enrolling at a US college among score senders (Panel C). See Table 5 for notes on controls and sample inclusion. Clustered standard errors at the region-level are in parentheses. ${ }^{* *}=\mathrm{p}<0.01,{ }^{* *}=\mathrm{p}<0.05$, and ${ }^{*}=\mathrm{p}<0.1$. 
Table A.5: Regression of the number and academic ability of new international students

\begin{tabular}{|c|c|c|c|c|c|c|c|}
\hline & \multicolumn{3}{|c|}{ Log(no. of enrollees) } & \multicolumn{2}{|c|}{ Median SAT in SD } & \multicolumn{2}{|c|}{$\%$ above $75^{\text {th }}$ pctl } \\
\hline & $\begin{array}{c}\text { OLS } \\
(1)\end{array}$ & $\begin{array}{l}\text { OLS } \\
(2)\end{array}$ & $\begin{array}{c}2 S L S \\
(3)\end{array}$ & $\begin{array}{c}\text { OLS } \\
(4)\end{array}$ & $\begin{array}{c}\text { 2SLS } \\
(5)\end{array}$ & $\begin{array}{c}\text { OLS } \\
(6)\end{array}$ & $\begin{array}{c}\text { 2SLS } \\
(7)\end{array}$ \\
\hline F-1 visa refusal rate & -0.349 & -0.143 & 0.299 & 0.063 & 0.301 & 0.012 & 0.130 \\
\hline in the current period & $(0.220)$ & (0.199) & $(0.411)$ & $(0.140)$ & $(0.290)$ & $(0.066)$ & $(0.131)$ \\
\hline F-1 visa refusal rate & $-0.449^{* *}$ & $-0.367^{*}$ & $-1.296^{* * *}$ & -0.017 & $-0.678^{* *}$ & -0.089 & $-0.345^{* * *}$ \\
\hline in the previous period & $(0.210)$ & $(0.201)$ & $(0.469)$ & $(0.127)$ & $(0.303)$ & $(0.058)$ & $(0.133)$ \\
\hline \multirow[t]{2}{*}{ Real GDP PC in USD } & & $0.203^{* * *}$ & $0.200^{* * *}$ & -0.064 & -0.068 & -0.015 & -0.016 \\
\hline & & $(0.074)$ & $(0.075)$ & $(0.049)$ & $(0.051)$ & $(0.021)$ & $(0.021)$ \\
\hline \multirow[t]{2}{*}{ Imports from the US } & & $0.174^{* * *}$ & $0.156^{* * *}$ & 0.017 & 0.000 & 0.011 & 0.006 \\
\hline & & $(0.044)$ & $(0.047)$ & $(0.032)$ & $(0.035)$ & $(0.012)$ & $(0.013)$ \\
\hline \multirow[t]{2}{*}{ Exports to the US } & & 0.050 & 0.053 & 0.008 & 0.010 & -0.003 & -0.002 \\
\hline & & $(0.032)$ & $(0.033)$ & $(0.024)$ & $(0.024)$ & $(0.011)$ & $(0.011)$ \\
\hline \multirow[t]{2}{*}{ College-aged pop. } & & 0.216 & 0.214 & -0.162 & $-0.163^{*}$ & -0.048 & -0.049 \\
\hline & & $(0.182)$ & $(0.178)$ & $(0.099)$ & $(0.098)$ & $(0.043)$ & $(0.042)$ \\
\hline Enrollment in other & & 0.076 & 0.077 & 0.002 & 0.003 & 0.007 & 0.008 \\
\hline popular destinations & & $(0.050)$ & $(0.051)$ & $(0.026)$ & $(0.027)$ & $(0.011)$ & $(0.011)$ \\
\hline \multirow{2}{*}{$\mathrm{H}-1 \mathrm{~B}$ issuance } & & $0.130^{* *}$ & $0.132^{* *}$ & $0.058^{*}$ & $0.060^{*}$ & $0.032^{* *}$ & $0.032^{* *}$ \\
\hline & & $(0.055)$ & $(0.054)$ & $(0.033)$ & $(0.033)$ & $(0.016)$ & $(0.016)$ \\
\hline Outcome mean & 4.081 & 4.081 & 4.081 & 5.226 & 5.226 & 0.409 & 0.409 \\
\hline F-stat on IV in $1^{\text {st }}$-stg & - & - & 40.76 & - & 40.76 & - & 40.76 \\
\hline Observations & 1,097 & 1,097 & 1,097 & 1,097 & 1,097 & 1,097 & 1,097 \\
\hline Year FE & Yes & Yes & Yes & Yes & Yes & Yes & Yes \\
\hline Region FE & Yes & Yes & Yes & Yes & Yes & Yes & Yes \\
\hline
\end{tabular}

Notes: The dependent variables are, at the region-year-level, the number of SAT takers enrolled in the US in natural $\log$, median SAT score among enrollees in SD unit, and the share of enrollees above the $75^{\text {th }}$ percentile. All independent variables are measured in the time period prior to a student's high school graduation year, and all except the visa refusal rate are in natural log. A region's enrollment in other popular destinations includes its higher education enrollment in Australia, Canada, and the UK. Data include 101 regions with the most test takers in 2004-15 and in periods that are not covered by the US Visa Waiver Program. Minimum enrollment of three students is required. Clustered standard errors at the region-level are in parentheses. ${ }^{* * *}=\mathrm{p}<0.01,{ }^{* *}=\mathrm{p}<0.05$, and ${ }^{*}=\mathrm{p}<0.1$. 
Table A.6: Regression of the number and academic ability of new international students

\begin{tabular}{|c|c|c|c|c|c|c|c|}
\hline & \multicolumn{3}{|c|}{ Log(no. of enrollees) } & \multicolumn{2}{|c|}{ Median SAT in SD } & \multicolumn{2}{|c|}{$\%$ above $75^{\text {th }}$ pctl } \\
\hline & $\begin{array}{c}\text { OLS } \\
(1)\end{array}$ & $\begin{array}{c}\text { OLS } \\
(2)\end{array}$ & $\begin{array}{c}\text { 2SLS } \\
(3)\end{array}$ & $\begin{array}{c}\text { OLS } \\
(4)\end{array}$ & $\begin{array}{c}\text { 2SLS } \\
(5)\end{array}$ & $\begin{array}{c}\text { OLS } \\
(6)\end{array}$ & $\begin{array}{c}2 \text { 2SLS } \\
(7)\end{array}$ \\
\hline F-1 visa refusal rate & $-0.399^{*}$ & -0.173 & -0.029 & 0.068 & 0.069 & -0.021 & -0.016 \\
\hline in the current period & $(0.208)$ & $(0.178)$ & $(0.326)$ & $(0.126)$ & $(0.232)$ & $(0.059)$ & $(0.100)$ \\
\hline F-1 visa refusal rate & $-0.738^{* *}$ & $-0.668^{* *}$ & $-1.774^{* * *}$ & -0.054 & $-0.706^{* *}$ & -0.058 & $-0.257^{*}$ \\
\hline in the last 3 periods & $(0.289)$ & $(0.270)$ & $(0.536)$ & $(0.140)$ & $(0.337)$ & $(0.059)$ & $(0.133)$ \\
\hline \multirow[t]{2}{*}{ Real GDP PC in USD } & & $0.203^{* * *}$ & $0.200^{* * *}$ & -0.064 & -0.068 & -0.015 & -0.016 \\
\hline & & $(0.073)$ & $(0.077)$ & $(0.049)$ & $(0.052)$ & $(0.021)$ & $(0.022)$ \\
\hline \multirow[t]{2}{*}{ Imports } & & $0.168^{* * *}$ & $0.141^{* * *}$ & 0.016 & -0.004 & 0.012 & 0.006 \\
\hline & & $(0.045)$ & $(0.049)$ & $(0.033)$ & $(0.036)$ & $(0.012)$ & $(0.013)$ \\
\hline \multirow[t]{2}{*}{ Exports } & & 0.050 & 0.053 & 0.008 & 0.009 & -0.003 & -0.003 \\
\hline & & $(0.032)$ & $(0.034)$ & $(0.024)$ & $(0.024)$ & $(0.011)$ & $(0.011)$ \\
\hline \multirow[t]{2}{*}{ College-aged pop. } & & 0.222 & 0.230 & -0.161 & -0.156 & -0.048 & -0.046 \\
\hline & & $(0.181)$ & $(0.179)$ & $(0.099)$ & $(0.100)$ & $(0.043)$ & $(0.043)$ \\
\hline Enrollment in other & & 0.077 & 0.080 & 0.002 & 0.004 & 0.007 & 0.008 \\
\hline popular destinations & & $(0.050)$ & $(0.052)$ & $(0.026)$ & $(0.027)$ & $(0.011)$ & $(0.011)$ \\
\hline \multirow[t]{2}{*}{$\mathrm{H}-1 \mathrm{~B}$ issuance } & & $0.135^{* *}$ & $0.145^{* * *}$ & $0.059^{*}$ & $0.065^{* *}$ & $0.032^{* *}$ & $0.034^{* *}$ \\
\hline & & $(0.055)$ & $(0.055)$ & $(0.033)$ & $(0.032)$ & $(0.016)$ & $(0.016)$ \\
\hline Outcome mean & 4.081 & 4.081 & 4.081 & 5.226 & 5.226 & 0.409 & 0.409 \\
\hline $1^{\text {st } \text {-stage F-stat }}$ & - & - & 42.02 & - & 42.02 & - & 42.02 \\
\hline Observations & 1,097 & 1,097 & 1,097 & 1,097 & 1,097 & 1,097 & 1,097 \\
\hline Year FE & Yes & Yes & Yes & Yes & Yes & Yes & Yes \\
\hline Region FE & Yes & Yes & Yes & Yes & Yes & Yes & Yes \\
\hline
\end{tabular}

Notes: The dependent variables are, at the region-year-level, the number of SAT takers enrolled in the US in natural log, median SAT score among enrollees in SD unit, and the share of enrollees above the $75^{\text {th }}$ percentile. All independent variables are measured in the time period prior to a student's high school graduation year, and all except the visa refusal rate are in natural log. A region's enrollment in other popular destinations includes its higher education enrollment in Australia, Canada, and the UK. Data include 101 regions with the most test takers in 2004-15 and in periods that are not covered by the US Visa Waiver Program. Minimum enrollment of three students is required. Clustered standard errors at the region-level are in parentheses. ${ }^{* * *}=\mathrm{p}<0.01,{ }^{* *}=\mathrm{p}<0.05$, and ${ }^{*}=\mathrm{p}<0.1$. 
Table A.7: Regression of enrollment outcomes from student-level analysis

\begin{tabular}{|c|c|c|c|c|c|c|}
\hline & \multicolumn{6}{|c|}{ A. OLS estimates } \\
\hline & \multicolumn{2}{|c|}{ Enrolled } & \multicolumn{2}{|c|}{ Enrolled selectivity } & \multicolumn{2}{|c|}{ Enrolled for sender } \\
\hline & $(1)$ & $(2)$ & (3) & (4) & (5) & (6) \\
\hline \multirow{8}{*}{$\begin{array}{l}\text { F-1 visa refusal rate } \\
\text { in the current period } \\
\text { F- } 1 \text { visa refusal rate } \\
\text { in the previous period } \\
\text { F- } 1 \text { visa refusal rate } \\
\text { in the last } 3 \text { periods }\end{array}$} & -0.004 & 0.001 & 2.158 & 2.553 & -0.003 & -0.010 \\
\hline & $(0.023)$ & $(0.021)$ & $(6.813)$ & (6.395) & $(0.031)$ & $(0.030)$ \\
\hline & $-0.048^{*}$ & & $9.928^{*}$ & & $-0.056^{* *}$ & \\
\hline & $(0.027)$ & & $(5.941)$ & & $(0.025)$ & \\
\hline & & $-0.088^{* *}$ & & $20.666^{* * *}$ & & $-0.096^{* * *}$ \\
\hline & & & & (7.900) & & $(0.036)$ \\
\hline & \multicolumn{6}{|c|}{ B. 2SLS estimates } \\
\hline & (1) & (2) & (3) & (4) & (5) & (6) \\
\hline F-1 visa refusal rate & 0.030 & 0.040 & -8.940 & -25.513 & 0.103 & 0.080 \\
\hline in the current period & $(0.053)$ & $(0.049)$ & (19.935) & $(17.304)$ & $(0.083)$ & $(0.069)$ \\
\hline F-1 visa refusal rate & $-0.136^{* *}$ & & 18.318 & & $-0.173^{* *}$ & \\
\hline in the previous period & $(0.054)$ & & $(18.189)$ & & $(0.078)$ & \\
\hline F-1 visa refusal rate & & $-0.211^{* * *}$ & & $63.850^{* * *}$ & & $-0.221^{* *}$ \\
\hline in the last 3 period & & $(0.074)$ & & (18.129) & & $(0.094)$ \\
\hline Outcome mean & 0.263 & 0.263 & 1213 & 1213 & 0.471 & 0.471 \\
\hline $1^{\text {st }}$-stage F-stat & 16.37 & 23.72 & 15.35 & 27.70 & 16.98 & 28.65 \\
\hline Observations & 709,213 & 709,213 & 156,073 & 156,073 & 319,881 & 319,881 \\
\hline Student-level controls & Yes & Yes & Yes & Yes & Yes & Yes \\
\hline Region-year controls & Yes & Yes & Yes & Yes & Yes & Yes \\
\hline Year FE & Yes & Yes & Yes & Yes & Yes & Yes \\
\hline Region FE & Yes & Yes & Yes & Yes & Yes & Yes \\
\hline
\end{tabular}

Notes: The dependent variables are an indicator for enrolling at a US college, selectivity of the enrolled college, and an indicator for enrollment among score senders. Columns 1-6 replicate column 3 in Table 7 with the addition of the current period F-1 visa refusal rate, respectively. See Table 5 for notes on controls and sample inclusion. Clustered standard errors at the region-level are in parentheses. ${ }^{* * *}=\mathrm{p}<0.01,{ }^{* *}=\mathrm{p}<0.05$, and ${ }^{*}=\mathrm{p}<0.1$. 
Table A.8: IV regression from student-level analysis with alternative measures of SAT

\begin{tabular}{|c|c|c|c|c|c|c|}
\hline & \multicolumn{6}{|c|}{ A. Score-sending behaviors } \\
\hline & \multicolumn{2}{|c|}{ Send a report } & \multicolumn{2}{|c|}{ No. of reports } & \multicolumn{2}{|c|}{ Sent selectivity } \\
\hline & $(1)$ & $(2)$ & (3) & (4) & (5) & (6) \\
\hline F-1 visa refusal rate & $\begin{array}{l}1.027^{* * *} \\
(0.346)\end{array}$ & & $\begin{array}{l}13.816^{* * *} \\
(3.108)\end{array}$ & & $\begin{array}{c}-78.669 \\
(73.750)\end{array}$ & \\
\hline$\times \operatorname{SAT}(/ 100)$ & $\begin{array}{c}-0.214^{* * *} \\
(0.064)\end{array}$ & $\begin{array}{c}-0.244^{* * *} \\
(0.064)\end{array}$ & $\begin{array}{c}-2.631^{* * *} \\
(0.632)\end{array}$ & $\begin{array}{c}-2.620^{* * *} \\
(0.621)\end{array}$ & $\begin{array}{l}23.441^{* *} \\
(11.843)\end{array}$ & $\begin{array}{c}17.651 \\
(12.293)\end{array}$ \\
\hline$\times \operatorname{SAT}^{2}(/ 10000)$ & $\begin{array}{l}0.009^{* * *} \\
(0.003)\end{array}$ & $\begin{array}{c}0.010^{* * *} \\
(0.003)\end{array}$ & $\begin{array}{c}0.116^{* * *} \\
(0.034)\end{array}$ & $\begin{array}{l}0.117^{* * *} \\
(0.033)\end{array}$ & $\begin{array}{c}-1.104^{* *} \\
(0.529)\end{array}$ & $\begin{array}{r}-0.931^{*} \\
(0.543)\end{array}$ \\
\hline Observations & 709,213 & 709,213 & 319,881 & 319,881 & 315,876 & 315,876 \\
\hline Outcome mean & 0.451 & 0.451 & 3.138 & 3.138 & 1266 & 1266 \\
\hline \multirow[t]{4}{*}{ F-stat on IV in $1^{\text {st }}$-stg } & 20.25 & 153.25 & 24.74 & 84.69 & 24.63 & 83.37 \\
\hline & \multicolumn{6}{|c|}{ B. Enrollment outcomes } \\
\hline & \multicolumn{2}{|c|}{ Enrolled } & \multicolumn{2}{|c|}{ Enrolled selectivity } & \multicolumn{2}{|c|}{ Enrolled for senders } \\
\hline & $(1)$ & $(2)$ & (3) & (4) & (5) & (6) \\
\hline F-1 visa refusal rate & $\begin{array}{l}0.703^{* * *} \\
(0.148)\end{array}$ & & $\begin{array}{c}-166.061 \\
(124.403)\end{array}$ & & $\begin{array}{l}0.720^{* * *} \\
(0.232)\end{array}$ & \\
\hline$\times \operatorname{SAT}(/ 100)$ & $\begin{array}{c}-0.163^{* * *} \\
(0.028)\end{array}$ & $\begin{array}{c}-0.183^{* * *} \\
(0.028)\end{array}$ & $\begin{array}{c}14.151 \\
(19.165)\end{array}$ & $\begin{array}{c}13.341 \\
(19.242)\end{array}$ & $\begin{array}{c}-0.202^{* * *} \\
(0.039)\end{array}$ & $\begin{array}{c}-0.198^{* * *} \\
(0.037)\end{array}$ \\
\hline$\times \operatorname{SAT}^{2}(/ 10000)$ & $\begin{array}{l}0.008^{* * *} \\
(0.001)\end{array}$ & $\begin{array}{c}0.009^{* * *} \\
(0.001)\end{array}$ & $\begin{array}{c}0.072 \\
(0.785)\end{array}$ & $\begin{array}{c}0.132 \\
(0.787)\end{array}$ & $\begin{array}{l}0.011^{* * *} \\
(0.002)\end{array}$ & $\begin{array}{c}0.011^{* * *} \\
(0.002)\end{array}$ \\
\hline Observations & 709,213 & 709,213 & 156,073 & 156,073 & 319,881 & 319,881 \\
\hline Outcome mean & 0.263 & 0.263 & 1213 & 1213 & 0.471 & 0.471 \\
\hline F-stat on IV in $1^{\text {st }}$-stg & 20.25 & 153.25 & 23.05 & 108.39 & 24.74 & 84.69 \\
\hline Student-level controls & Yes & Yes & Yes & Yes & Yes & Yes \\
\hline Region-year controls & Yes & No & Yes & No & Yes & No \\
\hline Year FE & Yes & No & Yes & No & Yes & No \\
\hline Region FE & Yes & No & Yes & No & Yes & No \\
\hline Region-year FE & No & Yes & No & Yes & No & Yes \\
\hline
\end{tabular}

Notes: The dependent variables are an indicator for sending a score to at least one US college, the number of score sends, selectivity of score sends, an indicator for enrolling in a US college, selectivity of the enrolled college, and an indicator for enrollment among score senders. See Table 5 for notes on controls and sample inclusion. Clustered standard errors at the region-level are in parentheses. ${ }^{* * *}=\mathrm{p}<0.01,{ }^{* *}=\mathrm{p}<0.05$ and $^{*}=\mathrm{p}<0.1$. 
Table A.9: Regression of log of the number of high-scoring international students

\begin{tabular}{|c|c|c|c|c|}
\hline & \multicolumn{2}{|c|}{ SAT enrollees } & \multicolumn{2}{|c|}{ SAT takers } \\
\hline & $\begin{array}{l}\text { OLS } \\
(1)\end{array}$ & $\begin{array}{l}\text { 2SLS } \\
(2)\end{array}$ & $\begin{array}{l}\text { OLS } \\
(3)\end{array}$ & $\begin{array}{l}\text { 2SLS } \\
(4)\end{array}$ \\
\hline F-1 visa refusal rate & $\begin{array}{c}-0.576^{* *} \\
(0.243)\end{array}$ & $\begin{array}{c}-1.671^{* * *} \\
(0.464)\end{array}$ & $\begin{array}{c}-0.338 \\
(0.222)\end{array}$ & $\begin{array}{c}-1.053^{* *} \\
(0.458)\end{array}$ \\
\hline Real GDP PC in USD & $\begin{array}{r}0.176^{*} \\
(0.092)\end{array}$ & $\begin{array}{c}0.159 \\
(0.097)\end{array}$ & $\begin{array}{l}0.326^{* * *} \\
(0.085)\end{array}$ & $\begin{array}{c}0.315^{* * *} \\
(0.084)\end{array}$ \\
\hline Imports from the US & $\begin{array}{l}0.219^{* * *} \\
(0.060)\end{array}$ & $\begin{array}{l}0.172^{* * *} \\
(0.065)\end{array}$ & $\begin{array}{l}0.210^{* * *} \\
(0.054)\end{array}$ & $\begin{array}{c}0.179^{* * *} \\
(0.057)\end{array}$ \\
\hline Exports to the US & $\begin{array}{c}0.013 \\
(0.046)\end{array}$ & $\begin{array}{c}0.016 \\
(0.046)\end{array}$ & $\begin{array}{c}0.045 \\
(0.051)\end{array}$ & $\begin{array}{c}0.047 \\
(0.051)\end{array}$ \\
\hline College-aged pop. & $\begin{array}{c}0.130 \\
(0.251)\end{array}$ & $\begin{array}{c}0.131 \\
(0.248)\end{array}$ & $\begin{array}{c}0.046 \\
(0.228)\end{array}$ & $\begin{array}{c}0.047 \\
(0.226)\end{array}$ \\
\hline $\begin{array}{l}\text { Enrollment in other } \\
\text { popular destinations } \\
\text { H-1B issuance }\end{array}$ & $\begin{array}{l}0.121^{*} \\
(0.069) \\
0.234^{* * *} \\
(0.077)\end{array}$ & $\begin{array}{c}0.123^{*} \\
(0.072) \\
0.238^{* * *} \\
(0.076)\end{array}$ & $\begin{array}{l}0.169^{* *} \\
(0.066) \\
0.233^{* * *} \\
(0.062)\end{array}$ & $\begin{array}{c}0.170^{* *} \\
(0.067) \\
0.236^{* * *} \\
(0.062)\end{array}$ \\
\hline $\begin{array}{l}\text { Outcome mean } \\
\text { F-stat on IV in } 1^{\text {st }} \text {-stg } \\
\text { Observations }\end{array}$ & $\begin{array}{c}3.066 \\
- \\
1,097\end{array}$ & $\begin{array}{l}3.066 \\
90.70 \\
1,097\end{array}$ & $\begin{array}{c}3.980 \\
- \\
1,097\end{array}$ & $\begin{array}{l}3.980 \\
90.70 \\
1,097\end{array}$ \\
\hline $\begin{array}{l}\text { Year FE } \\
\text { Region FE }\end{array}$ & $\begin{array}{l}\text { Yes } \\
\text { Yes }\end{array}$ & $\begin{array}{l}\text { Yes } \\
\text { Yes }\end{array}$ & $\begin{array}{l}\text { Yes } \\
\text { Yes }\end{array}$ & $\begin{array}{l}\text { Yes } \\
\text { Yes }\end{array}$ \\
\hline
\end{tabular}

Notes: The dependent variables are the number of new international enrollees in the US and SAT takers above the $75^{\text {th }}$ percentile in natural $\log$ at the region-year-level. All independent variables are measured in the time period prior to a student's high school graduation year, and all except the visa refusal rate are in natural log. A region's enrollment in other popular destinations includes its higher education enrollment in Australia, Canada, and the UK. Data include 101 regions with the most test takers in 2004-15 and in periods that are not covered by the US Visa Waiver Program. Minimum enrollment of three students is required. Clustered standard errors at the region-level are in parentheses. ${ }^{* *}=p<0.01,{ }^{* *}=p<0.05$, and $^{*}=p<0.1$. 
Table A.10: Poisson regression of the number of score sends

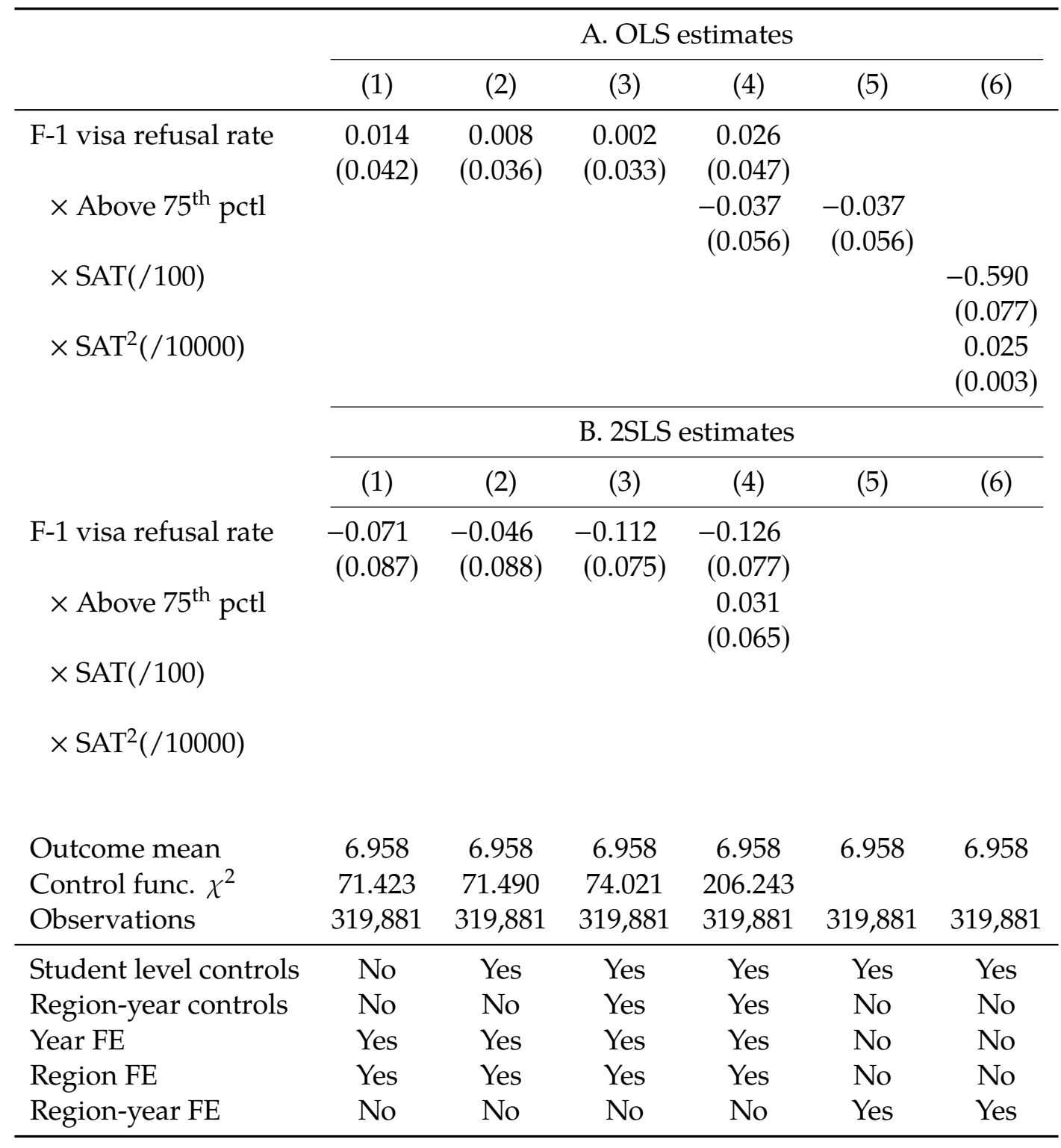

Notes: The dependent variable is the number of score sends to a US college. Data include only students who sent scores to at least one US college. See Table 5 for notes on controls and sample inclusion. Clustered standard errors at the region-level are in parentheses. ${ }^{* * *}=$ $\mathrm{p}<0.01,{ }^{* *}=\mathrm{p}<0.05$, and $^{*}=\mathrm{p}<0.1$. 
Table A.11: Region-year-level IV regressions excluding regions ever a VWP member

\begin{tabular}{|c|c|c|c|c|c|c|}
\hline & \multicolumn{3}{|c|}{ Enrollees } & \multicolumn{3}{|c|}{ SAT takers } \\
\hline & $\begin{array}{c}\log (\text { no. }) \\
\text { (1) }\end{array}$ & $\begin{array}{c}\text { SAT } \\
\text { median } \\
(2)\end{array}$ & $\begin{array}{l}\text { \% above } \\
75^{\text {th }} \text { pctl } \\
\text { (3) }\end{array}$ & $\begin{array}{c}\log (\text { no. }) \\
(4)\end{array}$ & $\begin{array}{c}\text { SAT } \\
\text { median } \\
(5)\end{array}$ & $\begin{array}{c}\text { \% above } \\
75^{\text {th }} \text { pctl } \\
(6)\end{array}$ \\
\hline F-1 visa refusal rate & $\begin{array}{c}-1.295^{* * *} \\
(0.373)\end{array}$ & $\begin{array}{c}-0.556^{* *} \\
(0.232)\end{array}$ & $\begin{array}{c}-0.299^{* * *} \\
(0.096)\end{array}$ & $\begin{array}{c}-0.879^{* *} \\
(0.376)\end{array}$ & $\begin{array}{c}-0.331^{* *} \\
(0.165)\end{array}$ & $\begin{array}{r}-0.166^{* *} \\
(0.065)\end{array}$ \\
\hline Real GDP PC in USD & $\begin{array}{c}0.199^{* *} \\
(0.078)\end{array}$ & $\begin{array}{c}-0.075 \\
(0.053)\end{array}$ & $\begin{array}{c}-0.020 \\
(0.022)\end{array}$ & $\begin{array}{l}0.372^{* * *} \\
(0.072)\end{array}$ & $\begin{array}{c}0.011 \\
(0.039)\end{array}$ & $\begin{array}{r}-0.011 \\
(0.014)\end{array}$ \\
\hline Imports & $\begin{array}{l}0.163^{* * *} \\
(0.047)\end{array}$ & $\begin{array}{c}-0.016 \\
(0.036)\end{array}$ & $\begin{array}{c}0.001 \\
(0.013)\end{array}$ & $\begin{array}{l}0.158^{* * *} \\
(0.045)\end{array}$ & $\begin{array}{c}0.012 \\
(0.022)\end{array}$ & $\begin{array}{c}0.009 \\
(0.008)\end{array}$ \\
\hline Exports & $\begin{array}{c}0.047 \\
(0.032)\end{array}$ & $\begin{array}{c}0.012 \\
(0.025)\end{array}$ & $\begin{array}{r}-0.002 \\
(0.011)\end{array}$ & $\begin{array}{c}-0.006 \\
(0.041)\end{array}$ & $\begin{array}{c}0.036^{* *} \\
(0.016)\end{array}$ & $\begin{array}{c}0.010 \\
(0.007)\end{array}$ \\
\hline College-aged pop. & $\begin{array}{c}0.224 \\
(0.184)\end{array}$ & $\begin{array}{c}-0.157 \\
(0.106)\end{array}$ & $\begin{array}{c}-0.049 \\
(0.045)\end{array}$ & $\begin{array}{c}0.213 \\
(0.178)\end{array}$ & $\begin{array}{c}-0.117 \\
(0.082)\end{array}$ & $\begin{array}{c}-0.063^{* *} \\
(0.028)\end{array}$ \\
\hline $\begin{array}{l}\text { Enrollment in other } \\
\text { popular destinations } \\
\text { H-1B issuance }\end{array}$ & $\begin{array}{c}0.102^{*} \\
(0.053) \\
0.126^{* *} \\
(0.054)\end{array}$ & $\begin{array}{c}-0.008 \\
(0.029) \\
0.065^{* *} \\
(0.033)\end{array}$ & $\begin{array}{c}0.005 \\
(0.012) \\
0.034^{* *} \\
(0.016)\end{array}$ & $\begin{array}{c}0.138^{* * *} \\
(0.050) \\
0.199^{* * *} \\
(0.049)\end{array}$ & $\begin{array}{c}0.008 \\
(0.017) \\
0.009 \\
(0.019)\end{array}$ & $\begin{array}{c}0.008 \\
(0.007) \\
0.004 \\
(0.009)\end{array}$ \\
\hline $\begin{array}{l}\text { Outcome mean } \\
\text { F-stat on IV in } 1^{\text {st }} \text {-stg } \\
\text { Observations }\end{array}$ & $\begin{array}{l}4.098 \\
82.16 \\
1,037\end{array}$ & $\begin{array}{l}5.212 \\
82.16 \\
1,037\end{array}$ & $\begin{array}{l}0.404 \\
82.16 \\
1,037\end{array}$ & $\begin{array}{l}5.395 \\
82.16 \\
1,037\end{array}$ & $\begin{array}{l}4.908 \\
82.16 \\
1,037\end{array}$ & $\begin{array}{l}0.294 \\
82.16 \\
1,037\end{array}$ \\
\hline $\begin{array}{l}\text { Year FE } \\
\text { Region FE }\end{array}$ & $\begin{array}{l}\text { Yes } \\
\text { Yes }\end{array}$ & $\begin{array}{l}\text { Yes } \\
\text { Yes }\end{array}$ & $\begin{array}{l}\text { Yes } \\
\text { Yes }\end{array}$ & $\begin{array}{l}\text { Yes } \\
\text { Yes }\end{array}$ & $\begin{array}{l}\text { Yes } \\
\text { Yes }\end{array}$ & $\begin{array}{l}\text { Yes } \\
\text { Yes }\end{array}$ \\
\hline
\end{tabular}

Notes: The dependent variables are the number of enrollees/SAT takers in natural log, median SAT score for enrollees/SAT takers in SD unit, and the share of enrollees/SAT takers above the $75^{\text {th }}$ percentile at the region-year-level. All independent variables are measured in the time period prior to a student's high school graduation year, and all except the visa refusal rate are in natural log. A region's enrollment in other popular destinations includes its higher education enrollment in Australia, Canada, and UK. Data include 101 regions with the most test takers in 2004-15 and in periods that are not covered by the US Visa Waiver Program. Minimum enrollment of three students is required. Clustered standard errors at the region-level are in parentheses. ${ }^{* * *}=\mathrm{p}<0.01$, ${ }^{* *}=\mathrm{p}<0.05$, and ${ }^{*}=\mathrm{p}<0.1$. 
Table A.12: Student-level IV regressions excluding regions ever a VWP member

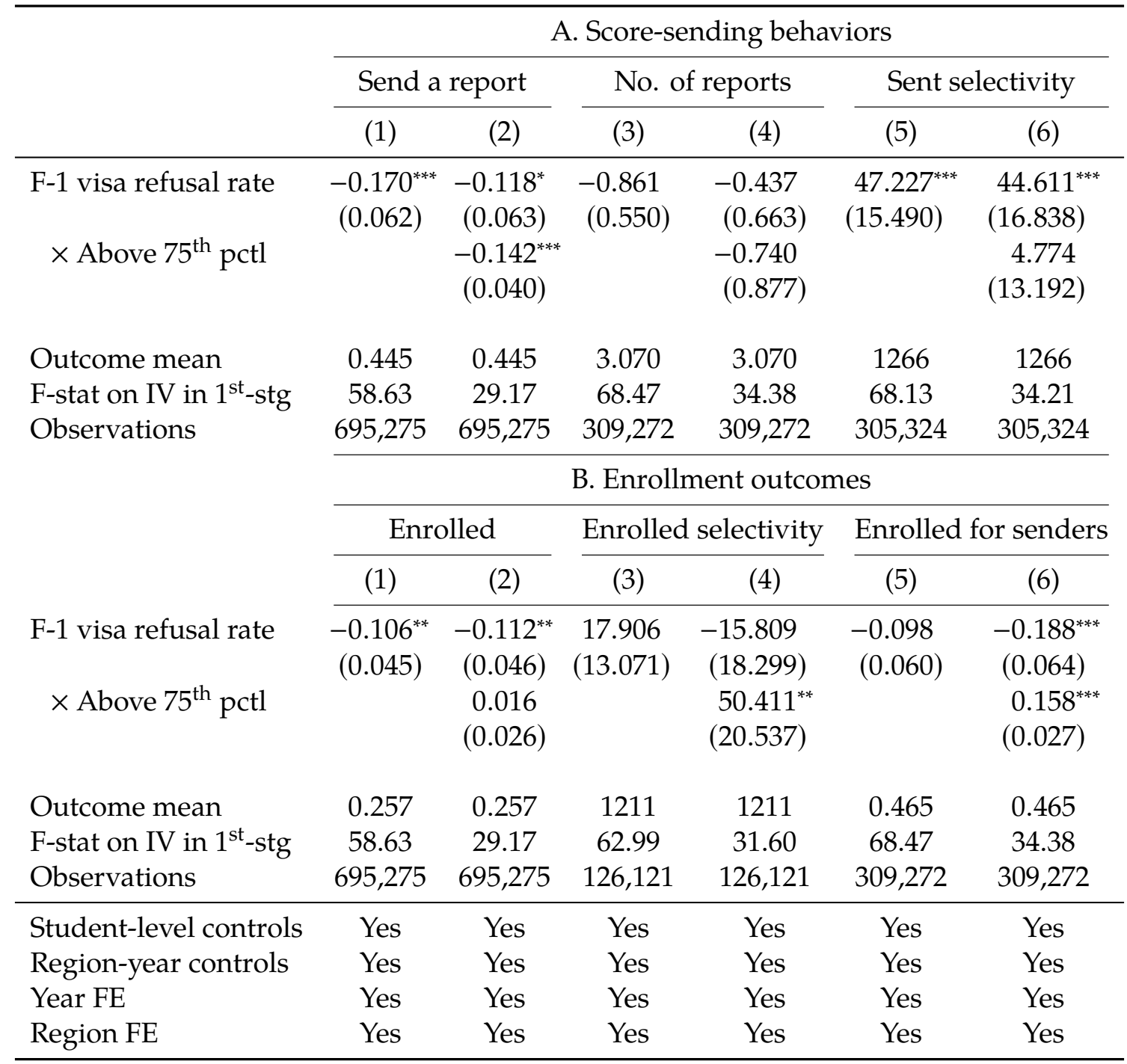

Notes: The dependent variables are an indicator for sending scores to at least one US college, the number of score sends, selectivity of score sends, an indicator for enrolling in a US college, selectivity of the enrolled college, and an indicator for enrollment among score senders. All regionyear-level variables are measured in the time period prior to a student's high school graduation year, and all except the visa refusal rate are in natural log. See Table 5 for notes on controls and sample inclusion. Clustered standard errors at the region-level are in parentheses. ${ }^{* * *}=\mathrm{p}<0.01{ }^{* *}$ $=\mathrm{p}<0.05$, and ${ }^{*}=\mathrm{p}<0.1$. 